\title{
Reliability of Ceramics For Heat Engine Applications
}

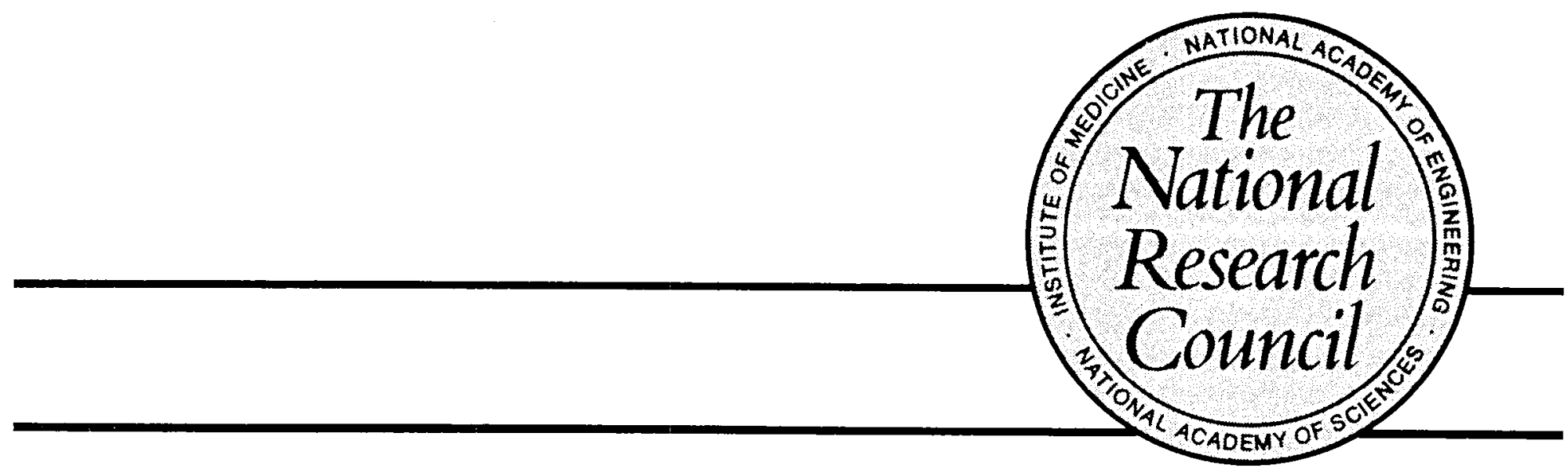

National Materials Advisory Board

Commission on Sociotechnical Systems 


\begin{tabular}{|c|c|}
\hline REPORT DOCUMENTATION PAGE & $\begin{array}{l}\text { READ DNSTRUCTIONS } \\
\text { BEFORE COMPETLIG FORM }\end{array}$ \\
\hline \begin{tabular}{l|l|} 
1. AEPOAT NUMBER & 2. GOVT ACCESSION NO. \\
$\qquad N M A B-357$ &
\end{tabular} & 3. RECIPIENT'S CATALOG NUMBER \\
\hline \multirow{2}{*}{$\begin{array}{l}\text { 4. TITLE (and Subtilo) } \\
\text { Rellability of Ceramics for } \\
\text { Heat Engine Applications }\end{array}$} & $\begin{array}{l}\text { 5. TYPE OF REPONT Q PERIOD COVERED } \\
\text { Final Report }\end{array}$ \\
\hline & $\begin{array}{l}\text { 6. PERFORMING ORG. REPORT MUMEER } \\
\text { NMAB-357 }\end{array}$ \\
\hline $\begin{array}{l}\text { 7. AUTHOR(o) } \\
\text { NMAB Committee on Reliability of Ceramics } \\
\text { for Heat Engine Applications }\end{array}$ & $\begin{array}{l}\text { 8. CONTRACT OR GRANT HUMBER(-) } \\
\text { MDA 903-78-C-0038 }\end{array}$ \\
\hline $\begin{array}{l}\text { 9. PERFORMING ORGANIZATION NAME AND ADORESS } \\
\text { National Materials Advisory Board } \\
\text { National Academy of Sciences } \\
\text { Washington, D.C. } 20418\end{array}$ & $\begin{array}{l}\text { 10. PROGRAM ELEMENT PROJECT, TASK } \\
\text { AREA \& WORK UNIT NUMUERS }\end{array}$ \\
\hline \multirow{2}{*}{ 11. CONTROLLING OFFICE NAME AND ADDRESS } & $\begin{array}{r}\text { 12. REPORT DATE } \\
1980\end{array}$ \\
\hline & 13. NUMBER OF PAGES 145 \\
\hline \multirow[t]{2}{*}{ Ta. MONITORING AGENCY NAME A AODRESS(II dIllerent from Controlline Ollice) } & $\begin{array}{l}\text { 15. SECURITY CLASS. (ol thle roport) } \\
\text { UNCLASSIFIED }\end{array}$ \\
\hline & $\begin{array}{l}\text { 15. DECLASSIFICATION/DOWNGRADING } \\
\text { SEHEDULE }\end{array}$ \\
\hline
\end{tabular}

16. DistRIBUTION STATEMENT (of thlo Report)

This document has been approved for public release and sale;

its distribution is unlimited.

17. OISTRIBUTION STATEMENT (of the abatgact enterod in Block 20, It dilferent (roen Repopt)

18. SUPPLEMENTARY NOTES

19. KEY WORDS (Continue on reveree side If neceecery end loentlly by block number)

Brittle Materials Design

Ceramic Processing

Ceramic Reliability

Fracture Modes

Gas Turbines

Heat Engines

Iterative Test \& Development
Life Prediction - Ceramics

Materials Characterization

Materials Development

Nondestructive Testing \& Evaluation

Powder Processing

Proof Testing

Quality Control

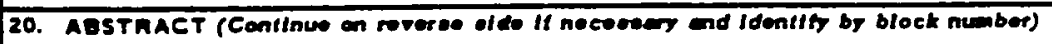

The potential for use of monolithic ceramics in lieat engines presents an attractive possibility for significant improvement in engine durability, efficiency, and multi-fuel capability. Moreover, many ceramics possess hot-corrosion and oxidation resistance properties that are much superior to those of any metal alloy. Still another impetus for considering ceramics for heat engine applications is their eventual relative low cost and 


\section{(ABSTRACT - Continued)}

availability, in contrast with the short supply of such expensive metals as cobalt, tungsten, nickel, and columbium, and the uncertain future avallability of less expensive metals such as chromium.

However, certain problems are involved in using ceramics in engine applications which stem basically from the nonductile nature of these materials. This requires the use of very precise analyses and test techniques to assist the designer in applying ceramic load-bearing components in engines. While some such techniques and methodologies are now available, much more data are required on the reliability of ceramics for these applications. The problems which must be addressed to provide acceptable levels of reliability, require further developments in design methodology, quality assurance, and testing procedures for their solution. Perhaps the most crucial problem is that of providing a system to maintain iterative test and development programs which integrate all of the above technology areas and assure effective feedback among them. Such problems and issues are discussed in this report, and recommendations for appropriate research and development programs are presented
and documented. 


\section{RELIABILITY OF CERAMICS FOR}

HEAT ENGINE APPLICATIONS

Report of

The Committee on Reliability of Ceramics for Heat Engine Applications

NATIONAL MATERIALS ADVISORY BOARD Commission on Sociotechnical Systems National Research Council

Publication NMAB-357

National Academy of Sciences

Washington, D.C.

1980 


\section{NOTICE}

The project that is the subject of this report was approved by the Governing Board of the National Research Council, whose members are drawn from the Councils of the National Academy of Sciences, the National Academy of Engineering, and the Institute of Medicine. The members of the committee responsible for the report were chosen for their special competence and with regard for appropriate balance.

This report has been reviewed by a group other than the authors according to procedures approved by a Report Review Committee consisting of members of the National Academy of Sciences, the National Academy of Engineering, and the Institute of Medicine.

This study by the National Materials Advisory Board was conducted under Contract No. MDA903-78-C-0038 with the Department of Defense and the National Aeronautics and Space Administration.

This report is for sale by the National Technical Information Service, Springfield, Virginia 22151.

Printed in the United States of America. 


\begin{abstract}
The potential for use of monolithic ceramics in heat engines presents an attractive possibility for significant improvement in engine durability, efficiency, and multi-fuel capability. Moreover, many ceramics possess hot-corrosion and oxidation resistance properties that are much superior to those of any metal alloy. Still another impetus for considering ceramics for heat engine applications is their eventual relative low cost and availability, in contrast with the short supply of such expensive metals as cobalt, tungsten, nickel, and columbium, and the uncertain future availability of less expensive metals such as chromium.

However, certain problems are involved in using ceramics in engine applications which stem basically from the nonductile nature of these materials. This requires the use of very precise analyses and test techniques to assist the designer in applying ceramic load-bearing components in engines. While some such techniques and methodologies are now available, much more data are required on the reliability of ceramics for these applications. The problems which must be addressed to provide acceptable levels of reliability require further developments in design methodology, quality assurance, and testing procedures for their solution. Perhaps the most crucial problem is that of providing a system to maintain iterative test and development programs which integrate all of the above technology areas and assure effective feedback among them. Such problems and issues are discussed in this report, and recommendations for appropriate research and development programs are presented and documented.
\end{abstract}


This Page Intentionally Left Blank 
PREFACE

The significant improvements in operating efficiencies that can be obtained through operation of heat engines at temperatures above those that can be attained with high-temperature metals and superalloys are well known. Recent advances in the field of ceramics have resulted in materials that have high-temperature capabilities, as well as improved mechanical properties and resistance to chemical attack. However, the structural use of these ceramics introduces problems arising from lack of experience which require resolution by development of design techniques, materials development, and materials processing approaches.

In view of this situation, in 1978 the Department of Defense, Office of the Deputy Under Secretary of Defense for Research and Engineering, requested that the National Materials Advisory Board (NMAB) of the National Research Council undertake a committee study on the Reliability of Ceramics for Heat Engine Applications. The purpose of the study effort was to identify the principal gaps in the state of understanding of ceramic materials, failure origins, nondestructive testing, life prediction, and proof testing; and to outline a more rigorous understanding of how various candidate ceramic materials can be used in the production of reliable component parts for gas turbine applications. The committee was requested also to suggest concepts and approaches designed to give a more rigorous definition of the integrity of ceramic engine components and how better integrity of ceramic engines can be attained. The findings of the committee in these regards are contained in this report.

In the work of the committee, valuable presentations of data and opinions were made by several individuals. Thus, the Committee on Reliability of Ceramics for Heat Engine Applications wishes to thank and acknowledge the assistance provided by the following persons: Herbert Probst and Richard Ashbrook, National Aeronautics and Space Administration; Norm Tallan and Henry Graham, United States Air Force; Robert Katz and Edward Lenoe, Army Materials and Mechanics Research Center; Roy Rice, Naval Research Laboratory; Jerome Persh, Department of Defense; Edward Van Reuth, Defense Advanced Research Projects Agency; and Don Groves of the National Materials Advisory 
Board. The committee also wishes to express its appreciation to those who were invited to share their technical expertise with the committee with regard to design, production, and quality control for ceramics used in heat engines. These are: Jack Tree, AiResearch Manufacturing Company; Roy Kamo, Cummins Engine Company; Robert J. Longenecker, Kawecki Berylco Industries, Inc.; Gene Fisher, Ford Motor Company; John A. Coppola, Carborundum Company; Peter Heitman, Detroit Diesel Allison Division, General Motors Corporation;

B. T. Khuri-Yakub, Stanford University; and John J. Schuldies, AiResearch Company.

Finally, I want to acknowledge the considerable help provided by my secretary, Ms. Donna Cahill, for assistance in typing the preliminary versions of the manuscript.

Seymour Bortz, Chairman

Committee on the Reliability

of Ceramics for Heat Engine Applications

National Materials Advisory Board 
COMMITTEE ON RELIABILITY OF CERAMICS

FOR HEAT ENGINE APPLICATIONS

\section{Chairman}

SEYMOUR A. BORTZ, IIT Research Institute, Chicago, I11inois

Members

RICHARD BRADT, Ceramics Science \& Engineering Section, Pennsylvania State University, University Park, Pennsylvania

WINSTON H. DUCKWORTH, Ceramic Division, Battelle-Columbus Laboratories, Columbus, Ohio

FREDERICK F. LANGE, Rockwell International Science Center, Thousand Oaks, California

ANTHONY PALUSZNY, Scientific Research Laboratory, Ford Motor Company, Dearborn, Michigan

DAVID W. RICHERSON, AiResearch Manufacturing Company of Arizona (Division of Garrett Corporation), Phoenix, Arizona

JOLN E. RITTER, Mechanical \& Aerospace Engineering, University of Massachusetts, Amherst, Massachusetts

SHELDON M. WIEDERHORN, Physical Properties Section, Organic Materials Division, National Bureau of Standards, Washington, D.C.

\section{Technica1 Consultant}

R. J. H. BOLLARD, Department of Aeronautics \& Astronautics, University of Washington, Seattle, Washington 


\section{Liaison Representatives}

RICHARD ASHBROOK, Lewis Research Center, National Aeronautics \& Space Administration, Cleveland, Ohio

JOHN W. FAIRBANKS, Division of Fossil Fuel Utilization, Department of Energy, Washington, D.C.

HENRY GRAHAM, Air Force Materials Laboratory, Wright-Patterson Air Force Base, Dayton, Ohio

ROBERT N. KATZ, Ceramics Division, U.S. Army Materials \& Mechanics Research Center, Watertown, Massachusetts

EDWARD LENOE, Ceramics Division, U.S. Army Materials \& Mechanics Research Center, Watertown, Massachusetts

JEROME PERSH, Office of Deputy Under Secretary of Defense for Research \& Engineering (Engineering Technology), The Pentagon, Washington, D.C.

ROY W. RICE, Ceramics Branch, Materials Science \& Technology Division, Naval Research Laboratory, Washington, D.C.

NORMAN TALLAN, Air Force Materials Laboratory, Wright-Patterson Air Force Base, Dayton, Ohio

EDWARD C. VAN REUTH, Materials Sciences Office, Defense Advanced Research Projects Agency, Arlington, Virginia

\section{NMAB Staff}

DONALD G. GROVES, Staff Engineer 


\section{TABLE OF CONTENTS}

1 SUMMARY AND RECOMMENDATIONS

$\begin{array}{llr}1.1 & \text { Introduction } & 1 \\ 1.2 & \text { Conclusions } & 2 \\ 1.3 & \text { Recommendations } & 4 \\ 1.3 .1 & \text { Recommendations for Short-Life } & 4 \\ & \begin{array}{l}\text { Applications } \\ 1.3 .2\end{array} & \begin{array}{l}\text { Recommendations for Long-Life } \\ \text { Applications }\end{array}\end{array}$

2 DESIGN METHODOLOGY

2.1 Introduction 9

2.2 Stress and Deformation Analysis 11

2.3 Strength Modeling 12

2.4 Design Practice 13

2.5 Technology Limitations and Current

2.5.1 Failure and Fracture Statistics 15

2.5.2 Quality of Failure Data 16

2.6 Proof Testing 17

2.7 Conclusions and Recommendations 17

References $\quad 20$

3 MATERIALS DEVELOPMENT AND MANUFACTURING

3.1 Introduction 23

3.2 Raw Material Selections 24

3.3 Powder Processing 25

3.4 Preconsolidation 26

$3: 5$ Consolidation 28

3.6 Green Machining 30

3.7 Densification (Sintering) 31

3.8 Postdensification Machining 33

3.9 Inspection 34

3.10 New Materials Development 35

3.10.1 Heat Exchanger Materials 35

3.10.2 Insulation Materials 35

3.10.3 Increased Fracture Resistance · 36

3.10.4 Chemical Vapor Deposition (CVD) 36

3.10.5 Sintered Materials 37

3.10.6 Hot Isostatically Pressed Materials 38

3.10.7 New Compounds 39

3.10.8 New Processes $\quad 39$

3.11 Conclusions and Recommendations 40

References $\quad 43$ 
TABLE OF CONTENTS (Cont'd)

CHAPTER

PAGE

4 MATERIALS CHARACTERIZATION

4.1 Introduction 47

4.2 Strength Analysis $\quad 47$

4.2.1 Failure Criterion 47

4.2.2 Stress-State Effects 48

4.2.3 Factors Affecting $K_{\mathrm{IC}} \quad 50$

4.2.4 The Nature of Strength-Controlling Flaws 51

4.2.5 Flaw Populations in Ceramics 52

4.2.6 Stable Crack Growth 57

4.3 Test Methods for Structural Ceramics 57

4.3.1 Strength Tests 57

4.3.2 Fracture Mechanics Tests 58

4.4 Fractography of Ceramics 60

4.5 Effects of Engine Environments on $\mathrm{Si}_{3} \mathrm{~N}_{4}$

4.5.1 Oxidation 61

4.5.2 Corrosion 63

4.5.3 Erosion 66

4.5.4 Cyclic Fatigue $\quad 69$

$\begin{array}{lll}4.5 .5 & \text { Vibration } & 70\end{array}$

4.5.6 Contact Loading 71

4.5.7 Temperature 73

4.5.8 Therma1 Shock 73

4.6 Recommendations 74

$\begin{array}{ll}\text { References } & 76\end{array}$

5 QUALITY CONTROL

5.1 Introduction 81

5.2 Nondestructive Evaluation 81

5.2.1 Current NDE Tools for Ceramics 82

5.2.2 Status of Emerging Developments 84

5.2.3 Summary of NDE Capabilities 85

5.2.4 Acceptance/Rejection Criteria 87

5.3 Proof Testing 89

5.3.1 Summary of Proof Testing 90

5.4 Fracture Models 90

5.4.1 Crack Size Responsible for Failure 90

5.4.2 Effect of Crack Location 94

5.4.3 Crack Shape and Orientation 94

5.4.4 Flaws as Stress Concentrators 94

5.4.5 Pores : 96

5.4.6 Experimental Data for $\mathrm{Si}_{3} \mathrm{~N}_{4} /$ Inclusion 96 


\section{TABLE OF CONTENTS (Cont'd)}

\section{CHAPTER}

PAGE

5

5.4 .7

Oxidation-Flaw Generation

96

5.4 .8

Summary of Fracture Models

98

5.5

Status of Life Prediction

98

5.5.1 Crack Growth Kinetics

98

5.5.2 Techniques for Characterizing Crack

Growth Kinetics

99

5.5.3 Data Extrapolation for Long-Term

$\begin{array}{ll}\text { Lifetime Predictions } & 101\end{array}$

5.5.4 Experimental Verification of the Basic Equations

103

5.5.5 Summary of Life Prediction Theory 106

5.6 Recommendations 109

References $\quad 112$

6 CASE HISTORY OF AN ITERATIVE DESIGN

$\begin{array}{lll}6.1 & \text { Introduction } & 117 \\ 6.2 & \text { Case History } & 117 \\ 6.3 & \text { Conclusions } & 122\end{array}$

$\begin{array}{ll}\text { APPENDIX } & 123\end{array}$ 
This Page Intentionally Left Blank 


\section{LIST OF FIGURES}

2-1 Flow Chart of Major Elements of Ceramic Technology and Iterative Development

4-1 Fracture-Initiating Flaws in a Glass

4-2 Weibul1 Plots of $\mathrm{Al}_{2} \mathrm{O}_{3}$ (Alsimag 614) Strength

4-3 Weibul1 Plot of the Data Obtained in Three Different Sizes of an Alumina Ceramic Tested in Dry Nitrogen. Failure Probabilities for the Small and Large 4-Point Bend Data Have Been Normalized to Those of the Small 3-Point Bend Specimen.

4-4 Results of Exposure of Hot-Pressed $\mathrm{Si}_{3} \mathrm{~N}_{4}$ and SiC in a Turbine Passage

4-5 Behavior of SiC in Gas-Molten Salt

5-1 Flexural Strength of Hot-Pressed $\mathrm{Si}_{3} \mathrm{~N}_{4}$ Seeded with Different Types of Inclusions vs. the Size of the Inclusion

5-2 Comparison of Strength Data for Soda-Lime Glass Before and After Proof Testing in Air Using Very Rapid Unloading Rate

5-3 Comparison of Strength Data for Soda-Lime Glass Before and After Proof Testing in Moist Environment Using Rapid Unloading Rate 


\section{LIST OF FIGURES (Cont'd)}

FIGURE

$\underline{\text { PAGE }}$

5-5 The Effect of a Room Temperature Proof Test

on the High Temperature Strength of

Hot-Pressed Silicon Nitride. The solid

curve gives the expected theoretical

distribution for the high temperature

strengths after proof testing.

5-6 - Proof Test Diagram Comparing Three

Representations of Crack Propagation Data

from an Ultralow Expansion Glass

5-7 Proof Test Diagram Comparing Crack Velocity,

Stress Rupture, and Stressing Rate Techniques Used in Determining Crack Growth Constants for Soda-Lime-Silicate Glass

5-8 Proof Test Diagram Comparing Crack Velocity and Stressing Rate Techniques Used in Determining Crack Growth Constants for an U1tralow Expansion Glass

5-9 Proof Test Diagram Comparing Crack Velocity, Stress Rupture, and Stressing Rate Techniques Used in Determining Crack Growth Constants for $\mathrm{Al}_{2} \mathrm{O}_{3}$

5-10 Proof Test Diagram Comparing Crack Velocity, Stress Rupture, and Stressing Rate Techniques Used in Determining Crack Growth Constants for Fused Silica

6-1 Engineering Development History - First Stage RBSN Stator ARPA/Ford Engine - A Case Study of Iterative, Brittle Materials Design 
Chapter 1

SUMMARY AND RECOMMENDATIONS

\subsection{Introduction}

The significant improvements in efficiencies that can be obtained by operating heat engines at temperatures above those that can be attained with high-temperature metals and superalloys are well known. Recent advances in ceramics have resulted in materials that have high-temperature capabilities as well as improved mechanical properties and resistance to chemical attack. However, the structural use of these ceramics introduces problems arising from lack of experience, which require resolution by design techniques, materials, and methods of materials processing.

Such problems have been recognized in past programs sponsored by the Department of Defense (DoD), the Department of Energy (DoE), and the National Aeronautics and Space Administration (NASA). In this work, ceramic components have been studied for advanced turbine, Stirling, and diesel engines. More recently, the DoE has begun research on ceramic turbines for use with coal-derived fuels. The DoD, NASA, and DoE programs have been extremely valuable in demonstrating the technical feasibility of ceramics for these applications. At the same time, they have revealed some of the problems with the reliability of ceramics in service.

The objectives of this study were: (1) to identify the principal gaps in knowledge of ceramic materials -- failure origins, nondestructive testing, life prediction, and proof testing; and (2) to outline how a more rigorous understanding of this class of materials can be used in the production of reliable component parts for heat engine applications.

Performance goals for military engines and national needs for fuel economy and environmental quality at affordable costs are responsible for the current emphasis on ceramics for heat engines. Recognizing the very high potential payoff to be obtained from successful exploitation of ceramics for heat engines, the Defense Advanced Research Projects Agency (DARPA) initiated a major program in "Brittle Materials Design" in 1971. The objective was to encourage the use of ceramic materials in heat engines by demonstrating 200-hour durability of ceramic components in an engine environment. This program was spurred by two technological developments necessary for such exploitation: (1) advances in finite-element stress analysis; 
and (2) new families of low-thermal-expansion, high-temperature ceramics which were approaching sufficient development to warrant a major demonstration program. Encouraged by the successes in component demonstration emerging from this iterative "Brittle Materials Design" program, the Department of Energy (DoE) and the National Aeronautics and Space Administration (NASA) initiated ceramic-engine programs aimed at highway vehicles. Subsequently, DoE initiated a program to utilize ceramics in high-temperature power turbines fired with coal-derived fuels.

Some of the major ceramic technology demonstrations achieved by these programs are 1isted in Table 1-1. These successes have been instrumental in changing the outlook among heat-engine designers. Considered a rather peculiar notion in 1971, ceramics for a wide variety of heat engines are now real engineering options. Such a major turnaround in outlook by the design community in eight years constitutes a major success of the existing ceramic demonstration programs. However, these programs also have defined problems to be resolved in the next phase of development and demonstration -- namely, the need for components and engines reliable enough to justify a commitment to manufacturing.

It is worth noting that the major progress attained to date has entailed a smaller total investment than is normally required to develop a new derivative gas turbine for aircraft application.

The problems that must be solved to provide requisite levels of reliability require further developments in design methodology, materials processing, component fabrication, materials development, quality assurance, and testing procedures including engine tests. Perhaps the most crucial problem is providing mechanisms to maintain iterative test and development programs that integrate all of the above technology areas and assure effective feedback loops among them. It is important to note that the reliability issues and requirements vary from component to component, depending on duty cycle, power level, etc. Accordingly, the recommendations of this report distinguish between the major issues for limited-life and extended-life engines.

\subsection{Conclusions}

It is concluded that limited-life engines utilizing ceramics in the rotating and static turbine components are feasible. Ceramic engine programs have already demonstrated 50 hour component lifetimes, and in general have shown that design with brittle materials is a reality. Engine manufacturers can build engines for feasibility demonstrations using the materials and manufacturing processes currently available. What remains to be demonstrated for these limited-life applications is whether such engines can produce the 
TABLE 1-1 Highlights of Heat-Engine Ceramic Technology Demonstration Program

\begin{tabular}{|c|c|c|c|}
\hline PROGRAM & & ACHIEVEMENT & COMMENT \\
\hline \multirow[t]{2}{*}{$\begin{array}{l}\text { DARPA/Ford } \\
\text { Gas Turbine } \\
\text { Test Engine }\end{array}$} & 1974 & $\begin{array}{l}\text { 50-h demonstration of an engine } \\
\text { with ceramic stationary compo- } \\
\text { nents and metal rotors } 1930^{\circ} \mathrm{F} \\
\text { (TIT) }\end{array}$ & $\begin{array}{l}\text { First integration of } \\
\text { multiple ceramic compo- } \\
\text { nents into an operating } \\
\text { engine }\end{array}$ \\
\hline & 1977 & $\begin{array}{l}36.5-\mathrm{h} \text { single-state engine } \\
\text { demonstration } 2200^{\circ}-2500^{\circ} \mathrm{F}+ \\
\text { (TIT) } 45-50,000 \mathrm{rpm} \text { with } \\
\text { ceramic rotor }\end{array}$ & $\begin{array}{l}\text { First integration and } \\
\text { successful demonstration } \\
\text { of an uncooled all- } \\
\text { ceramic flow path at } \\
\text { temperatures beyond } \\
\text { superalloy capability }\end{array}$ \\
\hline \multirow[t]{2}{*}{$\begin{array}{l}\text { DoE/Ford } \\
\text { Regenerator } \\
\text { Program }\end{array}$} & $977-1978$ & $\begin{array}{l}200-\mathrm{h} \text { rig demonstration of all- } \\
\text { stationary hardware to } 2500^{\circ} \mathrm{F} \\
-- \text { rotor to approximately } \\
2200^{\circ} \mathrm{F}\end{array}$ & $\begin{array}{l}\text { 200-h capability } \\
\text { demonstration }\end{array}$ \\
\hline & 1978 & $\begin{array}{l}\text { 10,000-h regenerator life } \\
\text { demonstrated in engines. } \\
1900^{\circ} \mathrm{F}(\mathrm{TIT})\end{array}$ & $\begin{array}{l}\text { Regenerator problem } \\
\text { solved }\end{array}$ \\
\hline $\begin{array}{l}\text { Army/solar } \\
10 \mathrm{KW} \\
\text { Turboalternator }\end{array}$ & 1978 & $\begin{array}{l}\text { 50-h demonstration of engine } \\
\text { with hybrid RBSN/HPSN/RSSIC } \\
\text { nozzle } 1750^{\circ} \mathrm{F} \text { (TIT) }\end{array}$ & $\begin{array}{l}\text { First ceramic-configured } \\
\text { engine providing elec- } \\
\text { tric power at required } \\
\text { performance levels }\end{array}$ \\
\hline $\begin{array}{l}\text { DoE-NASA/ } \\
\text { Detroit } \\
\text { Diesel Allison } \\
\text { GT-404 Test } \\
\text { Engine }\end{array}$ & 1978 & $\begin{array}{l}1200+-h \text { demonstration of } \mathrm{KT} \\
\mathrm{SiC} \text { stator vanes in engine } \\
1900^{\circ} \mathrm{F} \text { (TIT) }\end{array}$ & $\begin{array}{l}\text { No obvious deterioration } \\
\text { in the engine environ- } \\
\text { ment: first 1000-h+ } \\
\text { engine test of flow path } \\
\text { component. Engine } \\
\text { operating as a prime move } \\
\text { in a truck. }\end{array}$ \\
\hline $\begin{array}{l}\text { Army/Cummins } \\
\text { Adiabatic } \\
\text { Diesel }\end{array}$ & 1978 & $\begin{array}{l}250-\mathrm{h} \text { full engine performance } \\
\text { demonstration of HPSN Piston } \\
\text { cap. max. temp. approx. } \\
1750^{\circ} \mathrm{F}\end{array}$ & $\begin{array}{l}\text { First successful demon- } \\
\text { stration of a dynamic } \\
\text { component in a heat } \\
\text { engine to meet perform- } \\
\text { ance goals. }\end{array}$ \\
\hline NAVAIR/Garrett & 1978 & $\begin{array}{l}\text { Integration of more than } 100 \\
\text { ceramic components into an } \\
\text { engine. Engine run at design } \\
\text { conditions } 2200+{ }^{\circ} \mathrm{F}\end{array}$ & $\begin{array}{l}\text { Multistage ceramic } \\
\text { turbine largest engine } \\
\text { run to date. Most } \\
\text { components successfully } \\
\text { integrated into all. } \\
\text { engines. }\end{array}$ \\
\hline
\end{tabular}

TIT = Turbine Inlet Temperature

RBSN = Reaction Bonded Silicon Nitride

RSSIC = Reaction Sintered Silicon Carbide

HPSN $=$ Hot Pressed Silicon Nitride 
efficiencies and other benefits projected for the use of ceramics in heat engines.

The application of ceramics in long-life engines presents more formidable problems than those mentioned above. These problems are due to the lack of adequate or proven nondestructive evaluation (NDE) and proof testing approaches for the basis of acceptance or rejection criteria; the paucity of reliable data bases for materials properties as well as for ceramic engines (e.g., their failure modes); and finally, a lack of investigative programs predicated upon giving data that can be used to establish design limits.

An additional conclusion that pervades all of this work is that innovative designs should be encouraged. Examples of this design approach include the use of ceramics under compressive loading (i.e., prestressing tehcniques); the use of ceramic-matrix composites (note: refractory carbines and carbon-carbon composites have been used satisfactorily under stress conditions); and the use of appropriate coatings designed to protect materials from high temperature heat engine corrosion.

\subsection{Recommendations}

This section is divided into recommendations for short- and long-life application. The recommendations for short-life application also apply to long-1ife application.

\subsubsection{Recommendations for Short-Life Applications}

\section{(1) Manufacture of a Consistent Product}

Important gains in reliability can be achieved by decreasing the variability of the strength of components, particularly if their high-mean strengths are retained in the process. Variations in the chemistry, microstructure, and surface finish of materials must be controlled. Such gains have been realized in the ceramic industry when specific products -- spark plugs, grinding wheels, etc. -- have been mass produced.

\section{Recommendation:}

In order to achieve more reliable ceramic components for heat engine use, it is recommended that cooperative development programs be established between ceramic material suppliers and component manufacturers. With such interaction emphasis can be directed toward (1) continuing to improve existing materials, (2) developing new materials, and (3) evolving intelligent specifications for materials. 
A corollary to this recommendation relates to the need in any controlled ceramic manufacturing program for correlating processing parameters with selected microstructural characteristics of the product. Additionally, there is a need for enhancing the capability for correlating such features of the character of the product with Its properties and behavior.

\section{(2) Quality Assurance}

Engine testing is the only proven method for assuring component/design reliability. However, because of the low toughness and variable strength of current ceramics, engine testing of all ceramic components is impractical. Thus, two different, but complementary, quality assurance methods -- nondestructive evaluation (NDE) and proof-testing -- are under development. Both require the development of improved tests and analytical procedures.

Although the potential for detecting flaws of critical size by NDE techniques exists, criteria for accepting or rejecting a component have not been developed. For simple shapes, overload proof-testing methodology has been developed, but lacks adequate component verification. For complex shapes, no proof-test has been developed.

\section{Recommendation:}

Nondestructive evaluation (NDE) techniques should be further developed and used as a vital element of present and future ceramic heat engine development programs. In this evolutionary process, acceptance or rejection criteria for NDE must also be developed. Various NDE methods that currently show special promise, but require additional development, include high frequency C-scan and other ultrasonic methods, surface wave techniques, and microfocus $X-r a y$ techniques.

(3) Iteration of Design, Test, Materials Development and Component Manufacture

The exploitation of ceramic materials is in an early stage relative to metals. Current programs do not allow sufficient iteration of component design, testing, and materials and process development. Such iterations are essential for the efficient development of experience and confidence in the use of ceramics in heat engine applications:

\section{Recommendation:}

Future ceramic programs must have long-range goals to permit enough iterations in component design, manufacture, and engine testing and should provide for planned testing to destruction to verify and 
improve design methodology. These programs also should be structured to insure closure of the information loop between material and engine manufacturers. Alternate areas of investigation that should be evaluated are ceramic matrix components, compliant ceramics, and design of major ceramic components in compression.

\subsubsection{Recommendations for Long-Life Applications}

(1) Materials Development

For some long-term heat engine applications, there is a serious question as to what ceramic materials can be utilized. While a few of such materials that are in the experimental stage show promise for these long-term applications, they still require verification testing.

Recommendation:

Research based on the relationships among fabrication, microstructure, and properties of ceramic material systems should be encouraged. Science based materials programs to develop new materials for long-1ife, high-temperature heat engine applications are particularly recommended. These programs should emphasize the development of materials to meet critical requirements -- e.g., thermal shock and contact damage resistance - of the heat-engine environment. These developments must be coupled by some mechanism with materials manufacturing capability so that promising materials can be made commercially available for use in heat engines.

(2) Long-Term Environmental Effects and Life Prediction Methodology

Current programs use designs based primarily on fast-fracture criteria. For long-life applications, time-dependent effects such as slow crack growth, creep, new flaw generation, and environmental effects such as oxidation and corrosion must be incorporated into the lifeprediction methodology.

Recommendation:

Programs must be defined which develop life-prediction models that account for time-dependent and environmental sources of flaw initiation or flaw growth and changes in the properties of ceramic materials in heat engines. Concurrent programs must experimentally generate a data base and determine the mechanisms and kinetics required to verify or modify the life-prediction models. 
(3) Component Design for Long Life

Designs suitable for limited-life applications may not be suitable for long-life applications. Of special concern are metal-ceramic and ceramic-ceramic interfaces. Conditions at such interfaces can change with time because of friction, relative motion, oxidation, or other effects not observed in the limited time accumulated in tests to date.

Other design modifications may be required for economic manufacturability or to accommodate stress-rupture, fatigue, vibration, oxidation or corrosion, or other properties of a specific material.

Recommendation:

Programs should be initiated to determine design modifications and innovations that may be required for long-life applications of ceramics in heat engines. In particular, the effects at interfaces under typical cyclic engine loading must be evaluated as a function of time. 
This Page Intentionally Left Blank 


\section{Chapter 2}

\section{DESIGN METHODOLOGY}

\subsection{Introduction}

Considerable progress has been achieved over the past 10 years in design methodology, primarily through programs funded jointly by DoD, DoE, NASA, and industry and aimed at demonstrating high-temperature operation of ceramic hardware in actual engines. These programs fostered development of brittle materials design methodology within the framework of a complex iterative process that constitutes ceramic technology. The main features of the process are shown schematically in Figure 2-1, taken from McLean and Davis. (1) As shown in the diagram, the design activity is integrated very closely with material sciences, fabrication, nondestructive evaluation (NDE), and testing. The iterative approach on which the ceramic technology was structured in the referenced program (Ford/ARPA) provided for maximum interaction and immediate feedback between various disciplines. This close interaction has proven extremely effective throughout the Ford/ARPA program. It has facilitated quick identification of potential problem areas and has given everyone involved a much better understanding of structural ceramics. This technique is the one that recently has been generally used for designing components for heat engines. Other approaches are being investigated, but their effectiveness relative to the iterative approach is not known. Some of these techniques will be mentioned later in this section.

The design methodology that evolved for brittle materials addressed both the development of advanced analytical tools and techniques and the development of design practice for high-temperature structural ceramics. This latter aspect of the design methodology encompasses design and development of structural interfaces, attachments, assembly procedures, selection of fits, tolerances, surface finishes, etc. These steps, although routine with ductile metallic materials, require special attention in ceramic designs on account of the unforgiving nature of brittle materials. The state of the art in these two aspects of ceramic design methodology -- analytical techniques and design practice -- is reviewed in the following subsections. 


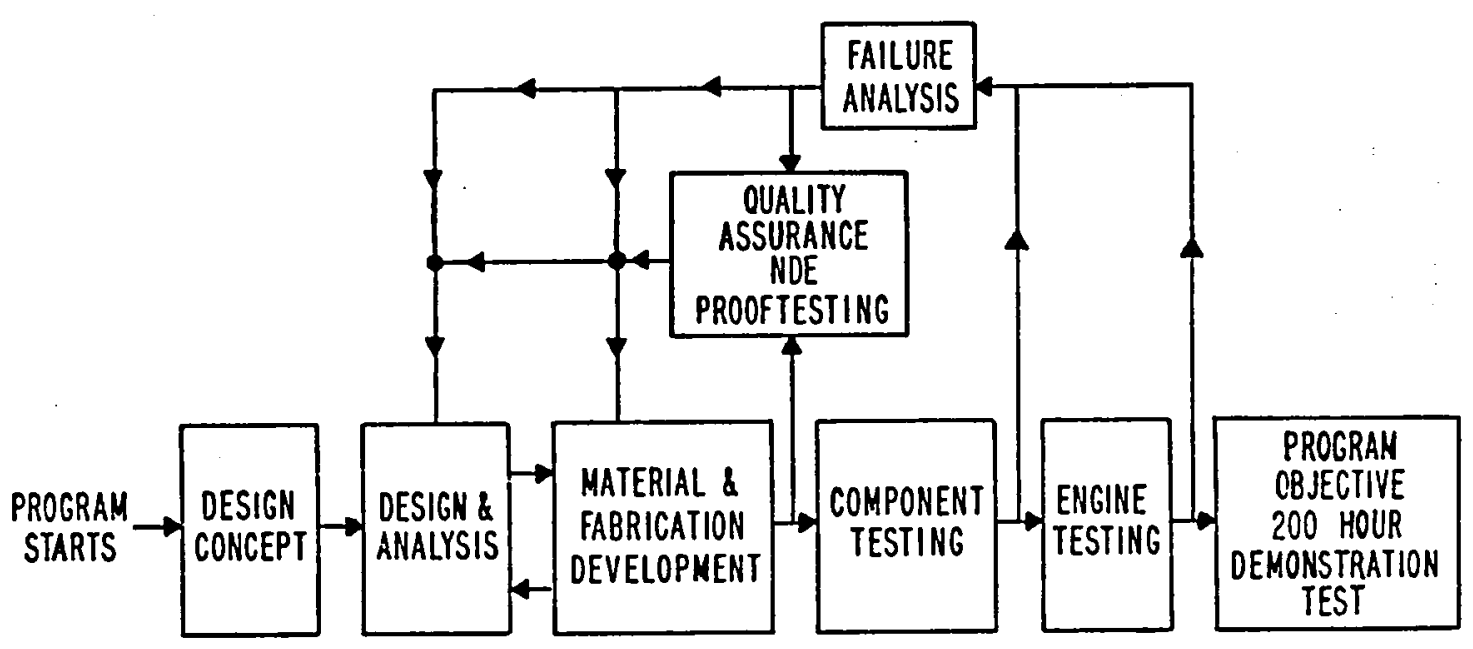

FIGURE 2-1 Flow Chart of Major Elements of Ceramic Technology and Iterative Development 


\subsection{Stress and Deformation Analysis}

Lack of ductility, or brittleness, in a material manifests itself in:

- Limited strain tolerance;

- Considerable variability in strength properties.

The limitation in strain tolerance necessitates very accurate modeling of service loadings and prediction of the resulting strains and deformations on a local scale. Advanced finite difference and finite element codes have been developed for this purpose and are available commercially. Most of these codes can be used to analyze, with a good degree of accuracy, temperature distributions, stresses, and deformations in geometrically complex, three-dimensional structures subjected to thermal, inertial, and other mechanical loadings.

The finite element method (FEM) has one intrinsic shortcoming: it cannot accurately define stresses at the free boundaries. Since failures of ceramic structures often originate at free surfaces, accurate determination of these stresses is extremely important. Methods are beoing developed to fill the gap in this area. A very promising method, the boundary integral evaluation, utilizes the powerful features of FEM while accurately predicting free surface stresses. A method always available to the designer is superposition, whereby the residual normal stresses introduced by FEM at the fress boundaries are eliminated by superposition of pressure loads that are equal but opposite in sign. This technique, however, is cumbersome, time consuming, and costly.

The modeling of loadings and boundary conditions, as they occur in service, is considerably more complex. For one thing, the loadings themselves are sometimes difficult to define. One instance is the vibratory loads induced in the stator vanes or turbine buckets of a gas turbine engine by fluid stream discontinuities. Furthermore, components operating in an engine environment interact with the surrounding structures and in the process cause additional constraints and loads to be applied to themselves. To help the designer solve these complex loading and boundary problems, analytical procedures have been devised (2) that allow the interaction of many components or structural elements to be studied in the desired detail in an economical manner. 


\subsection{Strength Modeling}

The treatment of the variability in strength properties of ceramic materials necessitates a probabilistic modeling of strength and a design methodology based on reliability. Two basic modes of failure are generally considered. One is a fast fracture, where a catastrophic failure occurs when a critical stress is reached anywhere in the structure; the other is a time-dependent failure, where the strength of the material changes with time and the structure fails at loads below the fast-fracture values.

In the current ceramic design program, the most widely used model of brittle-material strength is the Weibull weakest-link model. (3) This model is based on the flaw theory, with the assumption that the flaws are distributed randomly with a certain density per unit volume. The model represents the material as a series or chain of elements in which failure depends on the strength of the weakest link. The structure investigated is represented by an assemblage of uniformly stressed, finite elements, and it is assumed that the failure of any one element constitutes the failure of the entire structure. This representation complements the finite element stress codes and is easily adaptable to them. (4) Material strength is assumed to follow Weibull distribution, generally the two-parameter version.

Several versions of the analysis are used for the multiaxially stressed elements, depending on the particular failure criterion assumed to represent the material. In the Weibull failure criterion, the failure-controlling stress is taken as the averaged normal

stress. (4-6) If the maximum stress criterion is used, the controlling stress is the maximum principal tensile stress, (7) with the assumption that the fracture is independent of the other two principal stresses. In the Barnett-Freudenthal approximation, (8-9) the three principal stresses are considered as contributing independently to failure and are integrated individually. (10) This last approximation has been shown by Batdorf (11) to be generally nonconservative, and he suggests that it be considered the upper boundary on reliability. Batdorf's work implies that the maximum stress criterion is equally nonconservative.

Investigators have checked the applicability of the Weibul1 mode1 of brittle strength to hot-pressed $\mathrm{Si}_{3} \mathrm{~N}_{4}$ turbine rotors. They conducted correlative tests in which flat-sided disks $(4,10)$ and contoured turbine rotor hubs $(4)$ were spun to destruction and the results compared with failure predicted on the basis of Weibull strength parameters obtained from standard uniaxial modulus of rupture (MOR) tests

( $1 / 8$ in. $x 1 / 4$ in. $x 3 / 4$ in. test coupon). Remarkably good agreement with theory was demonstrated with both the characteristic burst speed and the distribution, in spite of the fact that the ratio of effective volumes in tension of the rotor disk to the MOR test bar exceeded 300 to 1 . However, considering the limited number of samples in each 
test (25 MOR test bars and four to none spin tests), (4) it is premature to draw definite conclusions about the predictive capabilities of Weibull analysis for the low end of the cumulative distribution curve, 1.e., at the level of failure probabilities considered practical for most heat engine applications.

As explained in Section 4, the strength of many structural ceramics deteriorates when they are exposed to the operating environment of a heat engine. One of the mechanisms identified as responsible for this deterioration is the subcritical crack growth (SCG), which manifests itself in delayed fracture or so-called static fatigue of a component. In static fatigue, as a consequence of SCG, the strength of the component and thus its probability of survival deteriorate with time, and the component fails at a load far below its fast-fracture load. A computer code has been developed for estimating this strength degradation and the resulting time-reliability relation for a ceramic heat-engine structure subjected to a random load history. (12) This life prediction code is compatible with the FEM and Weibull strength codes discussed earlier and is based on a power-functional relation proposed for the SCG model by Evans and Wiederhorn. (13)

\subsection{Design Practice}

Turning to the other aspect of the ceramic design methodology, design practice, it is well to reemphasize that brittle-material design is a generalized form of ductile-material design. Brittle materials are different, and the design process is different, but the difference is one of degree; tension, compression, and shear forces must be handled. The trick is to utilize the material in the most effective manner. The many aspects comprising a design concept must be considered in a different manner for ceramic than for ductile materials. One useful approach employs a critical evaluation of component functionality.

Every feature of a component has a function and, in providing that function, automatically causes constraints and loads to be applied to the structure. The more function the component will provide, the greater the number of loads and constraints on the structure and the greater the probability of failure.

Even relatively simple structures have many features. Every surface, edge, corner, and radius has a function that will affect the component's performance. The simplifying assumptions of ductility which are available in metallic design will not mitigate these effects for ceramic materials. A microfunctional analysis, analogous to the microanalysis used in determining local stress concentrations, is used to identify all of the functions provided by a design. These are then evaluated in an attempt to eliminate all redundant or nonrequired functions. An example of this type of evaluation is the design of the interface between two cylindrical 
bodies, where the service requirement is a closely controlled relative concentricity.

Many of the difficulties of designing with ceramics originate at the interface between the ceramic structure and its operational environment. Factors such as surface condition, contact loading, friction, compliance, (14) chemical compatibility, etc., will all affect the integrity of the structural interface and thus the reliability of individual components or their assemblies. Careful evaluation of each of these factors at the design stage, supplemented by simple bench tests, will greatly enhance the survival probability of the component and shorten its development time. A case in point is the attachment of ceramic turbine rotors to each other and to a metallic shaft in the Ford/ARPA program. $(12,15)$

\subsection{Technology Limitations and Current Developments}

Many problems are being overcome in the design of monolithic ceramics for structural use. Many problems remain.

In order to circumvent these problems and attempt to speed the development of high-temperature structural components, some researchers are beginning to look at compression design concepts for ceramic structural components. (16) These would attempt to place highly loaded ceramic parts in compression loading through either inertial loading or prestressing the part in some manner. This approach would take advantage of ceramics' strong point, high compression strength, and minimize the effects of flaw size and distribution. There are disadvantages to this method, in that the compression forces must be balanced by tension forces somewhere in the system. This means that the reactive part becomes large and cumbersome if it is ceramic; must be cooled in some manner if it is metal or a metal/ceramic composite; or must be protected from the engine environment or from high-temperature reactions between itself and other engine components if it is a high-strength nonmetallic composite such as carbon/carbon or boron/carbon, or a ceramic/ceramic composite such as a carbide fiber in a silicide matrix. Initial paper studies indicate some potential to this approach.(16)

Other problems can be introduced in manufacturing composites. These include packing flaws caused by the inability of powder to flow around the fibrous reinforcement; reduction of fiber strength by high-temperature reactions with the matrix; difficulty in pressing to net shape and the resulting need for final machining and consequent exposure of the reinforcement to the engine environment.

Researchers are just beginning to look at the aspects of structural design with regard to their effects on materials requirements. So little is known that their work cannot yet be evaluated. While this new work 
should be encouraged, it is the opinion of the committee that the present direction, as described in this report, has a greater payoff potential with regard to obtaining greater reliability for ceramic components for heat engine applications. The following sections, while general, have been written with this conclusion in mind.

\subsubsection{Failure and Fracture Statistics}

The statistical analyses of failure currently used in designing ceramic structures are based on certain simplifying assumptions. These assumptions, unless conservative, raise questions as to the appropriateness of such analyses as design tools for critical engine components that are to have high reliability.

One of the restrictive assumptions of the Weibull theory, for example, is that only the component of stress normal to the plane of flaw contributes to failure. In their recent works, Batdorf (17) and Evans (18) have addressed this problem and developed more fundamental approaches to the statistical treatment of fracture under multiaxial states of stress. These analyses account for shear-stress effects and allow analytical relations to be developed for specific distribution functions. Both analyses use as their basis the critical strain energy release criterion. In the same work, Batdorf and Heinisch(17) prove that in neglecting the shear in the plane of the crack, which reduces the normal stress needed to produce fracture, the Weibull theory is conservative in predicting biaxial failure stress on the basis of uniaxial tension data.

At this moment it is difficult to speculate which of these approaches will yield more reliable designs. Limited correlative tests by the individual investigators are inconclusive, and it is evident that considerably more experimentation is required to validate any or all of these analyses. Until this cycle is closed, the designer can only use his judgment in selecting the theory that best suits his purpose.

Fracture statistics is an intrinsic part of a probabilistic design methodology and, as such, is likely to affect its predictive capability and perhaps even the design itself. The subject is discussed separately in this report. Suffice it to say that new, more rigorous approaches to fracture statistics are being developed. $(19,20)$ They indicate that strength distributions can be obtained directly from measured fracture probability data and a knowledge of the location of the fracture-controlling flaws without resorting to assumptions about the nature of the distribution function, which is the shortcoming of the current practice. Again, at this moment, one can only speculate as to which of these approaches is more appropriate in the design stage. 


\subsubsection{Quality of Failure Data}

A more fundamental limitation exists, however, in most of the ongoing ceramic programs, with respect to the ability to design reliable structural components. This is the quality of the data used in the analysis. For example, a turbine rotor designed for a material with a high characteristic strength but low Weibull slope (large dispersion in strength) will be configured differently from a rotor designed for low strength and a large slope. In the first case, the volumetric effects, i.e., the volume of structure under high tension, will control the reliability, and the designer will attempt to reduce it. In the latter case, on the other had, the designer will try to reduce the highest stress as the reliability-controlling factor. Therefore, for the designer to develop a reliable concept, it is extremely important that these two statistical parameters be determined as accurately as possible.

Because of economics, statistical data on the strength of ceramic materials are generally limited to relatively small sample sizes (30 to 50 test coupons). From these data statistical parameters are estimated for a selected distribution function (e.g., the Weibull. function) by an appropriate technique. (21) The uncertaintly in the estimation of these parameters of the Weibull function with a sample size of 30 is quite significant $( \pm 20 \%)$. Increasing the sample size to 130 barely reduces the error to half the value, i.e., $10 \%$.

To compound the problem, the tests themselves are subject to errors. (22) Furthermore, the material tested is often still in the development stage, so that the strength variations observed are likely to be the cumulative result of the intrinsic flaw distribution and the variability of the fabrication parameters. Most importantly, the underlying premise of a probabilistic design methodology is the assumption that the material of the structure is statistically the same as that of the test coupons. It is well known that the strength properties of ceramics depend strongly on the fabrication process. Unless care is exercised in obtaining test coupons that are representative of the fabricated component, the strength distribution of the material in the fabricated component can be expected to differ considerably from the strength distribution derived from test coupons. In most current programs, the strength data used by designers are obtained on virgin material. Environmental effects, such as oxidation, corrosion, etc., discussed in Section 4, are neglected, as a rule, for lack of proper characterization. Although these effects may be omitted for many ceramics in some short-life applications, their omission will lead to grave errors in designing reliable components for long service life.

These different sources of error affect the quality of data available to the designer and raise uncertainties as to the adequacy or reliability of his design. Therefore, to improve the reliability of future designs, statistically meaningful sample sizes are needed, 
based either on large numbers of test specimens or test specimens with considerably increased volume in tension. The tests themselves must be analyzed for error and screened statistically. It is, of course, of utmost importance that the test specimens represent statistically as closely as possible the fabricated structure and that they reflect any strength degradation that the material may be subject to as a result of environmental effects. When this is not possible, the designer's only alternative at present is proof testing.

\subsection{Proof Testing}

Proof testing is essentially a quality control tool used by the designer to overcome the inadequacy of his predictive tools and to enhance reliability of the structure by destructively eliminating occasional weak components. The proof test, in effect, changes the two-parameter Weibull ditribution into a three-parameter distribution, with the proof stress becoming the zero-probability-of-failure stress, i.e., the third parameter that is directly determined in tests. The full significance of this has been aptly summed up by Dukes in his "Handbook of Brittle Material Design Technology":(5) "The distribution curve thus has a definite and experimentally determined end point and the use of the curve to predict stress levels for failure probabilities greater than zero becomes a matter of interpolation between available test data rather than extrapolation well beyond the limits of the experimental results."

The determination of an appropriate proof test of a complexly stressed engine component can become involved. To be effective, the proof test must closely simulate the actual level and distribution of the operating stresses. In engine structures which are loaded both thermally and mechanically, such a simulation may prove to be uneconomical, and the stress states in the critical areas of the structure are then approximated by simple, economically attainable loading states. The analysis itself of a proof-tested component is straightforward.(22) In some critical applications, where extremely high service reliabilities are demanded, proof testing may become the only reliable way of guaranteeing their achievement.

The concept of proof testing, in the context described above, is being applied very successfully in the qualification tests of certain structural ceramic turbine components $(23)$ prior to engine and rig tests conducted under the ARPA and DoD contracts.

\subsection{Conclusions and Recommendations}

The basic concepts of designing with brittle materials are fairly well defined. Analytical techniques are available which allow the designer to make rational assessments of the reliability of complex 
ceramic engine components when these are subjected to the operating loads. Whether the methodology, as it currently stands, will meet future reliability demands is difficult to assess for lack of adequate test experience with actual engine hardware. The methodology itself is sound. Limited tests conducted so far with simulated or actual turbine engine hardware show very good agreement with theory. The evidence, however, is still far from adequate to draw far-readhing conclusions and to extrapolate the results with confidence to future reliability requirements. Improvements are needed in both the analytical tools and the underlying theories of brittle failure and fracture statistics.

Current analytical tools, sophisticated as they may be, are still far too time consuming and costly to be used on the scale needed to meet the rising demand on reliability. Future programs, therefore, should stress operational efficiency and the adaptation of the more advanced design aids, such as computer graphics.

The reliability-based design methodology described in Subsection 2.2 appears so far to be the only viable approach with brittle materials in which strength varies considerably. This methodology will gain acceptance among designers once it is successfully demonstrated on actual engine hardware. The basic methodology as outlined by Dukes (5) and as it has evolved over the past 10 years $(4,7)$ is not likely to change much. Both the concept and the rationale are sound. Needed, however, is a better data base. The data available to the designer are far from adequate for a truly statistical analysis, and this is one of the most serious handicaps a designer working with ceramics currently faces.

Needed also are improvements and innovations in failure theories of multiaxially stressed brittle structures, in fracture statistics, and in statistical tools in general.

But perhaps the most significant shortcoming of the design methodology for brittle materials, as it stands, is that too few design iterations have been conducted on any one component -- iterations based on test experience from actual engine or rig tests involving the total design cycle from the concept through fabrication, NDE to test evaluation -- to truly assess the methodology's long-range potential.

Needed, therefore, are more ceramic technology programs that are product-oriented and yet closely integrated with basic research -programs that provide for extensive, statistically-meaningful, correlative testing of ceramic engine components under actual or simulated engine operating conditions and that also provide for the natural evolution of these design concepts through design iterations.

Future design concepts likely will remain as individual as the designers themselves. For this reason, it is difficult to generalize 
and to make specific recommendations regarding future trends. Certainly a much deeper understanding of ceramic materials and fabrication processes evolving from ongoing and future ceramic programs will be reflected in much sounder and more reliable designs. 


\section{REFERENCES}

1. McLean, A. F. and Davis, D. A., "The Ceramic Gas Turbine -- A Candidate Powerplant for the Middle and Long Term Future," SAE Publication $760239,1976$.

2. McLean, A. F., Fisher, E. A., and Bratton, R. J., "Brittle Materials Design, High Temperature Gas Turbine." Interim Report Jan. 1, 1972 through June 30, 1972, Ford Motor Co., Dearborn, Michigan. Army Materials and Mechanics Research Center Report, AMMRC-CTR-72-19, Sept. 1972 .

3. Weibull, W., "A Statistical Theory of the Strength of Materials," Ing. Vetenskaps Akad. No. 151, 139, pp. 1-45.

4. Paluszny, A. and Wu, W., "Probabilistic Aspects of Designing With Ceramics," Journal of Engineering for Power, Vol. 99, No. 4, Oct. 1977, pp. 617-630.

5. Dukes, W. H., "Handbook of Brittle Material Design Technology," AD 719712, published by the Advisory Group for Aerospace Research and Development, Paris, France, 1971.

6. Vadar, O. and Finnie, I., "An Analysis of Brazilian Disk Fracture Test Using the Weibul1 Probabilistic Treatment of Brittle Strength," International Journal of Fracture, Vo1. II, No. 3, June 1975, pp. 495-508.

7. Trantina, C. G. and DeLorenzi, H. G., "Design Methodology for Ceramic Structures," ASME Paper No. 77-GT-40, 1977.

8. Freudenthal, A. M., "Statistical Approach to Brittle Fracture," Fracture Vo1. 2, H. Liebovitz, ed., Academic Press, New York, 1968.

9. Barnett, R. L., "Fracture of Brittle Materials Under Transient Mechanical and Thermal Loading," AFFDL-TR-66-220, March 1967.

10. Fessler, H., Sivil1, A. D., and Stanley, P., "Thermo-Mechanical Stress Analysis of Silicon Nitride Components," University of Nottingham, Progress Report 7, April 1, 1973 to Oct. 1, 1973.

11. Batdorf, S. B., "Some Approximate Treatments of Fracture Statistics for Polyaxial Tension," International Journal of Fracture, Vol. B, No. 1, February 1977. 
12. Paluszny, A. and Nicholls, P. F., "Predicting Time-Dependent Reliability of Ceramic Rotors," Proceedings of the Fifth AMMRC Materials Technology Conference -- Ceramics for High Performance Applications, Newport, R.I., March 1977 (Proceedings to be published).

13. Evans., A. G. and Wiederhorn, S. M., "Crack Propagation and Failure Prediction in Silicon Nitride at Elevated Temperature," J. Mater. Sc1., Vo1. 9, 1974, pp. 270-278.

14. Sines, G. and Adams, M., "Compression Testing of Ceramics" Fracture Mechanics of Fracture, Vo1. 3, Bradt, R. C., Hasselman, D. P., and Lange, F. F., eds., Plenum Press, New York, 1978, pp. 403-434.

15. McLean, A. F., Fisher, E. A., and Harrison, D. E., "Brittle Materials Design, High Temperature Gas Turbine," Interim Report July 1, 1971-Dec. 31, 1971, Ford Motor Co., Dearborn, Michigan. Army Materials and Mechanics Research Center Report, AMMRC CTR 72-3, March 1972.

16. Coty, P. J., "Compression-Structured Ceramic Turbine Rotor Concept," Presented at the Sixth Army Materials Conference, Ceramics for High Performance Applications-III Reliability, Rosario Hote1, Orcus Island, Washington, July 10-13, 1979 (Proceedings to be published).

17. Batdorf, S. B. and Heinisch, H. C., Jr., "Weakest Link Theory Reformulated for Arbitrary Fracture Criterion," University of California Report UCLA-ENG-7728, April 1977.

18. Evans, A. G., "A General Approach for the Statistical Analysis of Multiaxial Fracture," Rockwell International, Thousand Oaks, California.

19. Matthews, J. R., McClintock, F. A., and Shack, W. J., "Statistical Determination of Surface Flaw Density on Brittle Materials," Journal of the American Ceramic Society, Vol. 59, No. 7-8, 1976, pp. 304-308.

20. Evans, A. G., "A General Approach for the Statistical Analysis of Fracture," Fracture Mechanics of Fracture, Vol. 3, Bradt, R. C., Hasselman, D. P., and Lange, F. F., eds., Plenum Press, New York, 1978 , pp. $31-49$.

21. Jeryan, R. A., "Use of Statistics in Ceramic Design and Analysis," Proceedings of the Fifth AMMRC Materials Technology Conference -- Ceramics for High Performance Applications, Newport, R.I., March 1977 (Proceedings to be published). 
22. Govila, R. K., "Methodology of Ceramic Life Prediction and Related Proof Testing," Interim FORD-DoE report (To be published).

23. Hartsock, D. L., "Test and Development of Ceramic Combustors, Stators, Nose Cones and Rotor Tip Shrouds," Proceedings of the Fifth AMMRC Materials Technology Conference -- Ceramics for High Performance Applications, Newport, Rhode Island, March 1977 (Proceedings to be published). 


\section{Chapter 3}

\section{MATERIALS DEVELOPMENT AND MANUFACTURING}

\subsection{Introduction}

Reliability of ceramic components begins at material selection and depends upon all the subsequent process steps. Ceramic materials for heat engine applications are at an early stage of development and their reliability can be increased significantly by process improvement and process control. This has been demonstrated for hot pressed $\mathrm{Si}_{3} \mathrm{~N}_{4}$ at Norton Company and for reaction bonded $\mathrm{Si}_{3} \mathrm{~N}_{4}$ at Ford Motor Company. In each case, iterative improvement of process parameters and process controls resulted in increased reproducibility, strength, and Weibull slope. The effect on component survivability was dramatic: before process improvement, the components failed typically during the first cycle; after process improvement, they operated for many cycles and hours.

Further process improvement can and should be conducted for these and other candidate ceramic materials. Depending on the material and its level of development, the Weibull slope (m) ranges from 5 to 12 . With proper processing, Weibull slopes of 20 and above with no decrease in current strength are attainable. This would represent a further dramatic increase in reliability.

Ceramic materials in the silicon nitride $\left(\mathrm{Si}_{3} \mathrm{~N}_{4}\right)$ and silicon carbide (SiC) families are the most prominent candidates for heat engine applications because of their excellent combination of high strength, thermal shock resistance, and oxidation resistance. However, the margin between material strength and component design stress typically is not large for the available materials. Therefore, it is necessary to achieve maximum reproducibility of these materials with minimum property variability and is desirable to develop improved strength. Attainment of both goals and the resulting component reliability depends on manufacturing process control.

In this section, component or material reliability will be discussed in terms of the effects of process control for the general process steps common to the fabrication of $\mathrm{Si}_{3} \mathrm{~N}_{4}$ and $\mathrm{SiC}$ components: 
- Raw material selection

- Powder processing

- Preconsolidation

- Consolidation

- Green machining

- Densification

- Final machining

- Inspection

Process limitations for specific materials will also be discussed, along with recommendations for improved process control and new material process development that will improve the level of component reliability.

\subsection{Raw Material Selections}

The nature of the raw material has a major effect on the final properties of a component. Small particle size is necessary to achieve high strength, as has been discussed by Rice. (1) For instance, hot pressed $\mathrm{Si}_{3} \mathrm{~N}_{4}$ and $\mathrm{SiC}$ typically are fabricated from starting powders having an average particle size under 5 microns.

Raw material reactivity is also important, expecially when pressureless sintering is used and maximum densification is required. The reactivity is primarily a function of particle size or, more specifically, surface area, and chemical condition. Sinterable $\mathrm{Si}_{3} \mathrm{~N}_{4}$ and SiC powders typically are of submicron size with a surface area of around $10 \mathrm{~m}^{2} / \mathrm{g}$.

Particle size distribution is important, and the optimum distribution varies with the consolidation or shaping technique to be used. In most cases the objective of the consolidation step is to achieve maximum particle packing and uniformity so that minimum shrinkage and retained porosity will result during densification.

High temperature properties such as strength, stress rupture life and oxidation resistance are strongly influenced by impurities. (2-4) The effect of the impurity depends on the chemistry of both the matrix material and the impurity, the distribution of the impurity, and the application temperature of the component. The trend during the past few years has been to develop raw materials having higher purity, resulting in significant improvements in high temperature properties.

$\mathrm{Si}_{3} \mathrm{~N}_{4}$, SiC, and many other ceramic compositions can occur in more than one crystallographic form. For instance, $\mathrm{Si}_{3} \mathrm{~N}_{4}$ occurs in two 
forms, $\alpha$ and $\beta$. Studies have shown that $\alpha \operatorname{Si}_{3} \mathrm{~N}_{4}$ is superior to $B \mathrm{Si}_{3} \mathrm{~N}_{4}$ as a starting powder for hot pressing. (5) ${ }^{3} \mathrm{SiC}$ also occurs in different crystallographic forms, $\alpha$ SiC being hexagonal and $\beta$ SiC being cubic. The hexagonal form is more stable at high temperature. When hot pressing or sintering $\beta$ SiC at the required high temperature, small contamination of $\alpha \mathrm{SiC}$ can result in exaggerated grain growth and a decrease in strength. (6) These examples illustrate that it is not adequate to characterize a starting powder only chemically; one must also determine the crystallographic phases.

Most manufacturers of $\mathrm{SiC}$ and $\mathrm{Si}_{3} \mathrm{~N}_{4}$ components have detailed specifications for raw materials which require routine measurement of chemical composition, crystallographic phases, and particle size distribution. Starting powders not meeting the specificaion are either reprocessed or rejected.

\subsection{Powder Processing}

Raw materials usually require additional processing to achieve the optimum particle size distribution or other characteristics necessary to produce a reliable, high strength component. Comminution of powder to the correct size distribution is especially important, since the potential for contamination, inhomogeneity, batch-to-batch variability, and other adverse factors is particularly high for this step in component manufacturing. The following examples will illustrate the problem as it relates to $\mathrm{Si}_{3} \mathrm{~N}_{4}$ and $\mathrm{SiC}$ processes.

Most $\mathrm{Si}_{3} \mathrm{~N}_{4}$ powder used for hot pressing $\mathrm{Si}_{3} \mathrm{~N}_{4}$ is produced initially by the reaction of silicon with nitrogen. The result of this nitridation step is a hard but porous cake of $\mathrm{Si}_{3} \mathrm{~N}_{4}$. This cake must be broken down from its initial size, measured in inches, to a fine powder, measured in microns. Approximately four stages of crushing and grinding are required, using such equipment as jaw crushers, roll crushers, hammer mills, pulverizors, fluid energy mills, classifiers, and ball mills. Most of these steps result in contamination by iron-based alloys. Ball milling, which is used widely to achieve the final particle size distribution, can result in other contamination, depending on the composition of the balls and mill lining. During early development, for example, $\mathrm{Si}_{3} \mathrm{~N}_{4}$ powder was milled with alumina $\left(\mathrm{Al}_{2} \mathrm{O}_{3}\right)$ balls in a porcelain-lined mill. The $\mathrm{Si}_{3} \mathrm{~N}_{4}$ powder picked up nearly 6 percent contamination, resulting in a pronounced reduction in high temperature properties. Later studies, using tungsten carbide balls with either tungsten carbide or rubber-lined mills, resulted in less than 2 percent contamination, and the resulting tungsten phases appeared to have no adverse effect on room-temperature or high-temperature strength.

The situation is similar for SiC. Most SiC is synthesized by the Acheson process, which produces large masses of intergrown SiC crystals 
that must be crushed and ground to micron size. Some contaminants, such as oxygen and alumina, cannot be readily removed. Others, such as iron alloys, can usually be removed chemically by processes such as acid leaching.

Impuritles can degrade high-temperature properties severly. The amount of process control required depends on the individual material and its susceptibility to contamination or impurity-related degradation. Thus, the ceramic-component manufacturer must thoroughly understand the material's properties and how they are affected by process variation and must have process controls that assure reproducibility.

The strength of ceramic materials depends on flaw size, number, and distribution. In powder processing, critical flaws can result either from contamination(7) (large inclusions, local inhomogeneity, or chemical reaction) or from a particle size distribution containing particles that are too large. The large particles or inclusions can be removed by sieving or classification as has been demonstrated by various research and development programs. $(8,9)$ The precise approaches used by commercial ceramic suppliers are proprietary.

The previous paragraphs illustrate the high probability of introducing contaminants when crushing and grinding $\mathrm{Si}_{3} \mathrm{~N}_{4}$ or $\mathrm{SiC}$ to the required particle size distribution. Processes are under development that produce high purity $\mathrm{Si}_{3} \mathrm{~N}_{4}$ and $\mathrm{SiC}$ powders directly in submicron size,(10-12) thus eliminating the need for many of the process steps known to result in contamination. These submicron powders have considerable potential, but they are expensive and have not been optimized to the necessary level of reproducibility.

\subsection{Preconsolidation}

Ceramic components typically are fabricated by compacting (or consolidating) the starting powder into the desired shape and densifying the shape by high temperature techniques that will be discussed later. To achieve a final component having uniform properties and no distortion requires a uniform particle compact. To achieve the required uniformity, the powder usually requires special treatments or processing prior to consolidation. Table 3-1 summarizes some of these preconsolidation considerations for various consolidation approaches.

The preconsolidation steps are additional parts of the fabrication process where contamination can occur. However, they are essential to prevent the formation of severe fabrication flaws during consolidation. For example, a powder that is not free-flowing can result in poor powder distribution in the pressing die and distortion and density variation in the final part. Likewise, improper viscosity control of a casting slurry can result in incomplete fill of the mold or a variety 
TABLE 3-1 Preconsolidation Steps for Several Consolidation Approaches

\begin{tabular}{|c|c|c|}
\hline Pressing & Slip Casting & Injection Molding \\
\hline $\begin{array}{l}\text { Binder addition } \\
\text { Iubricant addition } \\
\text { Sintering aid addition } \\
\text { Preparation of a } \\
\text { free-flowing powder by } \\
\text { spray drying or } \\
\text { granulation }\end{array}$ & $\begin{array}{l}\text { Slurry preparation } \\
\text { Binder addition } \\
\text { Deflocculant addition } \\
\text { Wetting agent addition } \\
\text { Sintering aid addition } \\
\text { pH control } \\
\text { Viscosity control } \\
\text { \% solids control } \\
\text { De-airing }\end{array}$ & $\begin{array}{l}\text { Sintering aid addition } \\
\text { Lubricant addition } \\
\text { Wetting agent addition } \\
\text { Deflocculant addition } \\
\text { Injection plasticizer } \\
\text { addition } \\
\text { De-airing } \\
\text { Granulation or } \\
\text { pelletizing }\end{array}$ \\
\hline
\end{tabular}


of other defects during slip casting. Inadequate de-airing of either a slurry or an injection molding mix and result in a strength-limiting void in the final slip-cast or injection-molded part. Such fabrication flaws can reduce the strength of the material to a fraction of its normal value.

\subsection{Consolidation}

The following techniques have been used or could be used to consolidate powders in the manufacture of $\mathrm{Si}_{3} \mathrm{~N}_{4}$ and $\mathrm{SiC}$ components:

- Uniaxial pressing

- Isostatic pressing

- Slip casting

- Extrusion

- Injection molding

- Uniaxial hot pressing

- Hot isostatic pressing
- Transfer molding

- Compression molding

- Vibratory compaction

- Taping

- Flame spray*

- Detonation*

- Electrophoretic deposition*

Each of these techniques has its own set of problems and specific process control requirements. Injection molding, which is currently of special interest as a low-cost, net-shape consolidation approach for heat engine components, will be used as an example.

Table 3-2 shows a process flow sheet for the powder preparation, preconsolidation, consolidation, and postconsolidation processing required for reliable injection molded components. The die design, material additives, material temperature, tool temperature distribution, tool lubrication, and injection pressure must all be optimized simultaneously if an acceptable part is to be produced. If these factors are not adequately controlled, flaws such as porosity, inhomogeneity, inclusions, incomplete fill, and laminations can occur.

The types of flaws vary with the consolidation process. Uniaxial pressing tends to produce density contours, laminations, or irregular pore distribution. Isostatic pressing is much less prone to these problems. Extrusion, compression molding, and transfer molding produce flaws similar to those of injection molding. Slip casting requires optimization to avoid casting pores, incomplete mold fill, particle size and density gradation, and cracking during mold removal or drying.

*These techniques combine consolidation and sintering in a single step. 


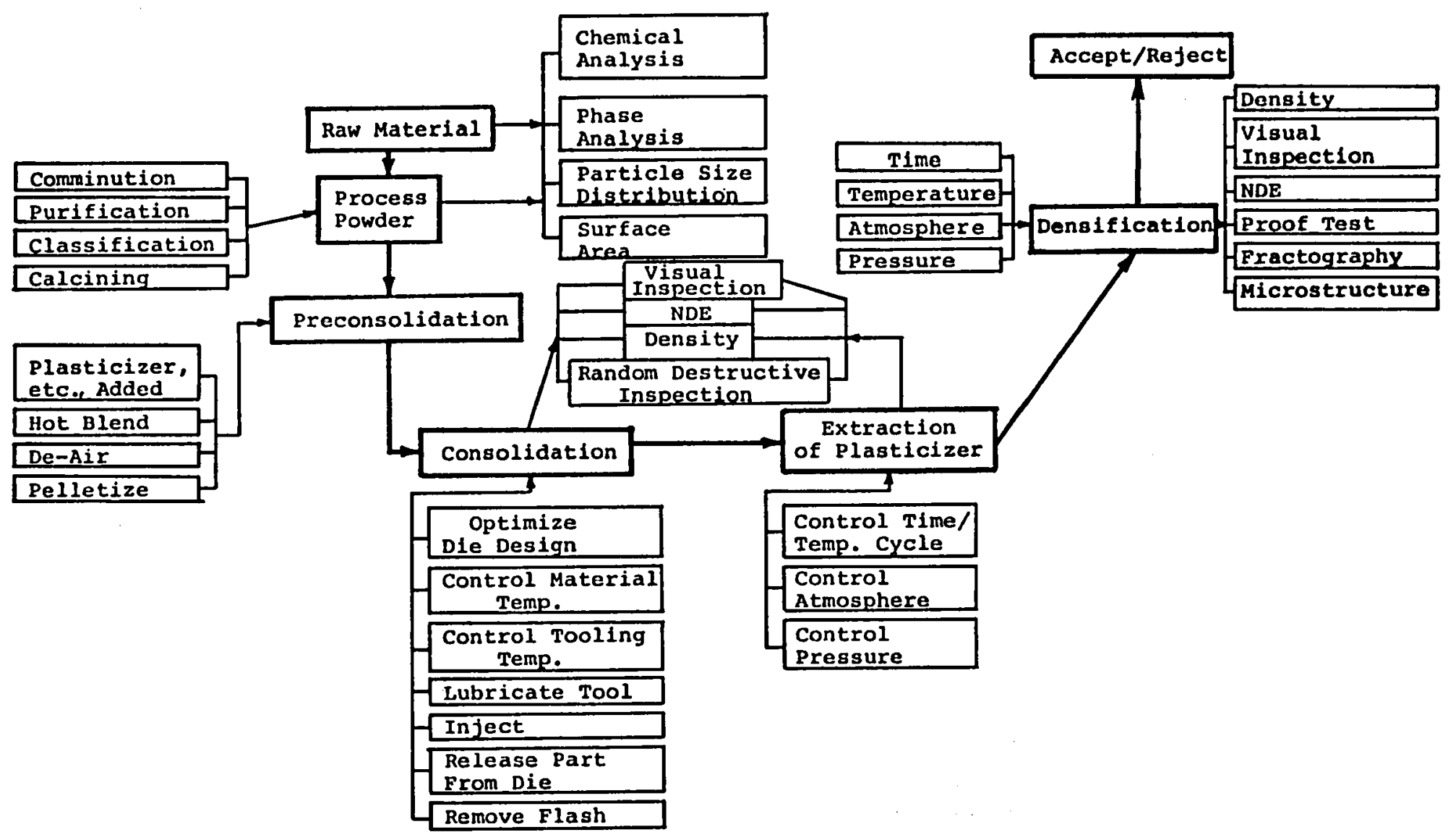

TABLE 3-2 Injection Molding Process Flow Sheet 
Flaws introduced during consolidation are the major cause of component rejection. At present, the typical yield of prototype heat engine components by the various approaches might be estimated as follows:

- Slip casting -- greater than 50 percent

- Injection molding -- less than 40 percent

- Isostatic press and machine -- greater than 75 percent

These yields are due partially to the small quantities being manufactured. As quantity increases from a prototype stage to a production stage, process control and reproducibility will improve and the yields will increase. A good example is spark plugs, where iterative development and largequantity production have achieved high reliability and very low reject rate of the ceramic insulator.

\subsection{Green Machining}

Machining of most fully densified ceramics requires diamond tooling and often is prohibitively expensive. To decrease the overall cost of machining, many heat engine parts are machined to final or near-final tolerances prior to densification, when the part is relatively soft and diamond tooling either has long life or is not required. Machining prior to densification will be referred to subsequently as green machining.

Green machining is used frequently in fabricating reaction bonded $\mathrm{Si}_{3} \mathrm{~N}_{4}$ and siliconized $\mathrm{SiC}$. In both cases, very little dimensional change occurs during densification so that near-final tolerances can be achieved by green machining.

Reaction bonded $\mathrm{Si}_{3} \mathrm{~N}_{4}$ will be used to illustrate the problems associated with green machining and the flaws that may result. The initial step in fabricating a reaction bonded $\mathrm{Si}_{3} \mathrm{~N}_{4}$ part is to produce a compact of silicon particles that subsequently can be reacted with nitrogen to produce the final densified $\mathrm{Si}_{3} \mathrm{~N}_{4}$ part. The initial silicon compact is too weak to be fixtured and machined, at least for most heat engine component configurations. The compact must first be strengthened, either by partial nitriding or by vacuum or inert gas sintering. Each represents an extra process step which must be carefully controlled to avoid formation of microstructural flaws which would reduce strength.

After pre-sintering or partial nitriding, the compact is stronger than the initial silicon compact, but still relatively weak. Careful handling and elaborate fixturing are required during the green machining. 
In addition, procedures must be used that do not allow the porous part to absorb fluids which later would affect the nitriding step or result in contamination.

The following summarizes the types of flaws that can be assoclated with green machining and result elther in rejection of the part or decreased rellability:

- Formation of microstructural flaws during pre-sintering or partial nitriding.

- Precipitation of impurities from binders or other additives.

- Handling damage.

- Dimensional variations from inadequate fixturing.

- Microcracks from overstressing during handling or machining.

- Absorption of grinding fluids.

\subsection{Densification (Sintering)}

Densification consists of converting a porous compact of unconnected particles into a nonporous or less-porous body with all the particles or grains strongly bonded together. Energy, usually in the form of heat (high temperature), plus a mechanism of material transport are required for densification to occur. Densification mechanisms of ceramics typically are called sintering.

There are three primary types of sintering:

- Liquid phase sintering

- Solid state sintering

- Reactive sintering.

In liquid phase sintering, a liquid is present at the densification temperature. This liquid aids in the transport of material and elimination of porosity. Liquid phase sintering appears currently to be the dominant mechanism of densification for hot-press and pressureless sintering of $\mathrm{Si}_{3} \mathrm{~N}_{4}$ compositions. 
Solid-state sintering does not involve a liquid. Material transport occurs by solid-state diffusion. Solid-state sintering appears to be the dominant mechanism of densiffcation for hot-press and pressureless sintering of SiC with small additions of boron and carbon.

Reactive sintering can occur by several mechanisms. One is referred to as "transient liquid sintering." In this case, a liquid is present initially at the sintering temperature, but then reacts chemically with the solid particles, being either absorbed into solid solution or precipitated as a separate phase.

Other mechanisms of reactive sintering are represented by reaction bonded $\mathrm{Si}_{3} \mathrm{~N}_{4}$ and siliconized $\mathrm{SiC}$. In the former, silicon metal reacts with nitrogen gas to form in-situ $\mathrm{Si}_{3} \mathrm{~N}_{4}$, resulting in approximately a 60 percent weight gain, but no volume change. In the latter, a porous mixture of SiC and carbon is infiltrated with molten silicon. The silicon reacts with the carbon to form in-situ SiC, which effectively bonds together the initial SiC particles. The pores are filled with silicon, resulting in a part of near-zero porosity. As with reaction bonded $\mathrm{Si}_{3} \mathrm{~N}_{4}$, this densification occurs with negligible dimensional change of the part.

Pure $\mathrm{Si}_{3} \mathrm{~N}_{4}$ and $\mathrm{SiC}$ do not soften and melt at high temperature like metals and oxide ceramics. Instead, these two materials decompose or sublime at temperatures where sintering would be expected to occur; they do not have an active energy mechanism to densify by transport of material between particles. Rather, the materials have a strong tendency to decompose to vapor species. Thus, pure $\mathrm{Si}_{3} \mathrm{~N}_{4}$ and pure $\mathrm{SiC}$ have not been successfully sintered.

Commercially available $\mathrm{Si}_{3} \mathrm{~N}_{4}$ and $\mathrm{SiC}$ have been densified only through the addition of sintering aids. $A$ ids such as $\mathrm{MgO}$ and $\mathrm{Y}_{2} \mathrm{O}_{3}$ (and others described in the literature) added to $\mathrm{Si}_{3} \mathrm{~N}_{4}$, and $\mathrm{Al}_{2} \mathrm{O}_{3}$ added to $\mathrm{SiC}$, result in liquidphase sintering at high temperature. Addition of boron plus carbon to SiC results in solid state sintering. Through the use of these sintering aids, densities higher than 99 percent of theoretical have been achieved by hot pressing and higher than 95 percent by pressureless sintering.

The strength of a ceramic material is a function of density. Achieving near-theoretical density of $\mathrm{Si}_{3} \mathrm{~N}_{4}$ and $\mathrm{SiC}$ through the use of sintering aids has resulted in very high room temperature strength, typically more than $100,000 \mathrm{psi}$ for hot pressed materials when measured in 3 point flexure.

Current commercial hot pressed and sintered $\mathrm{Si}_{3} \mathrm{~N}_{4}$ materials decrease in strength above $1200^{\circ} \mathrm{C}$, resulting in severe life-time limitations for components with even moderate stresses above about $1100^{\circ} \mathrm{C}$. The strength decrease results from the presence in the microstructure, especially at or near grain boundaries, of compositions which soften or melt. These compositions result from the 
sintering aid or interactions of the sintering aid with impurities. For example, when $\mathrm{MgO}$ is added to $\mathrm{Si}_{3} \mathrm{~N}_{4}$, the $\mathrm{MgO}$ reacts with $\mathrm{SiO}_{2}$ (present as a thin surface layer on the $\mathrm{Si}_{3} \mathrm{~N}_{4}$ particles) to produce a liquid magnesium silicate phase. This provides the mechanism for sintering, but also results in a grain boundary phase that softens within the intended temperature-of-use range of the material and results in decreased strength. Impurities such as $\mathrm{CaO}$ further reduce the melting temperature of the magnesium silicate phase.

Information from phase equilibrium diagrams has and can be used to optimize high temperature properties. Richerson (13) and Andersson, et al. (14) have demonstrated that the properties of $\mathrm{Si}_{3} \mathrm{~N}_{4}$ with $\mathrm{MgO}$ sintering aid can be improved significantly by reduction of impyrities and control of the $\mathrm{MgO}^{\mathrm{SiO}} \mathrm{Si}_{2}$ ratio. Gazza, (15) Vasilos, et al., (8) and McDonough, et a1. (16) have demonstrated that more refractory grain-boundary phases can be achieved by using $\mathrm{Y}_{2} \mathrm{O}_{3}$ or $\mathrm{ZrO}_{2}$ sintering aids which can significantly increase high temperature properties.

In addition to the effects of sintering aids and porosity on the properties and reliability of a heat engine component, are the types of defects that can occur if process parameters during densification are not properly controlled. Improper temperature control can result in strength-limiting defects. Too low a sintering temperature can cause excess porosity. Too high a sintering temperature can cause grain growth, isolated large pores, material loss due to dissociation or component distortion.

Densification is just like previously discussed process steps: it must be precisely controlled if reproducible, reliable components are to be produced.

\subsection{Postdensification Machining}

Once a ceramic component has been densified, diamond tooling normally is required for finish machining. In some cases excess stock can be removed by ultrasonic trepanning with boron carbinde abrasive, (17) but the final tolerances are achieved by diamond grinding.

Machining a hard ceramic with diamond (or other abrasive) results in surface flaws. Material is removed under high contact loading by a plowing mechanism which leaves visible grooves in the surface parallel to the direction of motion of the grinding tool. Mecholsky, et al. (18) have reported that shallow cracks perpendicular to the tool's motion and slightly deeper cracks parallel to the tool's motion extend into the material at the base of each grinding groove. Application of a tensile stress parallel to the groove (comparable to testing a longitudinally machined specimen in 3- or 4-point flexure) initiates fracture at the smaller machining cracks. For hot pressed $\mathrm{Si}_{3} \mathrm{~N}_{4}$ 
this would yield a strength of about 100,000 psi. Tensile stress perpendicular to the groove (comparable to testing a transverse machined specimen in 3- or 4-point flexure) results in a lower strength for hot pressed $\mathrm{Si}_{3} \mathrm{~N}_{4}$ of about 60,000 psi with fracture initiation at the larger machining cracks.

The above discussion points out the flaws generated by machining and the importance of orienting this grinding damage with respect to an applied stress. Proper orientation can significantly increase the load bearing capability of a component. Since the direction of peak tensile stress is defined by the application, the burden of controlling the machining orientation falls on the component manufacturer.

In a component such as a rotor blade the contours of the airfoil restrict the accessibility of grinding tooling and thus dictate grinding in the least desirable low strength orientation. Some progress has been made for inserted blade rotor configurations. Profile grinding techniques have been developed which align grinding grooves parallel to the tensile loading, but the more cost effective approaches, such as form wheel grinding, do not.

An alternative to ideal alignment of the grinding is to decrease the severity of grinding damage. This can be done by finish machining with smaller abrasive particles or lapping. It can also be achieved with some materials through crack blunting by controlled oxidation. A third approach, which has ben demonstrated in Germany, is postmachining blasting with fine grit to produce a smoother, nondirectional surface.

\subsection{Inspection}

Inspection is critical in the component processing sequence. This is so not because of the flaws that can occur in inspection, but because it is the final step in which critical flaws can be detected before the part is installed in an engine. The degree of success of inspection will have a large influence on the rated reliability of the ceramic component.

Inspection of ceramic components currently consists of dimensional inspection, nondestructive evaluation (NDE), and limited proof testing. $\mathrm{NDE}$ and proof testing are discussed in later sections. However, two points will also be noted here:

- Flaws can undergo stable growth during proof testing;

- NDE resolution capability needs to be improved, especially for complex shapes and for near-surface flaws. 


\subsection{New Materials Development}

The emphasis in the previous sections has been on commercial $\mathrm{Si}_{3} \mathrm{~N}_{4}$ and SiC materials. Other materials also are being used in heat engines, and new or improved materials are under development. These will be reviewed briefly in this section.

\subsubsection{Heat Exchanger Materials}

The performance of many types of heat engines can be improved significantly by recovering heat with heat exchangers. A variety of low-thermal-expansion materials, including lithium aluminum silicate, aluminous keatite, and magnesium aluminum silicate, are being evaluated for rotary regenerator and fixed-boundary-recuperator type heat exchangers. Both types of heat exchangers have similar development problems which will affect reliability:

- Fabrication of a core containing thin walled channels which must simultaneously provide high open volume for adequate flow and high surface area for effective heat transfer.

- Development of a material that can withstand the thermal environment and remain stable for at least 3500 hours in the potentially corrosive combustion environment.

- Development of a structure and sealing which hold leakage to acceptable levels.

For detailed information on current heat exchanger development, references 19-21 are recommended.

\subsubsection{Insulation Materials}

Optimization of the efficiency of heat engines will require use of insulating materials, both for packing (such as ceramic fiber insulation) and for structural components. For instance, heat loss in turbocompound reciprocating engines could be decreased by insulating pistons, cylinders, and exhaust ports.

The thermal conductivities of $\mathrm{Si}_{3} \mathrm{~N}_{4}$ and $\mathrm{SiC}$ are too high for these insulating requirements. Materials such as zirconium oxide, mullite, and aluminum titanate are being considered for these applications. However, very little development of insulating material for structural components has been conducted. 


\subsubsection{Increased Fracture Resistance}

An increase in the fracture toughness of a ceramic material can significantly increase its reliability in structural heat engine applications. The following summarizes methods that have been proposed for increasing the fracture toughness of ceramics and other methods of increasing the resistance to tensile fracture:

- Transformation toughening (22, 23)

- Particle dispersion

- Fiber dispersion.

Fracture resistance can also be increased by placing surfaces in compression. Methods used to do this include:

- Surface compression via quench

- Surface compression via material gradation

- Surface compression via chemical reaction

Energy absorbing surface layers also are being investigated to improve impact resistance.

Most of these methods have received some development in small R\&D programs and some appear quite promising. In German research, for example, transformation toughening of $\mathrm{Si}_{3} \mathrm{~N}_{4}$ by controlled addition of unstablized zirconium oxide increased the fracture toughness from approximately $5.5 \mathrm{MNm}^{-3 / 2}$ to $8.5 \mathrm{MNm}^{-3 / 2}$. This resulted in a dramatic increase in thermal shock resistance. Unfortunately, though, other properties (including cyclic stability) have not been measured, and processing has not been scaled up to provide specimen sizes suitable for more extensive characterization or component testing.

\subsubsection{Chemical Vapor Depostion}

Chemical vapor depostion (CVD) materials have potential as coatings for selected heat engine components. A variety of ceramic materials, including $\mathrm{Si}_{3} \mathrm{~N}_{4}, \mathrm{SiC}$, and aluminum nitride (A1N) have been applied to graphite and other substrates by chemical vapor deposition. These coatings typically are of high purity, very resistant to oxidation and creep, and show very little change in strength as a function of temperature.

A modified CVD approach, controlled nucleation thermochemical deposition (CNTD), has shown progress recently toward developing finegrained microstructures yielding high strength. Holzl (24) has reported 
strengths of 500,000 psi for CNTD SiC. Development of CNTD $\mathrm{Si}_{3} \mathrm{~N}_{4}$ is less advanced.

Engdahl ${ }^{(25)}$ has reported progress in net-shape fabrication by CVD of axial and radial rotor turbine configurations of SiC. Shape representation has been good, but a much greater effort will be required to achieve acceptable properties and reliable components.

Development in CVD is progressing, but there remain a number of problems:

- Crack-free deposition on $\mathrm{Si}_{3} \mathrm{~N}_{4}$ and $\mathrm{SiC}$

- Uniform deposition on a part of complex shape

- Nonmodular suface which does not require machining

- Composition control

- Contro1 of residual stresses.

\subsubsection{Sintered Materials}

Previously, the strongest ceramic materials were made by hot pressing. For example, both $\mathrm{Si}_{3} \mathrm{~N}_{4}$ and $\mathrm{SiC}$ have been fabricated by hot pressing to yield room temperature strength greater than $100,000 \mathrm{psi}$. The major problem with current hot pressing is the limitation on shape. To achieve the complex shapes required for heat engines, considerable diamond grinding is necessary. The resulting cost appears prohibitive for most applications.

Pressureless sintering is being developed to fabricate $\mathrm{Si}_{3} \mathrm{~N}_{4}$, SiC, and other compositions directly to net shape or near-net shape. So far, the strength has been significantly below that of comparable hot pressed compositions, ranging from 60,000 to 80,000 psi for both $\mathrm{Si}_{3} \mathrm{~N}_{4}$ and $\mathrm{SiC}$.

Development of pressureless sintered materials has been hindered by lack of commercial availability of suitable starting powders and lack of knowledge of material transport mechanisms that control sintering. Laboratory studies have demonstrated that such powders are feasible, but they have not been commercialized. 
Development of sintered ceramic materials for heat engines should continue with emphasis in the following areas:

- Development of sintering theory for $\mathrm{Si}_{3} \mathrm{~N}_{4}$ and $\mathrm{SiC}$ powder systems.

- Development of reproducible, high-purity, submicron starting powders.

- Development of net-shape, noncontaminating consolidation for these bulky fine powders.

- Improved room temperature strength.

- Improved high temperature strength of $\mathrm{Si}_{3} \mathrm{~N}_{4}$.

- Improved Weibull slopes.

\subsubsection{Hot Isostatically Pressed Materials}

Larker, et al. (26) have demonstrated recently that simple shapes of $\mathrm{Si}_{3} \mathrm{~N}_{4}$ can be densified by hot isostatic pressing (HIP) using glass encapsulation. Although this technology is just beginning to develop, it has the potential of producting net shape or near-net-shape heat engine components with properties comparable to or better than those of the best currently available uniaxially hot pressed $\mathrm{Si}_{3} \mathrm{~N}_{4}$.

In addition to net shape potential, HIP also has potential for improvement especially of high temperature time-dependent properties. As discussed previous1y, high temperature properties typically are controlled by impurities and/or the sintering aid required to achieve densification. Because HIP can be conducted at high pressures (45,000 psi compared to 5,000 psi for uniaxial hot pressing), it should be possible to achieve densification with higher purity powders or with less sintering aid. It should also be possible to go to higher temperature to provide additional flexibility in achieving densification. Maximum temperature in uniaxial hot pressing is limited by reactions with the graphite die material and by dissociation of the $\mathrm{Si}_{3} \mathrm{~N}_{4}$. In HIP, the $\mathrm{Si}_{3} \mathrm{~N}_{4}$ is only in contact with $\mathrm{SiO}_{2}$ glass (or an intermediate layer, such as boron nitride), which is surrounded by high pressure argon, which should allow increased flexibility in temperature selection.

HIP requires considerable development before it can be used routinely to produce heat engine components. Much of this development must be applied to the glass encapsulation technology. The following must be optimized: 
- Glass composition not reactive with material.

- Viscosity at temperature which provides seal, but does not permit impregnation.

- Low cost method of applying encapsulation.

- Development of a thin encapsulation layer which will fracture rather than thin sections of the part (such as an airfoil trailing edge) during cool-down.

A further consideration applies to HIP and other net shape approaches during which shrinkage occurs. The preform (the part prior to densification) must be completely uniform, or distortion or loss of tolerances will occur during densification.

\subsubsection{New Compounds}

As mentioned previously, most prior materials development for heat engines has involved the binary compounds $\mathrm{Si}_{3} \mathrm{~N}_{4}$ and $\mathrm{SiC}$. The only other binary compound receiving some consideration has been AlN. Very little work has been conducted to evaluate ternary or quaternary compounds, excepting some oxynitrides which have been popularly referred to as SiAlON's.

Rice ${ }^{(27)}$ points out that ternary systems and some quaternary systems completely dominate some other facets of ceramic technology. For instance, all modern piezoelectric and ferrite ceramics are ternary or higher compounds. So also are many of our electrical, electrooptical, and low thermal expansion ceramics. It seems likely, therefore, that some ternary or quaternary systems may have a better balance of properties for heat engine applications than $\mathrm{Si}_{3} \mathrm{~N}_{4}$ or $\mathrm{SiC}$.

\subsubsection{New Processes}

It is also likely that new processes exist for making ceramic components. One potential process is polymer pyrolysis, which currently is used to make carbon fibers, glassy carbon, and SiC fibers. $(28,29)$ Rice, et al. (30) suggest that heat engine parts could be made by pyrolyzing inorganic polymers such as polycarbosilanes (Si-C-H) or silizanes $(\mathrm{Si}-\mathrm{N}-\mathrm{H})$. Further variation in processing could be copyrolysis to achieve composite structures. 


\subsection{Conclusions and Recommendations}

Many processing steps are required in the fabrication of components for heat engines. Precise control of each process step is necessary to produce a reliable component.

Development effort in the past has been concentrated on $\mathrm{Si}_{3} \mathrm{~N}_{4}$ and SiC. Hot pressed $\mathrm{Si}_{3} \mathrm{~N}_{4}$ materials have excellent room temperature properties, but above $1100^{\circ}$ or $1200^{\circ} \mathrm{C}$ are limited by oxidation and slow crack growth to relatively short-life applications. Reaction bonded $\mathrm{Si}_{3} \mathrm{~N}_{4}$ materials do not suffer from slow crack growth, but are marginal for many heat engine applications because of inadequate strength and oxidation resistance. SiC materials have been developed which do not appear to be limited by slow crack growth or oxidation. However, because of their higher (relative to $\mathrm{Si}_{3} \mathrm{~N}_{4}$ ) elastic modulus and coefficient of thermal expansion, SiC materials are exposed to higher thermal stresses.

Materials suitable for heat engines have been evolving rapidly. We are now at a point where these materials and the mechanisms that control their properties are understood well enough so that we should be able to make significant improvements in reliability.

Reliability can be improved by improving process control. Table 3-3 summarizes specific recommendations. Implementation of these recommendations will require capital equipment, detailed parametric studies, and extensive physical, chemical, and mechanical analyses. Since a large market for ceramic heat engine components does not yet exist, it is not likely that ceramic manufacturers will be able to invest the funds and manpower required. Support will have to come from government sources if significant progress is to be made.

Réliability also can be improved by developing better materials. Table 3-4 defines three levels of development: short range, consisting of improvement of existing materials; intermediate range, consisting of development of approaches for which some feasibility has already been demonstrated; and long range, consisting of development. of new approaches or new materials. All three must be pursued if we are to meet the challenges of today's technology where, in so many cases, we cannot progress further until material limitations have been resolved. 
TABLE 3-3 Recommended Processing Improvements to Achieve Increased Reliability

Raw Material Selection

Powder Processing

Preconsolidation

Consolidation

Densification
- Develop powder synthesis techniques that produce high purity submicron powder directly, eliminating the requirement for comminution and thus eliminating a major source of contamination.

- Above, with sintering aid included.

- Incorporate controls into powder processing to minimize pickup of contamination or to positively remove the contamination by techniques such as leaching, screening, or magnetic separation.

- Incorporate clean-room procedures or set up closed systems.

- Increase effort in preconsolidation to assure uniform distribution of additives and elimination of the types of agglomerates that will end up as flaws during consolidation.

- Set up closed system on controlled-environment processing.

- Incorporate instrumentation and/or automation to achieve greater reproducibility.

- Incorporate in-process nondestructive evaluation both for process improvement and for process monitoring.

- Continue development of net-shape approaches such as pressureless sintering, hot isostatic pressing, and chemical vapor deposition.

- Incorporate instrumentation and/or automation to achieve greater reproducibility.

- Develop solid state or reactive-sintering compositions that yield improved high temperature properties. 
TABLE 3-4 Recommended Materials Development to Achieve Increased Reliability

\begin{tabular}{|c|c|c|}
\hline & $\begin{array}{l}\text { PARALLEL DEVELOPMENT PATHS } \\
\text { HAVING POTENTIAL }\end{array}$ & \\
\hline IMPROVE EXISTING MATERIALS & DEVELOP EMERGING MATERIALS & DEVELOP NEW MATERIAL \\
\hline $\begin{array}{l}\text { - OPTIMIZE HIGH TEMPERA- } \\
\text { TURE PROPERTIES } \\
\text { - IMPROVE PURITY } \\
\text { - IMPROVE PROCESSING } \\
\text { - DEVELOP MONOLITHIC } \\
\text { CAPABILITY FOR HIGH } \\
\text { PURITY CVD MATERIALS } \\
\text { - OPTIMIZE CNTD AND/OR } \\
\text { CVD COATINGS }\end{array}$ & $\begin{array}{l}\text { - OPTIMIZE TRANSFORMATION- } \\
\text { TOUGHENED CERAMICS SUCH } \\
\text { AS } \mathrm{Al}_{2} \mathrm{O}_{3}-\mathrm{ZrO} 2 \text { AND } \\
\mathrm{Si}_{3} \mathrm{~N}_{4}-\mathrm{ZrO}_{2} \\
\text { - DEVELOP SIALON TYPE } \\
\text { COMPOSITIONS OPTIMIZED } \\
\text { FOR HIGH TEMPERATURE } \\
\text { ENVIRONMENTS } \\
\text { - OPTIMIZE UNIFORMITY AND } \\
\text { CHEMISTRY VIA HIP } \\
\text { - DEVELOP FIBER AND SECOND } \\
\text { PHASE DISPERSIONS TO } \\
\text { OPTIMIZE PROPERTIES }\end{array}$ & $\begin{array}{l}\text { - EVALUATE AIN AND SIMILAR } \\
\text { SYSTEMS } \\
\text { - DEVELOP TERNARY AND } \\
\text { HIGHER COMPOSITIONS } \\
\text { - DEVELOP MIXED COMPOSI- } \\
\text { TIONS WITH SPECIFICALLY } \\
\text { ENGINEERED PROPERTIES } \\
\text { - DEVELOP NEW COMPOSITES } \\
\text { - DEVELOP "DUCTILE" } \\
\text { CERAMICS FOR IMPROVED } \\
\text { TOUGHNESS } \\
\text { - DERIVE SIC AND Si }{ }^{\mathrm{N}} 4 \\
\text { MONOLITHIC COMPONENTS } \\
\text { BY POLYMER PYROLYSIS }\end{array}$ \\
\hline
\end{tabular}




\section{REFERENCES}

1. Rice, R. W., "Microstructure Dependence or Mechanical Behavior of Ceramics," Treatise on Materials Science and Technology, Vo1. 11: Properties and Microstructure, R. K. MacCrove, ed., Academic Press, 1977.

2. Richerson, D. W. and Washburn, M. E., "Hot Pressed Silicon Nitride," U.S. Patent 3,836,374, Sept. 17, 1974.

3. Lange, F. F. and Iskoe, J. L., "High Temperature Strength Behavior of Hot Pressed $\mathrm{Si}_{3} \mathrm{~N}_{4}$ and SiC: Effects of Impurities," in Ceramics for High Performance Applications, Proceedings of the 2nd Army Materials Technology Conference, Hyannis, Massachusetts, November 13-16, 1973. J. J. Burke, A. E. Gorum and R. N. Katz, eds., Chestnut Hill, Mass.: Brook Hill Publishing Co., 1974, pp. 223-238.

4. Singhal, S. C., "Oxidation and Corrosion Erosion Behavior of $\mathrm{Si}_{3} \mathrm{~N}_{4}$ and $\mathrm{SiC}, "$ in Ceramics for High Performance Applications, Proceedings of the 2nd Army Materials Technology Conference, Hyannis, Massachusetts, November 13-16, 1973. J. J. Burke, A. E. Gorum and R. N. Katz, eds., Chestnut Hill, Mass.: Brook Hill Publishing Co., 1974, pp. 533-548.

5. Coe, R. F., Lumby, R. J., and Pawson, M. F., "Some Properties and Applications of Hot Pressed Silicon Nitride," Special Ceramics, Vo1. 5, 1972, pp. 361-376.

6. Prochazka, S., "Sintering of Silicon Carbide," in Ceramics for High Performance Applications, Proceedings of the 2nd Army Materials Technology Conference, Hyannis, Massachusetts, November 13-16, 1973. J. J. Burke, A. E. Gorum and R. N. Katz, eds., Chestnut Hill, Mass.: Brook Hill Publishing Co., 1974, pp. 239-252.

7. Baumgartner, H. R. and Richerson, D. W., "Inclusion Effects on the Strength of hot Pressed $\mathrm{Si}_{3} \mathrm{~N}_{4}$," Fracture Mechanics of Ceramics, Vol. 1: Concepts, Flaws and Fractography, R. C. Bradt, D. P. H. Hasselman, and F. F. Lange, eds., Plenum Press, New York and London, 1974, pp. 367-386.

8. Vasilos, T., Cannon, R. M., Jr., and Wuensch, B. J., "Improving The Stress Rupture and Creep of Silicon Nitride," Quarterly Report \#3, NASA Contract NAS3-20088, June 1978. 
9. Prochaszka, S., Johnson, C. A., and Giddings, R. A., "Investigation of Ceramics for High-Temperature Turbine Vanes," NADC Contract N62269-74-C-0255, Quarter1y Progress Report \#1, April 1974.

10. Personal Communications with GTE Sylvania, Towanda, Pennsylvania, March 1978.

11. Prochazka, S., "Investigation of Ceramics for High Temperature Turbine Vanes," NASC Contract N00019-72-C-0129, Fina1 Report, December 1972 .

12. Pa1m, J. A. and Greskowich, C. D., "Silicon Nitride for Airborne Turbine Applications," Final Report, NASC Contract N00019-77-C0259.

13. Richerson, D. W., "Effects of Impurities on the High Temperature Properties of Hot Pressed Silicon Nitride," Am. Ceram. Soc. Bu11., 52, 7 560-62, 569, 1973.

14. Andersson, C. A., Lange, F. F., and Iskoe, J. L., "Effects of the $\mathrm{MgO} / \mathrm{SiO}_{2}$ Ratio on Strength of Hot Pressed $\mathrm{Si}_{3} \mathrm{~N}_{4}$," Office of Nava1 Research Contract Report, October 1975 (AD-A016803).

15. Gazza, G. E., "Effect of $\mathrm{Y}_{2} \mathrm{O}_{3}$ Additions on Hot Pressed $\mathrm{Si}_{3} \mathrm{~N}_{4}$," Am. Ceram. Soc. Bull., 54, 9 778-81, 1975.

16. McDonough, W. J., Freiman, S. W., Rice, R. W., and Becher, P. F., "Preliminary Strength Tests of $\mathrm{Si}_{3} \mathrm{~N}_{4}$ Hot Pressed with $\mathrm{ZrO}_{2}$ or $\mathrm{ZrSiO}_{4}$ Additions," from Proceedings of the 1977 DARPA/NAVSEA Ceramic Gas Turbine Demonstration Engine Program Review, J. W. Fairbanks and R. W. Rice, eds., MC/C Report 78-36, 1978, pp. 625-626.

17. Robare, M. W. and Richerson, D. W., "Rotor Blade Machining Development," from Proceedings of the 1977 DARPA/NAVSEA Ceramic Gas Turbine Demonstration Fngine Program Review, J. W. Fairbanks and R. W. Rice, eds., MC/C Report 78-36, 1978, pp. 291-311.

18. Mecholsky, J. J., Freiman, S. W., and Rice, R. W., "Effect of Grinding on Flaw Geometry and Fracture Stress of Glass,"

J. Am. Ceram. Soc. 60, 3-4 114-117, 1977.

19. Cook, J. A., Fucinari, C. A., Lingscheit, J. N., and Rahnke, C. J., "Ceramic Regenerator Systems Development Program," Annual Summary Report, No. NASA CR-135330, NASA Contract No. DEN 3-8, December 1977.

20. Rauch, H.W., Sr., "Improved Ceramic Heat Exchanger Material," Interim Report, NASA CR-135292, November 1977. 
21. McCollister, H. L., "Improved Ceramic Heat Exchanger Materials," NASA Contract NAS 3-19733, Quarterly Report \#8 (Oct. 1977).

22. Claussen, N. and Jahn, J., "Mechanical Properties of Sintered and Hot Pressed $\mathrm{Si}_{3} \mathrm{~N}_{4}-\mathrm{ZrO}_{2}$ Composites," J. Am. Ceram. Soc., Vol. 61, No. 1-2 (1978), pp. 94-95.

23. Lange, F. F., "Microstructurally Developed Toughening Mechanisms in Ceramics," Technical Report \#1, ONR Contract N00014-77-C-0441 (July 1978).

24. Holz1, R. A., "Investigations of CNTD Mechanism and its Effect on Microstructural Properties," Interim Report \#1 AFOSR Contract F49620-77-C-0086 (Feb. 1978).

25. Engdahl, R. E., "Progress Toward Ceramic Turbine Rotors by CVD," in Proceedings of the Workshop on Ceramics for Advanced Heat Engines, Orlando, Florida, Jan. 24-26, 1977, NTIS Document No. CONF-770110, pp. 197-208.

26. Larker, H., Adlerborn, J., and Bohman, H., "Fabrication of Dense Silicon Nitride Parts by Hot Isostatic Pressing," presented at the Am. Ceram. Soc. Meeting, April 1977.

27. Rice, R. W., "Overview of the Naval Research Laboratory Ceramic Turbine Materials Program," from Proceedings of the 1977 DARPA/ NAVSEA Ceramic Gas Turbine Demonstration Engine Program Review, J. W. Fairbanks and R. W. Rice, eds., MC/C Report 78-36 (1978), pp. 613-623.

28. Yajima, S., Okamura, K., Hayaski, J., and Omori, M., "Synthesis of Continuous SiC Fiber with High Tensile Strength," J. Am. Ceram. Soc., 59 7-8 (1975), pp. 324-327.

29. Verbeek, W., "Production of Shaped Articles of Homogeneous Mixtures of Silicon Carbide and Nitride," U.S. Patent \#3,853,567 (1974).

30. Rice, R. W., Walker, B. E., Fox, W. B., and Wynne, K. J., "Preparation of Turbine and Related Ceramics by Polymer Pyrolysis," from Proceedings of the 1977 DARPA/NAVSEA Ceramic Gas Turbine Demonstration Engine Program Review, J. W. Fairbanks and R. W. Rice, eds., MC/C Report 78-36 (1978), pp. 633-639. 
This Page Intentionally Left Blank 
Chapter 4

MATERIALS CHARACTERIZATION

\subsection{Introduction}

In Chapter 2, DESIGN METHODOLOGY, it was pointed out that the brittle nature of ceramics imposes the need to use a probabilistic rather than a deterministic approach in structural designing. It was also pointed out that the ability to design reliable structures is limited seriously by inadequate characterizations of ceramic strengths. We address this problem here.

\subsection{Strength Analysis}

A statistical description of the strength of a ceramic is required for designing with the probabilistic approach. The description is a mathematical formulation of the failure probability of a material in terms of stress and size (i.e., volume or surface area subjected to tension). It is obtained from an analysis of strength measurements made under appropriate experimental conditions and is based on modern theories of brittle failure. Practical problems are encountered in describing ceramic strengths for design purposes for a number of reasons, including insufficient basic knowledge of brittle behavior, as will be discussed.

\subsubsection{Failure Criterion}

In formulating statistical descriptions of ceramic strengths, it is normally assumed that failure will occur when Griffith's criterion is met. This criterion assumes that failure results from a local condition developing at a flaw site in the material where a crack becomes unstable and grows spontaneously. The criterion states that crack instability occurs when $\mathrm{K}_{\mathrm{I}}$, the stress-intensity factor for crack-opening tension, reaches a critical value, $\mathrm{K}_{\mathrm{IC}}$, at any site. $\mathrm{K}_{\mathrm{IC}}$ is assumed to be a material constant related to two material properties, as follows:

$$
\mathrm{K}_{\mathrm{IC}}=\sqrt{2 \gamma_{\mathrm{f}}^{\mathrm{E}}}
$$


where $\gamma_{f}$ is fracture surface energy and $E$ is Young's modulus. Fundamental understanding of fracture energy, $\gamma_{f}$, is lacking. It is known, however, that the thermodynamic free surface energy of the material can account for only a fraction of the surface energy consumed in fracturing a ceramic.

As indicated in Section 4.2.3, the validity of the assumption that $\mathrm{K}_{\mathrm{IC}}$ is a bulk-material constant requires attention in analyzing the strength of a ceramic. Instances are reported where $\mathrm{K}_{\mathrm{IC}}$ depends on local conditions.

When Griffith's criterion is met, the resultant crack extension in the component usually will result in complete separation or serious damage. The extent of propagation of an unstable crack, however, depends on the available stored strain energy; in the case of highly localized and transient loading (e.g., particle impact or thermal shock), serious damage may not result even though $\mathrm{K}_{I C}$ is reached at a local site.

\subsubsection{Stress-State Effects}

Our knowledge of fracture of ceramics is based largely on its occurence from uniaxial tension. Effects that stresses normal to the crack-opening tension might have on failure probability have not been resolved, even though it is recognized that ceramics will be subjected to multiaxial stresses in heat-engine service.

It is norma11y assumed that a component will fracture at the same tensile stress under multiaxial stresses as under uniaxial tension, and uniaxial strength data are used in assessing the failure probability of a component subjected to combined stresses. In making the assessment, the failure probability associated with each of the three principal stresses acting on an element usually is included in one way or another in the summation of element probabilities (see Section 2.1). Thus, when more than one principal stress is tensile, the calculated failure probability will be greater under combined stresses than under uniaxial tension.

The assumption that each principal stress acts independently has not been validated and could be a source of unreliable component performance. If the assumption is not valid, it would be convenient to be able to express failure probability under combined stresses in terms of an equivalent uniaxial tensil stress, $\sigma_{\mathrm{eq}}$ :

$$
\sigma_{e q}=f\left(\sigma_{1}, \sigma_{2}, \sigma_{3}\right)
$$


where $\sigma_{1}, \sigma_{2}$, and $\sigma_{3}$ are the principal stresses on an element. Several theoretical forms have been proposed for Equation (2), including the proposed adaption of yield criteria to the fracture problem, but none has been established as generally applicable. (1)

Without change in the failure mode (i.e., with distinct tensile fracture), the interpretation of stress-state effects requires consideration of three problems:

- The fracture mechanics problem of defining the critical condition for crack instability for an arbitrary state of stress and a crack geometry of a form resulting from natural flaws.

- The constitutive relation problem of defining the effects of multiaxial loadings on strength -- i.e., the problem of formulating strength in terms of principal stresses.

- The statistical problem of defining the effect of stress-state on variance of strength data -- i.e., the problem of adjusting the Weibull description of the strength of a ceramic to account for the stress-state dependency of failure probability as a function of stress.

Concerning the fracture mechanics problem, it will be recalled that fracture occurs in uniaxial tension when $\mathrm{K}_{\mathrm{I}}=\mathrm{K}_{\mathrm{IC}}$. The effective stress on a two-dimensional crack depends on its orientation with respect to the crack-opening tension, owing to a shear-stress contribution. For this reason, $\mathrm{K}_{\mathrm{I}}$ under a given combined stress will differ from that for uniaxial tension to an extent dependent on the shear components, $\mathrm{K}_{\mathrm{II}}$ and $\mathrm{K}_{\mathrm{III}} \cdot(2-4)$ Crack shape constitutes a related factor. Cracks that become unstable in ceramics cannot be treated as two-dimensional with assurance since, as will be discussed later, their shapes depend on the variable geometry of precursor microstructural features or extrinsic surface defects, and the contribution of $\mathrm{K}_{\mathrm{II}}$ and $\mathrm{K}_{\mathrm{III}}$ to crack instability will depend on orientation effects associated with the geometry of the crack.

These sources of variability in the effects of $\mathrm{K}_{\mathrm{II}}$ and $\mathrm{K}_{\mathrm{III}}$ on crack severity suggest that a functional relation for $\sigma_{e q}$ in terms of principal stresses with general applicability is unlikely, and that one can expect a characteristic dispersion of strength values associated with each stress state. However, it is possible that the nature and distribution of critical flaws in a ceramic are such that, for practical purposes, the variability in the effects of $\mathrm{K}_{\mathrm{II}}$ and $\mathrm{K}_{\mathrm{III}}$ is insignificant, allowing analytical expressions for failure probability that account for stress-state effects. 
Finally, it should be noted that the strength of a ceramic will not necessarily be isotropic even though the material is homogeneous and elastically isotropic. Flaws associated with machining or pressing, for example, tend to have directional severities and will result in different strengths, depending on the orientation of the tensile stress causing crack instability. Any anisotropy in strength, of course, must be accounted for in the treatment of both fracture mechanics and statistical effects of combined stresses on failure probability.

\subsubsection{Factors Affecting KIC}

To have a valid statistical definition of the strength of a ceramic component for structural-design purposes, $\mathrm{K}_{\mathrm{IC}}$ of the material in the component must be the same as that of the strength-test specimens. Further, it is normally assumed that $\mathrm{K}_{\mathrm{IC}}$ of the material is a bulk property, independent of local conditions at any possible fractureinitiating site.

As a bulk property of a ceramic, $K_{\text {fi }}$ can be sensitive to microstructure and temperature. This means that strength data from specimens processed in a manner different from that of the component or tested at a temperature different from the component service temperature may not provide a correct statistical definition of the strength of the component, even though strength-controlling flaws are not changed by processing or temperature. Relations for predicting the effects of microstructure and temperature on $\mathrm{K}_{\mathrm{IC}}$ are not established. It follows that data are needed from either service-temperature strength tests or measurements of $\mathrm{K}_{\mathrm{IC}}$ on specimens processed identically to the component to obtain a correct statistical definition of the strength of the ceramic.

Whether and when $\mathrm{K}_{\mathrm{IC}}$ can be considered a bulk material property, as assumed, has not been extensively investigated. If $\mathrm{K}_{\mathrm{IC}}$ is not a bulk property, but varies randomly among sites of strength-controlling flaws, the variation would be correctly accounted for in a statistical definition of strength. In effect, this means that statistical theory assumes the ceramic is populated with weak places of random weakness rather than with flaws of random severity. In the statistical treatment of strength data, it is immaterial which assumption is made. On the other hand, if $\mathrm{K}_{\mathrm{IC}}$ is not a bulk property, but varies in a fixed way with flaw size and hence strength, it will bias the strength dispersion in a way that makes statistics inapplicable for defining strength. In such cases, to obtain a statistical description of strength, the relation between $\mathrm{K}_{\mathrm{IC}}$ and strength (or flaw size) must be determined and strength data normalized so that they reflect only intrinsic random variations of strength before use. Instances are reported where $\mathrm{K}_{\mathrm{IC}}$ is not a material constant. Specifically, in rocks (5) and dense, high-purity $\mathrm{Al}_{2} \mathrm{O}_{3},(6) \mathrm{K}_{\text {IC }}$ has been found to increase with crack size, apparently because the extent of subsidiary crack branching that occurs at the 
tip of the propagating crack and consumes energy depends on crack size. Also, investigators have reported variable $\mathrm{K}_{\mathrm{IC}}$ in fractures of hot-pressed $\mathrm{Si}_{3} \mathrm{~N}_{4} \cdot{ }^{(7)}$ This variability possibly is associated with a known anisotropy of $\mathrm{K}_{\mathrm{IC}}$, such that $\mathrm{K}_{\mathrm{IC}}$ depends on the orientation of the crack that becomes unstable.

Fracture mirrors in strength-tested specimens offer a possible approach to examining the question of whether $\mathrm{K}_{\mathrm{IC}}$ of a ceramic is a bulk property. $\mathrm{K}_{\mathrm{IC}}$ for individual specimens can be calculated from the following approximate relation: (8)

$$
K_{I C} \simeq \sigma_{f} \sqrt{r} / 2.35
$$

where $r$ is mirror radius and $\sigma_{f}$ is fracture stress.

\subsubsection{The Nature of Strength-Controlling Flaws}

The statistical theories of fracture assume that the scatter in strength values results solely from variability in strength-controlling flaws. Flaws that cause fracture can be of two distinct types: (a) intrinsic features of the microstructure of a ceramic, such as large grains, pores, inclusions, or weak grain boundaries; or (b) extrinsic surface defects introduced in surface finishing or from service-incurred damage. Sometimes two or more neighboring flaws of either or both types link together and initiate fracture. The intrinsic flaws, being microstructural features, are sensitive to ceramic processing, which again emphasizes the importance of obtaining strength data from specimens prepared identically to the component. In the case of fracture from surface-finishing flaws, it is, of course, necessary that both the strength-test specimens and the component be finished alike. Finally, the possibility of strength alteration from surface changes in service cannot be neglected. Service effects could obliterate surface-finishing flaws as fracture-initiating sites with the introduction of a different population of more or less severe flaws in the surface. In any event, investigation of possible service effects on the component surface is imperative in obtaining a valid statistical description of the strength of the ceramic.

Flaws in a ceramic, if not themselves cracks, give rise to the formation of cracks. The severity, $s$, of a crack is given by the following relations: 


$$
\begin{aligned}
s & =Y \sqrt{a} / Z \\
& \simeq 0.59 \mathrm{Y}(\mathrm{A})^{\frac{1}{4}}
\end{aligned}
$$

where a is the depth normal to the tensile stress of a surface crack or, in the case of a circular or elliptical subsurface crack, is the radius or half the minor axis. $Y \simeq 1.99$ for surface cracks and $\simeq 1.77$ for subsurface cracks. Z varies with crack shape, having a value of 1.0 for a long, shallow crack and increasing with depth-towidth ratio. For a circular crack, $\mathrm{Z} \simeq \pi / 2$. A is the crack area. The approximate form, Equation (4b), introduces a maximum error of less than 5 percent in computing s. (9) This relation shows that the area and location of a crack are the sole determinants of its severity.

The photomicrographs in Figure 4-1 of fracture origins in glass and high-strength ceramics illustrate the point that a range of flaw types can be responsible for a fracture. They also illustrate the fact that the size of a microstructural feature or extrinsic surface defect at which fracture begins provides only a rough measure of the Griffith crack size. For example, the $70 \mu \mathrm{m}$-diameter pore in Figure 4-1b apparently caused a $150 \mu \mathrm{m}$-diameter surrounding crack that ultimately became unstable. Our lack of knowledge of the association between the size of potentially detectable microstructural features or surface defects and the size of Griffith cracks impedes nondestructive assessments of the strength of a ceramic. There is little question that, preceding the fracture event, environmentally independent and stable cracks often develop and grow at sites of stress intensification. Both fractographs and acoustic emissions give evidence of the phenomenon. The formation of Griffith cracks constitutes a poorly understood facet of the crack instability event in ceramics, and we need to learn more about it to predict reliably the failure of stressed ceramic components, particularly by NDE techniques.

\subsubsection{Flaw Populations in Ceramics}

No basis exists for extrapolating plots of failure probability as a function of stress. As a consequence, the utility of statistical descriptions of strength is limited to the stress range covered by experimental data. A ceramic component can be expected to perform unreliably if its failure probability is determined for a stress outside this range.

Because of this limitation on statistical descriptions of strength, component size tends to dictate the size of specimens to be strengthtested. For example, if specimens much smaller than the component of 


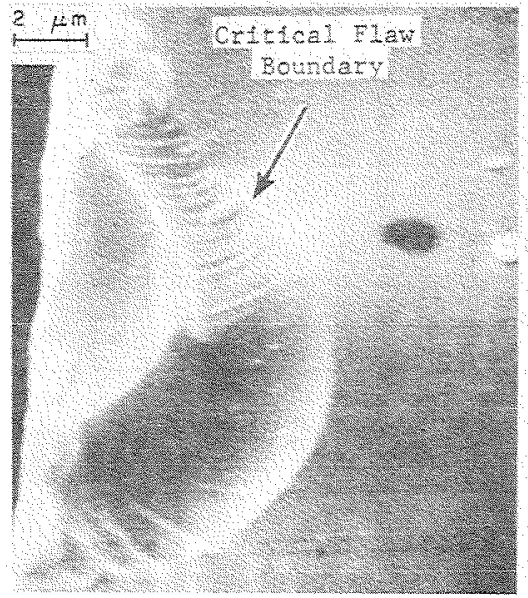

a

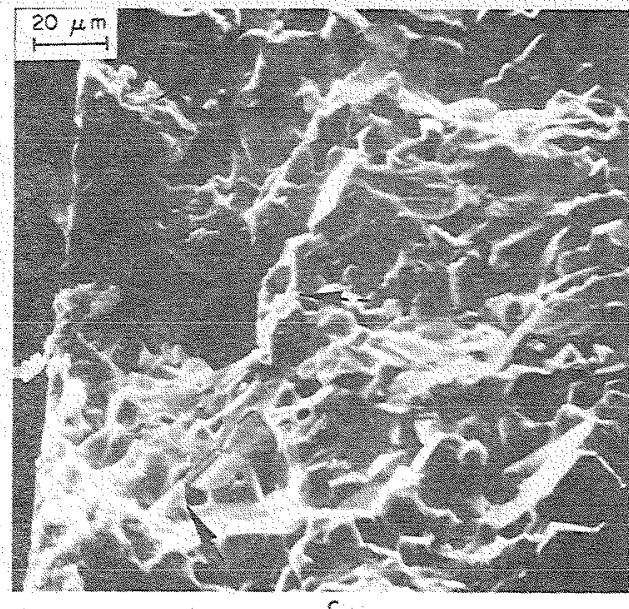

$\bar{c}$

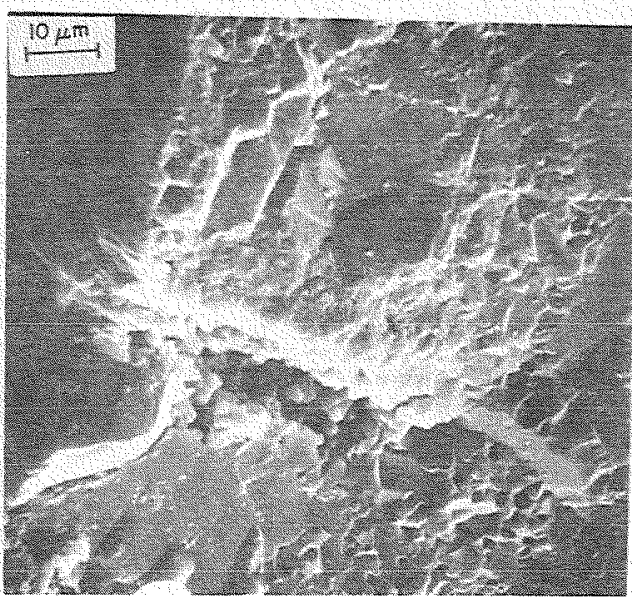

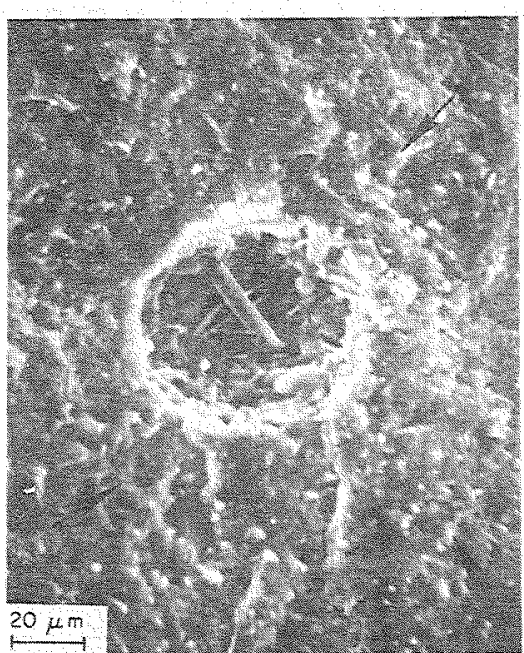

b

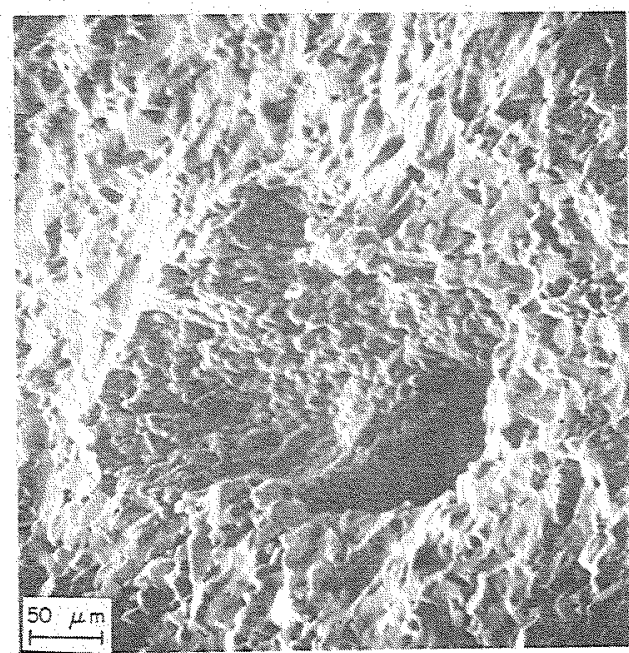

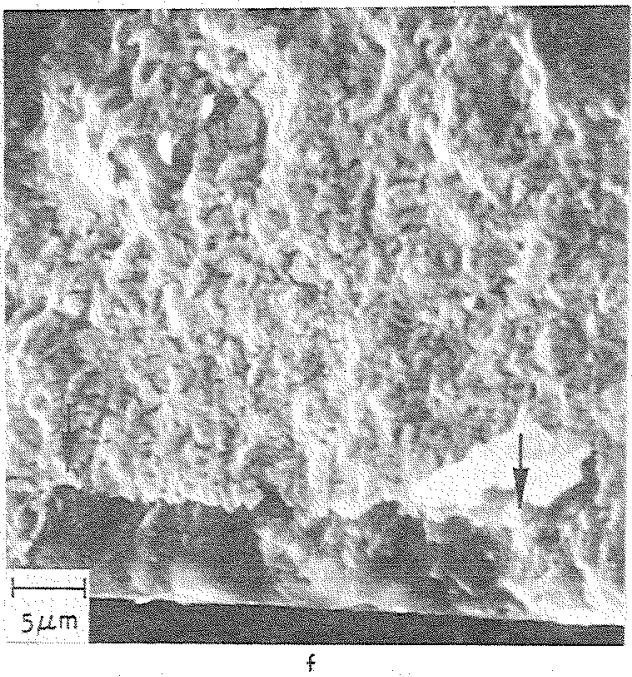

$f$

FIGURE 4-1 Fracture-Initiating Flaws in Ceramic Materials 
interest are tested, the bulk of the data can be expected to fall in the high probability region of the component's failure-stress range; a very large number of specimens would have to be tested to define strength in the low probability region of prinary concern in structural designing.

Weibull plots of strength data for an $\mathrm{Al}_{2} \mathrm{O}_{3}$ ceramic (10) (Figure 4-2) illustrate the danger of extrapolating failure probability plots. The plots shown are for three sizes of specimens. The effective size of the smaller specimen has been varied by using both 3- and 4-point binding, thus giving three plots, each covering a different failure-stress range. The Weibull descriptions of strength differ in each range, as indicated by the different slopes, and consequent Weibull moduli, m, with the difference being quite pronounced between the large and small specimens $(\mathrm{m}=11$ versus $\mathrm{m}=25$ or 34$)$. Fractography showed that fractures in the small specimens were associated with machining flaws (Figure 4-1c) and those in the large specimens with intrinsic microstructural defects (Figure 4-1d). Obviously, extrapolation of the smal1-specimen data to obtain a failure probability at stresses below approximately $50 \mathrm{ksi}$ would greatly underestimate the probability, as reflected by the large-specimen data. Presumably, if enough small specimens had been tested in 3-point binding, a Weibull plot (Figure 4-3) would have been obtained. In this plot, Weibull statistical relations have been used to normalize the data from 4-point small and large specimens to that of the 3-point small specimen. $(10,11)$

This example of a complex, bimodal strength dispersion owing to the presence of two statistical populations of strength-controlling flaws illustrates the importance of using fractography in conjunction with statistical treatments of strength data. One could not expect a single Weibull formulation to describe the failure probability of a ceramic if fractography revealed that some specimens failed from machining flaws and others from intrinsic microstructural defects.

Flaw populations in ceramics apparently can be such that specimen strengths are neither dispersed significantly nor size-dependent. This fact has been demonstrated to a degree in tests of glass-ceramic. (12) Specimens of widely varying size exhibited no size dependence and small standard deviations ( 3 percent) when failure was from extrinsic surface flaws. No abnormal procedures were used in surface finishing the specimens, and the absence of a size dependence was observed in strength tests in which slow crack growth was present as well as absent. However, the ceramic contained a sparse population of pores which were responsible for some low-stress failures, and there was a size dependence when pore failures were represented in the strength data. The absence of a size dependence indicates a very large Weibull modulus, evaluated to be greater than 50 for the surface flaw failures. 


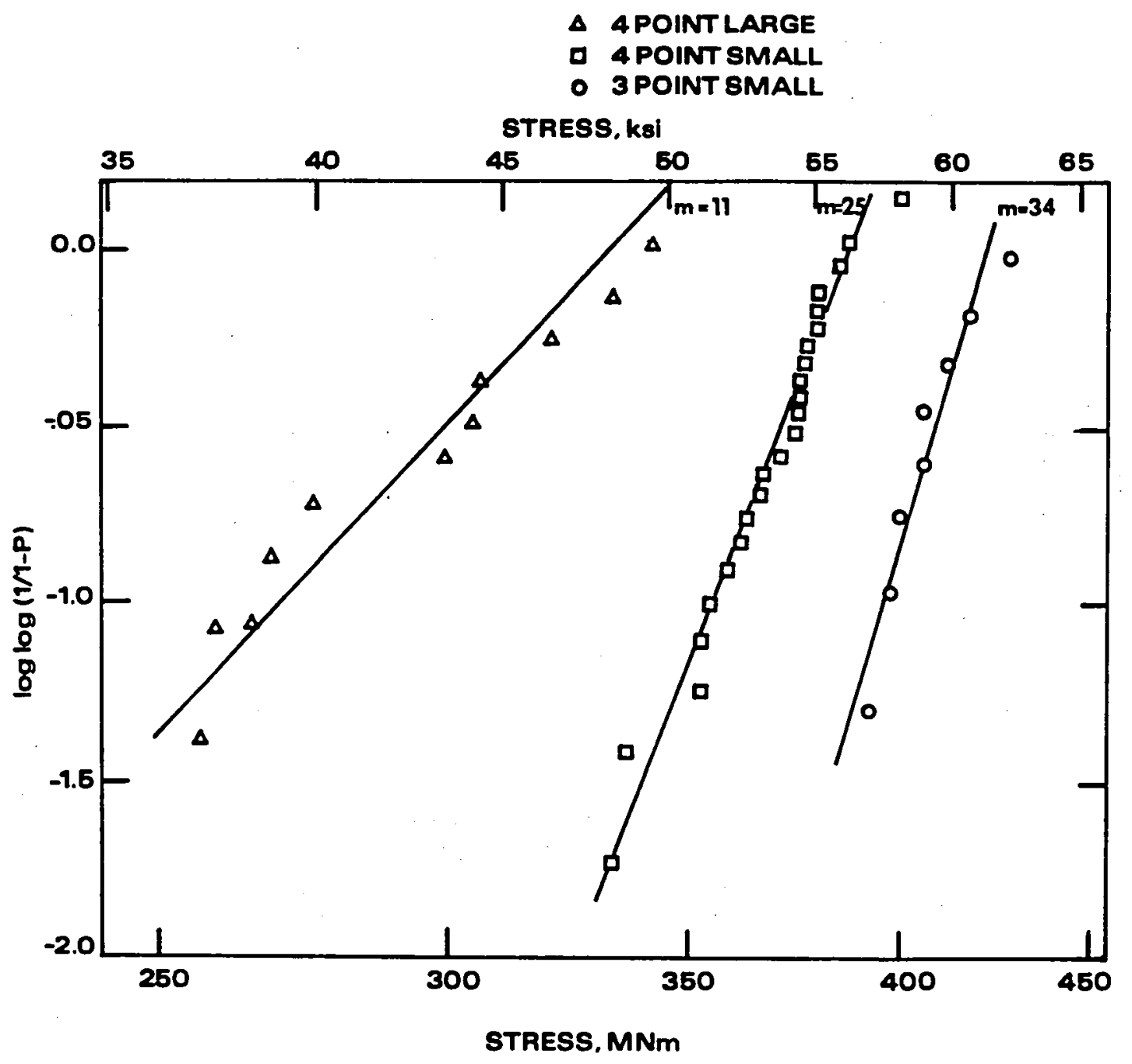

FIGURE 4-2 Weibull Plots of $\mathrm{Al}_{2} \mathrm{O}_{3}$ (Alsimag 614) Strength Data from Specimens of Three Sizes 


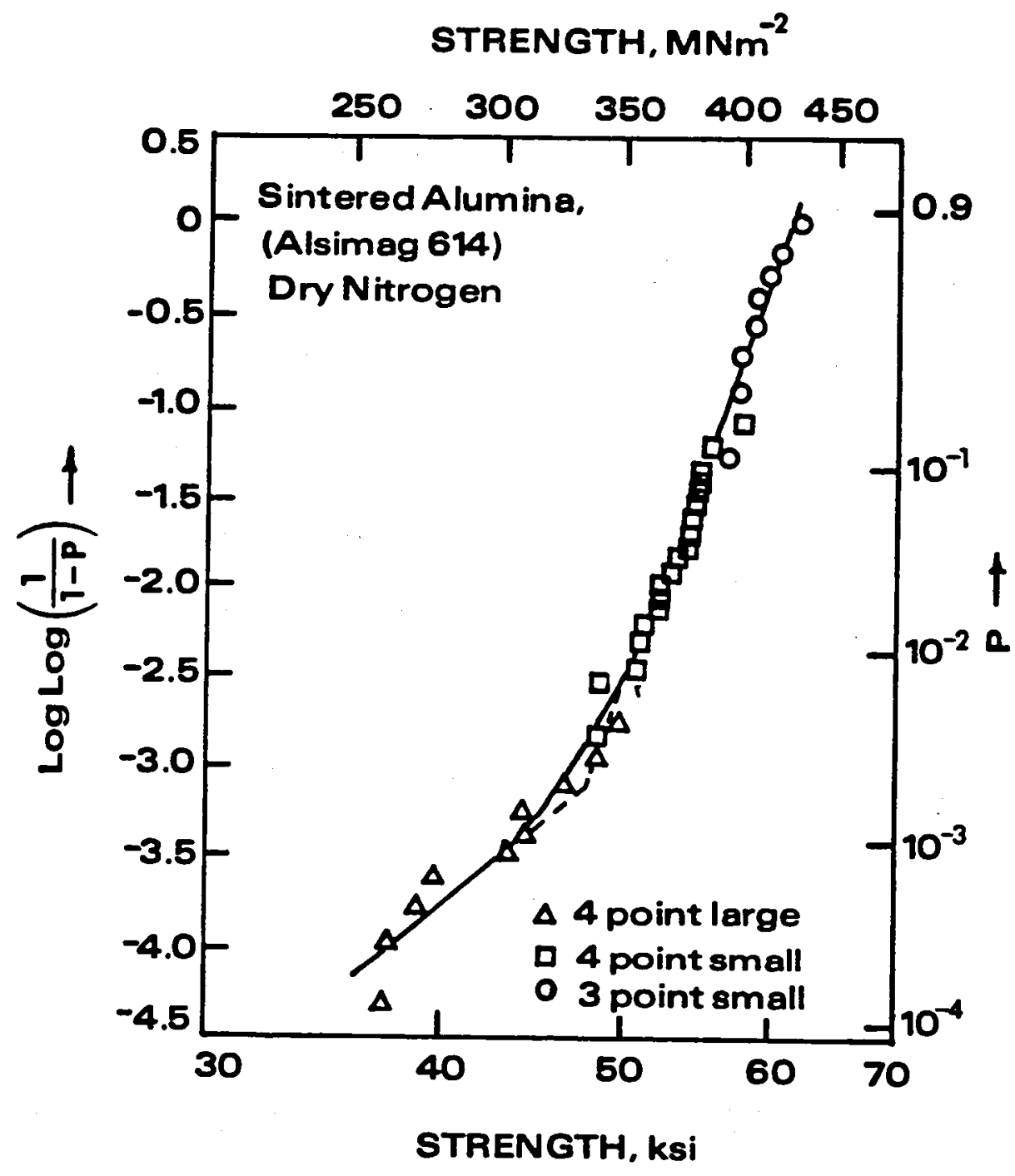

FIGURE 4-3 Weibull plot of the data obtained in three different sizes of an alumina ceramic tested in dry nitrogen. Failure probabilities for the small and large 4-point bend data have been normalized to those of the small 3-point bend specimen. 


\subsubsection{Stable Crack Growth}

Stable crack growth causes strength to decrease with time, limiting the service life of a stressed ceramic component. Although considerable progress has been made with life prediction (Section 5.5), much remains to be learned about the time dependence of failure probability. From the standpoint of reliability, if a choice exists, it is certainly preferable today to use ceramics for heat-engine components that do not exhibit stable crack growth.

Such growth can result from chemical (water) action, even at low temperatures, or from mass transport (creep) at high temperatures. Also, at sufficiently high $\mathrm{K}_{\mathrm{I}}$, stable crack growth is observed in the absence of chemical action or creep. This environmentally independent stable crack growth has important implications. It suggests that a time dependency of failure is unavoidable at sufficiently high $\mathrm{K}_{\mathrm{I}}$, but below $\mathrm{K}_{\mathrm{IC}}$, and that a failure criterion less than $\mathrm{K}_{\mathrm{IC}}$ should be used in designing. Very little research has been devoted to this matter. We have no basis today for specifying the $\mathrm{K}_{\mathrm{I}}$ range for environmentally independent crack growth or the rate at which it proceeds. These questions require resolution through research.

\subsection{Test Methods for Structural Ceramics}

The tests for characterizing the resistance of ceramics to stress fall into two general categories -- strength and fracture-mechanics tests. The latter tests yield information about parameters describing stable flaw growth, so that the time dependence of. failure can be predicted, and about the flaw conditions for unstable crack growth. Stable crack growth rate $(V)$ is expressed in terms of a stress intensity factor $\left(\mathrm{K}_{\mathrm{I}}\right)$ and, as noted in Section 4.2.1, the condition for unstable crack growth is defined by a critical stress intensity factor $\left(\mathrm{K}_{\mathrm{IC}}\right)$.

\subsubsection{Strength Tests}

Ceramic strength data must meet stringent quality demands if they are to be used to determine the failure probability of a stressed component. Statistical fracture theory is based on the premise that specimen-to-specimen variability of strength is an intrinsic property of the ceramic, reflecting its flaw population and not unassignable measurement errors. Use of statistics to account for a variability having an assigned cause, of course, is quite different from normal usage of statistics in experimental work, and it introduces a peculiar problem -- namely, that the ceramic strength data must be essentially free of experimental error. If data reflect experimental error as well as flaw variability, the resulting statistical description of the 
strength of the ceramic will be incorrect (i.e., the Weibull moduli will be too sma11), and any stressed ceramic component designed on the basis of the description will perform unreliably.

In general, insufficient attention is given to this need for error-free data in applying statistical fracture theory to design problems. No data should be used without experimental validation of its freedom from error through analyses and instrumentation. In view of current practice in strength testing of ceramics, we think it possible that lack of adequate care in testing is a major cause of the unreliability problem being addressed here.

Uniaxial bend tests are commonly used to obtain ceramic strength data. Errors in these tests can result from unequal moments, friction, wedging, and torsion, in addition to the usual measurement errors. Procedures are available that will provide reasonable assurance of the absence of these errors in strength testing. (13) The procedures include experimental stress analyses using instrumented specimens of a standard material to ensure that the test setup imposes the assumed stress distribution in specimens and that computed stresses are accurate. Measurements of strain or deflection during testing also provide a means of assuring freedom from error in strength data, in that load-strain or load-deflection curves should be constant. Finally, fractographic examination of each tested specimen to determine mirror radii can reveal errors in testing, since mirror radii are related to fracture stress.

It is difficult to assure freedom from error resulting from superposed bending in direct tension tests of ceramics. Such assurance can be achieved if the specimens are instrumented to reveal the strain distribution in the cross section, but this is a troublesome and usually impractical procedure.

A frequent source of error in strength data is nonrepresentative edge failures caused by flaws introduced in machining rectangular specimens. Fractographic examination of tested specimens is needed to assure freedom from this source of error. Careful attention also must be given to the possibility of scatter in data resulting from strainrate variations or environmental effects if the material exhibits environmentally sensitive stable crack growth.

\subsubsection{Fracture Mechanics Tests}

Tests for determining crack growth parameters fall into two distinct categories: (a) the conventional strength tests and derivatives thereof, and (b) the macrocrack fracture-mechanics specimens. A basic difference is that the strength-related tests involve real flaws of the same dimensions as the critical flaws in actual design pieces, whereas the fracture-mechanics specimens have large artificial flaws. To date, 
indications are that glasses probably yield similar results for both types of tests, but that microstructural effects may cause difference in polycrystalline ceramics for some conditions.

Conventional strength tests for crack growth parameters are of two basic varieties: (a) the static fatigue test, and (b) the dynamic fatigue or stressing-rate tests. In the first type, a large number of specimens are subjected to different stress loads, and their times to failure are analyzed to yield crack growth data. This test assumes tacitly that failure occurs by growth of preexisting flaws and that new flaws are not nucleating and leading to failure. The test consumes samples and time. Only limited reliable results exist for glasses and few for crystalline ceramics. Unfortunately, the static fatigue test may prove to be the most reliable in terms of approximating actual conditions.

The dynamic fatigue, or stressing rate, test utilizes the increase in strength with faster stressing rates to gain information about crack growth parameters. It has been widely applied to glasses, yielding results consistent with static fatigue tests. For example, most soda-lime glasses yield an $n$ value near 16 for the relation $V=A K_{I}^{n}$. Recently, however, testing in different stressing states has yielded different $n$ values for some crystalline ceramics, thus confusing the issue. Nevertheless, the dynamic fatigue test is rapid and easily performed and undoubtedly will remain popular.

Both of the aforementioned tests involve the growth to critical dimensions of the failure-causing flaw. Thus, both will be subject to the statistical variations inherent in the flaw populations of the test specimens. As a result, there has been a recent trend to attempt to standardize the size of the to-be-critical flaw by introducing a microflaw larger than the natural flaws by a hardness indentation. This technique has some promise when integrated with the static fatigue and dynamic fatigue tests, but currently is in too early a developmental stage for critical review.

Crack Growth Tests using large fracture-mechanics specimens which contain microcracks have concentrated on the use of the double cantilever beam or the double torsion specimen, or modifications thereof, such as the constant moment arm. The double cantilever beam specimen is generally utilized as a crack-length-dependent $\mathrm{K}_{\mathrm{I}}$ specimen for which the crack length must be measured to obtain crack growth data. As a result of this limitation, it has proven most valuable for glasses. The double torsion specimen, a constant $\mathrm{K}_{\mathrm{I}}$ specimen, has received greater attention for use with dense, opaque, polycrystalline ceramics. Other fracture mechanics specimens are no doubt applicable. However, the rather costly specimen preparation processes have limited specimens to relatively simple configurations. Again, as previously mentioned with regard to strength tests, microstructural effects on crack growth appear to exist. 
In summary, it seems a fair analysis that knowledge and capability currently exist for determining crack growth parameters in ceramic materials. The agreement between tests and the effect of microstructure on the test are not fully understood. However, it is possible to construct $\mathrm{K}_{\mathrm{I}}-\mathrm{V}$ diagrams, which may then be applied to design practices. Limitations in the determination of crack growth parameters will be discussed further in Section 5.5.

Tests for $K_{\text {IC }}$ are of several varieties, but can be conveniently grouped into the large crack fracture-mechanics specimens and the microcrack hardness indentation techniques. The same large crack specimens used for crack growth studies, the double cantilever beam and the double torsion specimens, have been extensively applied, as have the notch beam specimens (analogous to the single edge crack). Numerous other specimen configurations have also been ntilized, and undoubtedly many more will be. However, as previously noted, the specimen cost is a very important factor, as is the ability to introduce an atomically sharp crack into the specimen. The microhardness indentation crack techniques have not had the benefit of prior work comparable to that which has been done by ASTM on metallic materials, and as a result they are in the less formal stage of acceptance. They have the advantage that the test flaws are of the same general size as the critical flaws in applications. One of the techniques involves introducing a flaw by a microhardness indentor, then fracturing the sample and utilizing the artificial flaw as the critical flaw in a $\mathrm{K}_{\mathrm{IC}}$ calculation. The other technique only measures the extent of crack propagation from a high-load, microhardness indent. Both of these methods offer advantages in sample preparation and size over the more conventional fracture-mechanics specimens. As with the crack growth parameters, we have the knowledge and capability for determining $\mathrm{K}_{\mathrm{IC}}$ values.

\subsection{Fractography of Ceramics}

Fractography of ceramics is not as highly developed as fractography of metals. However, considerable failure analysis is possible, although on an empirical basis.

Generally, intergranular (grain boundary) and transgranular fracture paths are readily distinguishable after the fact. Elevated temperatures and fine grain sizes tend toward intergranular fractures. Distinct, geometric cleavage steps on particular crystallographic planes are also clearly identifiable as transgranular fractures and are prevalent in large grain bodies and large crystals. It appears that these characteristics of polycrystalline ceramic fractures are understood to some degree, for they can be identified, although not always predicted a priori. 
Perhaps the most successful aspect of ceramic fractography is the identification of fracture origins. Glass technology has been transferred to polycrystalline ceramics via the fracture mirror and hackle surface features, where the origin usually is centered within the mirror and the hackle lines can be traced back to locate the origin. In high quality ceramics, these techniques have been demonstrated to locate pores, large grains, and inclusions as the obvious sources of failure. These features -- their size, orientation, etc. -- have also been utilized to estimate stress at the fracture origin. With simple laboratory geometries, this approach has been highly successful; but for complex stress states its utility remains to be fully demonstrated. Lacking is fundamental understanding of the kinetic or dynamic crack situation -that is, what criteria may be applied to moving cracks and how. This topic has proved extremely important in metal systems, but has not received comparable attention in ceramics. For example, on fracture surfaces, it has not been routine to separate subcritical and fast fracture regions of crack growth; in fact, it is difficult to separate them in most cases. Some success has been achieved, particularly in glass, in monitoring crack growth by superimposing ultrasonic pulses on the propagating crack. However, as cracks accelerate toward a branching condition, or their terminal velocity, this technique is less useful. It has not been applied to polycrystalline ceramics.

Macrofractography, as opposed to microfractography, can also yield information about ceramic fractures. For example, when point impacts are the source, often the classic Hertzian cone crack results, and frequently an extensive starlike pattern radiates from the point of impact. Pressure breaks of ceramic containers, such as glass bottles, also yield a distinctive fracture pattern.

\subsection{Effects of Engine Environments on $\mathrm{Si}_{3} \mathrm{~N}_{4}$ and $\mathrm{SiC}$ Ceramics}

For the purpose of this study, environmental effects will be defined as any effects of an engine's operating environment that potentially could decrease the performance or load-bearing capability (and thus the reliability) of the ceramic components. This is a broad definition, and the effects on reliability are difficult to evaluate. There are two major reasons: the data base is very limited, especially for long-life applications; and so little ceramic engine testing has been done that all of the critical environmental effects may not yet have been encountered and defined.

\subsubsection{Oxidation}

Most heat engines operate at high temperature in an oxidizing environment. There are usually impurities in the gas stream, and they will be discussed under Corrosion. 
Most oxides and stoichiometric silicates are stable at high temperature in oxygen or a mixed oxygen/nitrogen atmosphere. $\mathrm{Si}_{3} \mathrm{~N}_{4}$ and $\mathrm{SiC}$ are not; described in Gulbransen and Singhal, (15) both react at free surfaces with oxygen. If the partial pressure of oxygen is roughly $1 \mathrm{~mm} \mathrm{Hg}$ or higher, $\mathrm{SiO}_{2}$ will form a protective layer at the surface. This behavior has been referred to as passive oxidation. The rate of formation or $\mathrm{SiO}_{2}$ is rapid initially, but decreases as the thickness of the layer increases. The oxidation rate is controlled by oxygen diffusion through the $\mathrm{SiO}_{2}$ layer and increases as temperature rises.

The kinetics of passive oxidation are determined by measuring weight gain and dimensional change. More important for heat engine design, however, is the effect of oxidation on the strength of the material. Depending on the material and the initial surface condition, oxidation can increase, decrease, or not affect the strength. (16) Short term oxidation at the appropriate temperature can increase strength significantly by blunting surface flaws formed during fabrication or machining. This effect has been demonstrated for improving the useful strength and reliability of $\mathrm{NC}-132$ hot-pressed $\mathrm{Si}_{3} \mathrm{~N}_{4}$ rotor blades.

The strength and stability of reaction bonded $\mathrm{Si}_{3} \mathrm{~N}_{4}$ have also been improved by controlled oxidation. Rapid oxidation above roughly $1300^{\circ} \mathrm{C}$ (temperature depends on porosity) forms an $\mathrm{SiO}_{2}$ layer that seals the surface and protects the porous interior from oxidation, providing increased stability for engine use. (13) other studies indicate that sinilar results can be achieved at $900^{\circ} \mathrm{C}$ for reaction bonded $\mathrm{Si}_{3} \mathrm{~N}_{4}$ denser than approximately $2.6 \mathrm{~g} / \mathrm{cm}^{3}$. (19)

Oxidation in certain temperature regimes can reduce strength significantly. Oxidation exposure of reaction bonded $\mathrm{Si}_{3} \mathrm{~N}_{4}$ in the range $1000^{\circ}$ to $1300^{\circ} \mathrm{C}$ results in internal oxidation along the interconnected pore channels, forming cristobalite or amorphous silica. Godfrey and Pitman $(20)$ report that reaction-bonded $\mathrm{Si}_{3} \mathrm{~N}_{4}$ with an . initial density of $2.55 \mathrm{~g} / \mathrm{cm}^{3}$. lost at least 30 percent of its strength, on the average, after oxidation exposure for $250 \mathrm{~h}$ at $1250^{\circ} \mathrm{C}$.

Hot-pressed $\mathrm{Si}_{3} \mathrm{~N}_{4}$ materials have also been shown to lose strength because of oxidation. (16) In this case, the mechanism of degradation appears to be impurity-controlled. In $\mathrm{NC}-132$, hot-pressed $\mathrm{Si}_{3} \mathrm{~N}_{4}$, magnesium, calcium, and other impurities diffuse to the surface and combine with the $\mathrm{SiO}_{2}$ to form complex silicates in which $\mathrm{Si}_{3} \mathrm{~N}_{4}$ appears to be only slightly soluble. As a result of this silicate formation, surface pits form after $24 \mathrm{~h}$ at $1375^{\circ} \mathrm{C}$ or $250 \mathrm{~h}$ at $1200^{\circ} \mathrm{C}$. These surface pits become the strength-limiting flaws in hot-pressed $\mathrm{Si}_{3} \mathrm{~N}_{4}$. After such oxidation exposure the strength is 60 to $65 \mathrm{ksi}$, 40 percent below that for unoxidized specimens.

An important complication that arises when flaws are generated by oxidation is that the strength distribution (i.e., flaw population) 
changes with time. When this occurs, all of the possible techniques used to assure reliability (NDE, overload proof test, or statistical evaluation) are no longer valid.(2la, b) (For example, see

Section 5.4.7 on proof testing.) Thus, a need clearly exists for a better understanding of the oxidation/flaw generation phenomenon and for a failure prediction scheme accounting for flaw generation.

Hot-pressed $\mathrm{Si}_{3} \mathrm{~N}_{4}$ materials with sintering aids such as $\mathrm{MgO}$ and $\mathrm{Y}_{2} \mathrm{O}_{3}$ are more resistant to oxidation; they do not appear to undergo significant diffusion of impurities to the surface with modification of the protective $\mathrm{SiO}_{2}$ layer. However, some of the $\mathrm{Y}_{2} \mathrm{O}_{3}$-containing compositions have $\mathrm{Y}-\mathrm{S} i-\mathrm{O}-\mathrm{N}$ phases which are unstable in an oxidizing environment at below $1000^{\circ} \mathrm{C}$ and result in severe cracking. Careful control of composition and processing is required to avoid formation of these phases.

The above examples have been for conditions of high partial pressure of oxygen. For oxygen partial pressures in the range of $1 \mathrm{~mm} \mathrm{Hg}$ or below, silicon monoxide (SiO) gas forms. The part loses weight and acquires no protective layer. This so-called active oxidation is linear and continuous, and the component can be completely consumed. Active oxidation is not likely to occur with most current heat engines, which operate with excess oxygen. However, the following conditions could lead to active oxidation:

- Localized reducing conditions caused by carbonaceous deposits.

- Closed cycle engines with a nonoxygen working fluid.

- Engines operating under conditions where almost all the oxygen is consumed in combustion.

\subsubsection{Corrosion}

For the purpose of this discussion, corrosion will be defined as the combined effects on ceramic components of oxidation plus gaseous, condensed, or particulate impurities introduced via the gas stream. These impurities can increase the rate of passive oxidation (i.e., increase the transport rate of oxygen through the protective scale), cause active oxidation, or produce compositions that chemically attack the ceramic. The following mechanisms have been reported: 
- Change in the chemistry of the $\mathrm{SiO}_{2}$ layer, increasing the oxygen diffusion rate.

- Bubble formation, disrupting the protective $\mathrm{SiO}_{2}$ layer and allowing increased oxygen access.

- Decreased viscosity of the protective surface layer, which is then swept off the surface by the high velocity gas flow.

- Formation, at the ceramic surface, of a molten composition in which the ceramic is soluble.

- Localized reducing conditions decreasing the oxygen partial pressure at the ceramic surface to a level at which active oxidation can occur.

- Formation of new surface flaws, such as pits or degraded microstructure, which decrease the load-bearing capability of the component.

Singhal (22) has evaluated the dynamic corrosion-erosion behavior of $\mathrm{Si}_{3} \mathrm{~N}_{4}$ and $\mathrm{SiC}$ in a pressurized turbine test passage operating at $1100^{\circ} \mathrm{C}, 0.9 \mathrm{MPa}$ pressure, and $152 \mathrm{~m} / \mathrm{s}$ gas velocity using Exxon No. 2 diese 1 fuel. After $250 \mathrm{~h}$ exposure, the surfaces of test specimens were smooth and free of adherent deposits. Average surface erosion was only $2.3 \mu \mathrm{m}$ for the $\mathrm{SiC}$ and $3 \mu \mathrm{m}$ for the $\mathrm{Si}_{3} \mathrm{~N}_{4}$. No strength degradation occurred. Tests in the same turbine test passage with $4 \mathrm{ppm}$ barium in the fuel produced drastically different results: massive surface deposits containing barium silicates with iron, magnesium, nickel, chromium, and other trace impurities. This example shows that small quantities of some impurities can have a pronounced effect on corrosion behavior. This is especially important in applications where heavy residual fuels or coal-derived fuels are being considered.

Continuation of the above turbine passage testing, without barium additions, has been reported by Miller, et al. (23) for longer time and higher temperature. The results are summarized in Figure 4-4. The strength of the hot-pressed $\mathrm{Si}_{3} \mathrm{~N}_{4}$ was degraded significantly by formation 


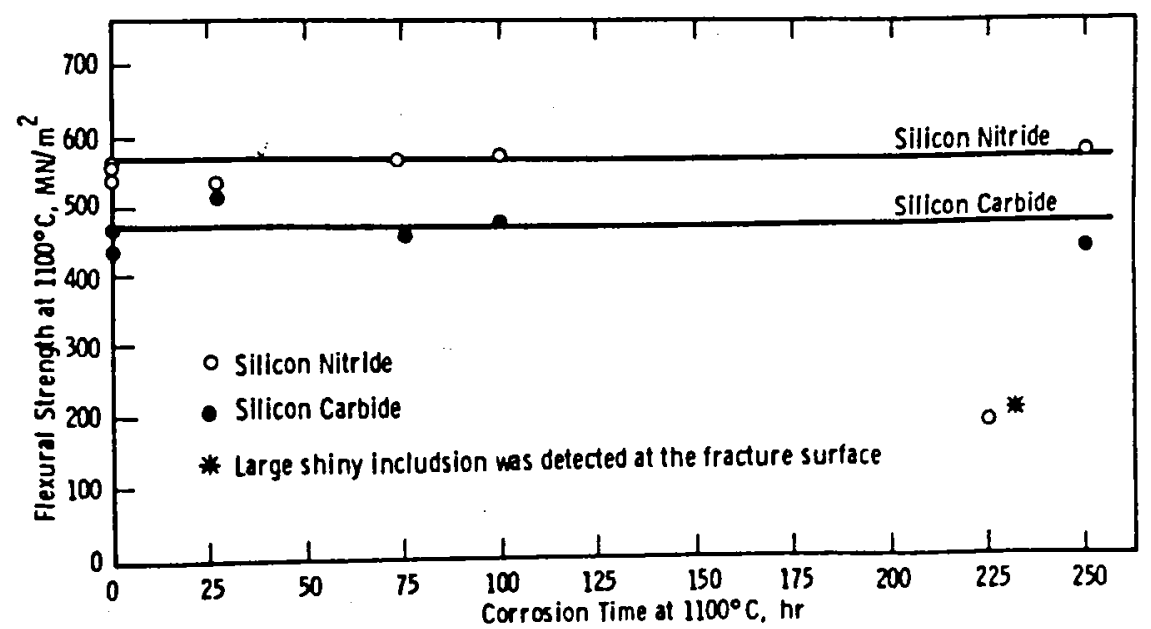

FIGURE 4-4 Effect of Gas Turbine Environment on the Flexural Strength of Hot Pressed $\mathrm{Si}_{3} \mathrm{~N}_{4}$ and SiC (From Reference 23) 
of surface pits. The hot-pressed SiC showed no degradation in high temperature strength after $4000 \mathrm{~h}$ exposure. The slight decrease in room temperature strength was attributed to cracking of the $\mathrm{SiO}_{2}$ surface layer during cooling.

Mckee and Chatterji ${ }^{(24)}$ have evaluated the stability of $97-99 \%$ dense sintered $\mathrm{SiC}$ at $900^{\circ} \mathrm{C}$ in a gas stream flowing at $250 \mathrm{~m} / \mathrm{min}$ at 1 atm total pressure. Gases evaluated were $\mathrm{N}_{2}, \mathrm{O}_{2}$, air, $\mathrm{O}_{2}-\mathrm{N}_{2}$ mixture, $0.2 \% \mathrm{SO}_{2}-\mathrm{O}_{2}, 2 \% \mathrm{SO}_{2}-\mathrm{N}_{2}, 2 \% \mathrm{SO}_{2}-5 \% \mathrm{CH}_{4}$ - balance $\mathrm{N}_{2}, 10 \% \mathrm{H}_{2} \mathrm{~S}-\mathrm{H}_{2}$, and $\mathrm{H}_{2}$. Gas-molten salt environments were also evaluated using constant gas compositions and the following salt mixtures: $\mathrm{Na}_{2} \mathrm{SO}_{4} ; \mathrm{Na}_{2} \mathrm{SO}_{4}+\mathrm{C}$ (graphite); $\mathrm{Na}_{2} \mathrm{SO}_{4}+\mathrm{Na}_{2} \mathrm{CO}_{3} ; \mathrm{Na}_{2} \mathrm{SO}_{4}+\mathrm{Na}_{2} \mathrm{O} ; \mathrm{Na}_{2} \mathrm{SO}_{4}+\mathrm{NaNO}_{3} ;$ and $\mathrm{Na}_{2} \mathrm{SO}_{4}+\mathrm{Na}_{2} \mathrm{~S}$. Corrosion behavior was studied by continuous monitoring of the specimen weight in the tests environment using standard thermobalance techniques, followed by examination of polished sections of the specimen cross section. The results are summarized in Figure 4-5. The authors concluded that $\mathrm{SiC}$ at $900^{\circ} \mathrm{C}$ is inert in $\mathrm{H}_{2}, \mathrm{H}_{2} \mathrm{~S}$, and high purity $\mathrm{N}_{2}$; that passive oxidation provides protection under normal gas turbine operating conditions or when thin condensed layers of $\mathrm{Na}_{2} \mathrm{SO}_{4}$ are present in an oxidizing atmosphere; and that corrosion occurs in the presence of $\mathrm{Na}_{2} \mathrm{O}$, a carbonaceous condensed phase, or a thick $\mathrm{Na}_{2} \mathrm{SO}_{4}$ surface layer.

Richerson and Yonushonis (16) have evaluated the effect on the strength of $\mathrm{Si}_{3} \mathrm{~N}_{4}$ materials of $50 \mathrm{~h}$ cyclic oxidation/corrosion at specimen temperatures up to $1200^{\circ} \mathrm{C}$ using a combustor. rig burning typical aircraft fuels with 5 percent sea salt additions. Where $\mathrm{Na}_{2} \mathrm{SO}_{4}$ was present in the condensed form, corrosion resulting in slight material recession occurred. This was accompanied by buildup of a glassy surface layer containing many bubbles which appeared to be nucleating at the $\mathrm{Si}_{3} \mathrm{~N}_{4}$ surface. The strength of $\mathrm{Si}_{3} \mathrm{~N}_{4}$ hot-pressed with $\mathrm{MgO}$ was degraded by 30 percent. The strength of reaction bonded $\mathrm{Si}_{3} \mathrm{~N}_{4}$ of $2.5 \mathrm{~g} / \mathrm{cm}^{3}$ density was degraded by as much as 45 percent.

\subsubsection{Erosion}

Erosion can affect the reliability of heat engine components in at least three ways. First, it can result in dimensional change of a component, causing aerodynamic or leakage losses and thus reducing engine performance. Second, erosion can produce surface flaws or reduce cross sections, decreasing the load-bearing capability of the component. Third, erosion can produce a roughened surface or abrasive particles that increase friction and limit relative motion, resulting in abnormally high localized stresses and fracture or chipping.

Erosion can operate alone by the abrasive action of small particle impingement or in conjunction with other environmental effects such as oxidation or corrosion. The latter case is of special concern for heat 


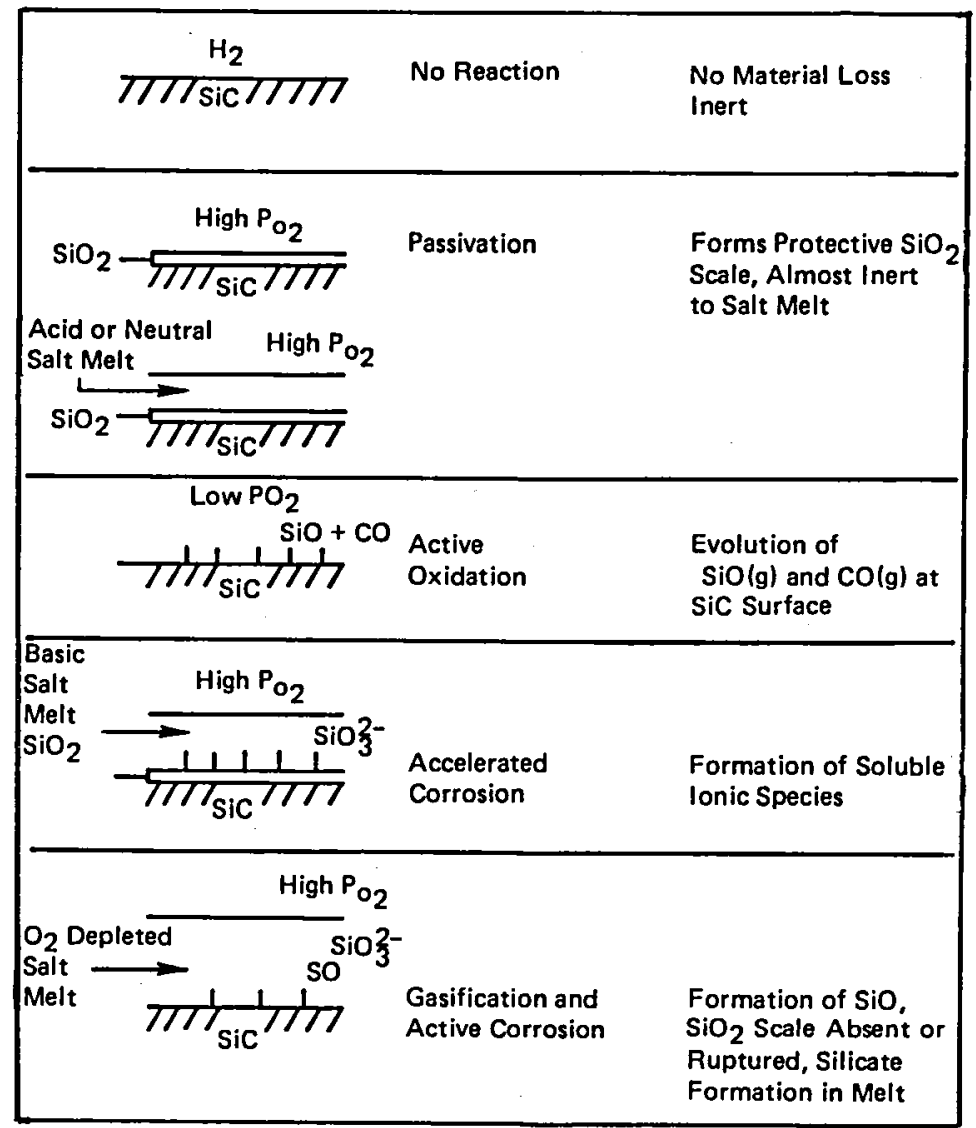

FIGURE 4-5 Behavior of SiC in Gas-Molten Salt Environments 
engines. Initially, ceramic materials such as $\mathrm{Si}_{3} \mathrm{~N}_{4}$ and $\mathrm{SiC}$ are very resistant to particulate erosion because of their extreme hardness. However, as the surface oxidizes or corrodes, a much softer layer results which is more easily eroded. Removal of this surface layer exposes fresh $\mathrm{Si}_{3} \mathrm{~N}_{4}$ or $\mathrm{SiC}$ which can then be oxidized or corroded. Such a coupled effect can potentially have a much more severe effect on the reliability and life of a component than either mechanism alone.

Relatively little experiemental evaluation has been conducted on the erosion resistance or the coupled erosion/oxidation resistance of: heat engine materials.

Metcalfe ${ }^{(25)}$ has reported the results of erosion resistance tests on hot-pressed and reaction bonded $\mathrm{Si}_{3} \mathrm{~N}_{4}$ in both erosion rig tests and in a small gas turbine engine. The erosion rig tests were conducted at room temperature with $80 \mathrm{mg} / \mathrm{ft}^{3}$ of silica dust in air flowing at 650 to $700 \mathrm{ft} / \mathrm{s}$. All test specimens were of the same size and configuration. Losses are given for comparison purposes only. 410 stainless steel was used as a standard. At 30 deg. impingement angle, hot-pressed $\mathrm{Si}_{3} \mathrm{~N}_{4}$ showed no erosion after $40 \mathrm{~min}$. Reaction bonded $\mathrm{Si}_{3} \mathrm{~N}_{4}$ lost $2.2 \times \mathrm{x}^{-3} \mathrm{cc}$ and 410 stainless steel lost $3.7 \times 10^{-3} \mathrm{cc}$. At $90 \mathrm{deg}$. impingement angle the hot-pressed $\mathrm{Si}_{3} \mathrm{~N}_{4}$ lost $0.13 \times 10^{-3} \mathrm{cc}$, the reaction bonded $\mathrm{Si}_{3} \mathrm{~N}_{4}$ $5.6 \times 10^{-3} \mathrm{cc}$, and the 410 stainless steel $1.9 \times 10^{-3} \mathrm{cc}$. In each case, the dust particle size was 43 to 74 microns $(\sim .002-.003$ in.). For low impingement angles, the reaction bonded $\mathrm{Si}_{3} \mathrm{~N}_{4}$ was slightly better than the metal, but not enough to warrant engine testing. The hot-pressed $\mathrm{Si}_{3} \mathrm{~N}_{4}$ showed negligible loss and was selected for engine testing.

The tests were conducted in the Solar R62T-27 turbine engine. Hot-pressed $\mathrm{Si}_{3} \mathrm{~N}_{4}$ nozzle guide vanes were incorporated in the engine in place of some of the metal vanes. The engine was run $10 \mathrm{~h}$ under normal operating conditions at $925^{\circ} \mathrm{C}$ inlet temperature. Minus 140 mesh silica was added to the air inlet at a rate of $172.5 \mathrm{~g} / \mathrm{h}$. The metal vanes were severely eroded, but no erosion was visible for the ceramic vanes.

More recent laboratory studies on the erosion of hot-pressed silicon nitride have confirmed the findings of Metcalfe and coworkers. Pettit(26) showed that, under simulated turbine operating conditions, hot-pressed silicon nitride has about 10 times the erosion resistance of high performance alloys usually used in these applications. Furthermore, a comparison of erosion data collected by Ives ${ }^{(27)}$ on 310 stainless steel and by Hockey, et a1.(28) on hot-pressed silicon nitride revealed a superior erosion resistance of the silicon nitride under identical erosion conditions $\left(\sim 1000^{\circ} \mathrm{C} ; 150 \mu \mathrm{m} \mathrm{SiC}\right.$ particles at $\left.\sim 50 \mathrm{~m} / \mathrm{s}\right)$. At an impingement angle of $90 \mathrm{deg}$, the erosion rate of the stainless steel was bout four times that of the hot-pressed silicon nitride. At angles of impingement less than $90 \mathrm{deg}$, the relative erosion resistance of the hot-pressed silicon nitride is even better becuase of the way in which the erosion resistance of metals and ceramics changes as a function of 
impingement angle. From the data on hot-pressed silicon nitride, one can conclude that its superior resistance to erosion is an important factor in selecting this material for heat engine environments in which erosion will be a problem. Similar results are expected for high density silicon carbine, which also exhibits good erosion resistance.

A fundamental understanding of erosion as a mechanism of material degradation is currently being developed for ceramic materials. Recent experimental and theoretical studies indicate the importance of plastic deformation and fracture toughness to the erosion process. Erosion of ceramics is recognized as an elastic-plastic process in which chips are removed from the ceramic as a result of the formation of a plastic zone at the erosion-particle impact site. (29) Quantitative theories have been developed to express the erosion rate as a function of particle velocity, mass, and density and target hardness and toughness. Experimental investigations are being conducted to evaluate and discriminate between the different theories.

Fundamental studies of erosive wear show that several important factors should be recognized when selecting ceramic materials for heat engine applications:

- The rate of erosion increases with impingement angle, particle density, particle mass, and particle velocity.

- Temperature appears to affect the erosion of ceramic materials only modestly.

- Although the effects of microstructure have not been fully explored, porosity appears to decrease erosion resistance, whereas decreasing the grain size appears to increase the erosion resistance of ceramic materials.

Systematic studies have not yet been conducted to evaluate coupled effects of erosion and corrosion. These effects may turn out to be life-limiting in severe environments resulting from combustion of coal or ash-containing fuels.

\subsubsection{Cyclic Fatigue}

The effect of cyclic fatigue on ceramic heat engine components is relatively unknown. Some data were generated at Westinghouse under the DARPA "Brittle Materials Design, High Temperature Gas Turbine," program for two grades of Norton Company hot-pressed $\mathrm{Si}_{3} \mathrm{~N}_{4}-\mathrm{HS}-110$ (10w purity) and HS-130 (higher purity). (33) Fatigue tests were run on cantilevered flat plate specimens loaded by an eccentric driver rotating at $1800 \mathrm{rpm}$ 
in a Baldwin (BLH) Model SF 2 universal fatigue machine. Neither material showed fatigue at $472^{\circ} \mathrm{F}$, only the HS -110 at $1800^{\circ} \mathrm{F}$ and $2200^{\circ} \mathrm{F}$, and both at $2350^{\circ} \mathrm{F}$. Transmission electron microscopy suggested that the fatigue characteristics of the two materials were controlled by viscoelastic mechanisms -- i.e., grain boundary sliding and triple-point cavitation -- and that the higher purity $\mathrm{Si}_{3} \mathrm{~N}_{4}$ has significantly longer life. However, the viscoelastic mechanisms also controlled life under static loading at comparable temperatures, suggesting that the life was controlled more by the temperature, the size of the load, and the material's microstructure than by the cyclic nature of the loading.

Godfrey (34) conducted a limited number of cyclic fatigue tests on reaction bonded $\mathrm{Si}_{3} \mathrm{~N}_{4}$ at room temperature and $1750^{\circ} \mathrm{F}$. He concluded that it was difficult to interpret the significance of the data because of the difficulty of separating cyclic from noncyclic effects.

More recent cyclic fatigue tests have been conducted under the DARPA/Navy/AiResearch Ceramic Engine Demonstration Program. Tests have been made on a variety of reaction bonded and hot-pressed $\mathrm{Si}_{3} \mathrm{~N}_{4}$ materials using a simple flexural tensile-tensile mode on an MTS hydraulic machine. $(35,36)$ Stress rupture tests were run in parallel to provide a baseline for static effects. These tests have shown that the properties of hot-pressed $\mathrm{Si}_{3} \mathrm{~N}_{4}$ and reaction bonded $\mathrm{Si}_{3} \mathrm{~N}_{4}$ can be affected by cyclic or static loading at high temperature. However, considerable data scatter occurred in each study, so that a basic understanding of mechanisms and design limitations does not yet exist. The same is true for thermal fatigue. Further work under closely controlled conditions is necessary before mechanical and thermal fatigue of ceramic materials can be routinely handled in design and life predictions.

\subsubsection{Vibration}

Steady-state stress is a complex triaxial condition and usually can be defined relatively accurately analytically. Vibratory stress is also a complex triaxial, but varies in direction from steady-state stresses and is cyclic. Vibratory stresses are not as easily defined analytically. For instance, in a gas turbine engine of inserted rotor blade design, the vibratory stresses will vary from blade to blade depending on blade mass, blade dimensional tolerances, and local conditions in the blade attachment slot. For a ceramic blade, which has a higher elastic modulus than metals, these effects will be compounded. Thorough understanding of the boundary conditions is necessary to predict analytically the level of vibratory stresses in a ceramic rotor blade. This understanding must be obtained by experiment.

Individual components or parts of components in heat engines are exposed to varying degrees of vibration, ranging from low frequency to very high frequency, depending on the type of engine and the application. 
Small gas turbine engines, for instance, with rotating components operating typically at more than 40,000 rpm (rotor blade tip speeds $>1400 \mathrm{ft} / \mathrm{s}$ ), can generate vibration by a number of mechanisms. Perhaps the most important is forced vibration, in which pressure disturbance or wakes result in high amplitude vibration of a component. Forced vibration is affected by such things as the number of fuel nozzles, the relative numbers of stator vanes and rotor blades, and the distance between components. A pressure disturbance vibration problem was encountered for a hot-pressed $\mathrm{Si}_{3} \mathrm{~N}_{4}$ rotor blade in the DARPA/Navy/AiResearch program. (37) A critical flexural vibration occurred within the engine operating range and interacted with a complex triaxial stress in the blade attachment region, resulting in fracture. The problem was remedied by changing the number of stator vanes so that a critical pressure disturbance would not occur within the design operating range of the engine. However, the experience pointed out that a ceramic material can lose some of its normal tolerance to vibration when under certain complex stress distributions and that further controlled tests are necessary to provide a base for analytical design.

Another source of vibration is interaction of the vehicle with its environment. This road vibration typically is low frequency, but may be of high amplitude and must be considered in terms of shock damage and maintenance of clearances.

other sources of vibration include the following:

- Aeroelastic -- for metals, flutter, in which blades undergo high amplitude cyclic displacement.

- Acoustic -- low amplitude, but wide frequency range.

- Mechanical coupling -- such as gear-induced vibration.

\subsubsection{Contact Loading}

Due to their brittle nature and low fracture toughness, ceramic materials are not as tolerant of contact loads as metals. Metals can redistribute stress concentrations to a much higher degree than ceramics. This has placed special requirements on designers to analyze interfaces and load transmittal paths through an engine containing ceramic components more carefully to avoid stress concentration in the engine operating range. There has been some success in relieving stress concentrations caused by point contact, as demonstrated by successful rig and engine tests in the
DARPA/AMMRC/Ford, (38) DARPA/Navy/AiResearch, (39) and DoE/NASA/DDA $(40)$ programs. 
Studies in the DARPA/Navy/AiResearch programs have shown that environmental effects can modify the contact loading as a function of time and result in stress concentration and possible component fracture. To date, three principal areas of concern -- impact, friction, and relative motion -- have been defined, although more extensive engine testing may uncover additional areas. Impact resulted in a rotor blade fracture. Hertzian damage was clearly visible on the fracture surface at the initiation point. Whirl pit tests were conducted with actual engine rotor blades of hot-pressed $\mathrm{NC}-132 \mathrm{Si}_{3} \mathrm{~N}_{4}$ to assess tolerance to impact. (39) At $32,500 \mathrm{rpm}$ the rotor blade survived 10 impacts with 0.033 -in. diameter $(0.0024 \mathrm{~g})$ steel shot, but fractured on the third impact with $0.055 \mathrm{in}$. $(0.0112 \mathrm{~g})$ stee 1 shot. At $45,000 \mathrm{rpm}$, the rotor blade fractured on the third impact with 0.033 in. steel shot, but survived 10 impacts with 0.018-0.023 in. steel shot. Hard carbon removed from a combustor wall did not damage a rotor blade even when particles as large as $0.9 \mathrm{~g}$ struck blades spinning at $32,000 \mathrm{rpm}$. Under the same conditions, a $0.6-\mathrm{g}$ particle of reaction bonded $\mathrm{Si}_{3} \mathrm{~N}_{4}$ fractured the blade. At 16,000 rpm no damage occurred.

Impact resistance of ceramic engine components appears to be a function of particle mass, mass or thickness of component, relative velocity, and relative hardness or elastic modulus of the particle and component. Recent theoretical and experimental work has identified two types of impact damage, both of which lead to strength degradation. (41) The first type of damage is the result of elastic impact with relatively blunt particles, leading to Hertzian crack formation at the impact site. The second type of damage results from an elastic-plastic impact with relatively sharp particles, leading to the formation of penny-shaped cracks at the impact site. Of the two types of damage, strength degradation by penny-shaped cracks is the most severe. Although additional research is required to fully characterize impact phenomena, these recent advances demonstrate the role of particle and component properties in the impact process and point the way for future studies.

Friction and relative motion are tied closely together. During heat-up and cool-down of all heat engines and during the operation of some engines, components must slide relative to each other. If this relative motion is restricted, very high localized stresses can occur, resulting in damage or breakage. Use of compliant layers and lubricants has been evaluated in the DARPA/Navy/AiResearch program. (36) The sliding coefficient of friction at reaction bonded $\mathrm{Si}_{3} \mathrm{~N}_{4}$ interfaces has been reduced from 0.7 to 0.2 , and the assembly has survived multiple engine operation cycles. However, testing has been short term, and it remains uncertain how well the compliant layers and lubricants will last during longer term application. It would be advisable to develop designs and materials not requiring lubricants or compliant layers.

Fundamental aspects of static and sliding friction of metals have been presented in a number of we11-known treatises, and the theory is well developed. (42-44) Although these references also present information 
on ceramic materials, our understanding of sliding friction and wear processes in ceramics is still in an active stage of development. Nevertheless, the roles of plastic deformation and crack formation in sliding processes are recognized, and mechanisms of crack formation during the sliding process have been developed. As with contact loading, the material parameters that controll crack formation during sliding processes are the component hardness and the stress intensity factor. $(45,46)$

Perhaps the most important type of contact loading for heat engine applications results from glass formation at high temperatures. As shown by Rabinowicz $(47)$ and Miller, et al.,(48) coefficients of friction increase by a factor of 10 ( $f \sim 0.2$ at ambient temperature to $f \sim 3$ at $1200^{\circ} \mathrm{C}$ ) when oxide glasses form on ceramic surfaces. Since forces during sliding are proportional to the coefficient of friction, oxidation results in surface stresses an order of magnitude larger than observed when oxidation does not occur. Surface oxidation causes more serious contact damage if sintering occurs between two components. In that event, the components are no longer separated by a viscous interface, but are bonded into a monolithic structure. Rupture of this bond by relative motion of components will result in serious surface cracks. Although preliminary investigations have been conducted on this usbject, further exploration of high temperature contact is necessary.

\subsubsection{Temperature}

At elevated temperatures under high stresses, stress rupture occurs under conditions where limited creep occurs. Several authors $(49,50)$ have proposed that the effect of the limited creep is to accelerate subcritical crack growth through grain boundary sliding. By applying fracture-mechanics principles and making some critical, simplifying assumptions, times-to-failure under these conditions were derived. Unfortunately, little experimental confirmation of these models exists. It follows that until lifetime prediction schemes can be verified, the creep regimes should be avoided in the interests of reliability in the application of ceramics to heat engines.

\subsubsection{Thermal Shock}

Using a simple fracture-mechanics approach, Hasselman (51) was able to define strength degradation and fracture conditions for a wide range of thermal shock conditions. He identified two limiting conditions for thermal shock degradation: one occurs when heat flux into the material is so high that thermal stresses in the material are not controlled by thermal conductivity; the other limiting condition occurs when the flux of heat to the material is low so that thermal conductivity is important. Strength degradation depends on the temperature difference, $\Delta T$, between 
the ceramic and the ambient environment. As $\Delta T$ increases, it reaches a threshold at which strength degradation occurs.

Reasonable correlations between thermal shock theory and experimental behavior have been obtained. $(52-54)$ Although the theory probably is adequate for predicting relative material behavior, caution must be exercised in using these equations for absolute predictive purposes in real applications because of the dependence of thermal shock on component geometry. Furthermore, the approach has to be modified when subcritical crack growth occurs during thermal shock. (54)

\subsection{Recommendations}

The above review indicates several research needs in the area of characterization of ceramics for structural use in heat engines. Some of these concern the further development of a structural design methodology for brittle materials. Others relate to specific effects of engine service on $\mathrm{Si}_{3} \mathrm{~N}_{4}$ and $\mathrm{SiC}$ ceramics.

Concerning the general problem, research is highly recommended on the following subjects:

- Establish limitations on the basic assumption of statistical fracture theories that $\mathrm{K}_{\mathrm{IC}}$ is a bulk property.

- Determine effects of multiaxial stress on failure.

- Determine effects of microstructure and temperature on $\mathrm{K}_{\mathrm{IC}}$.

- Establish relations between microstructura1 features and crack genesis.

- Determine kinetics of environmentally independent stable crack growth.

- Improve techniques for statistical descriptions of strength and for relating these to flaw populations, particularly in failures from multimodal populations.

- Improve descriptions and basic knowledge of environmentally dependent $\mathrm{V}-\mathrm{K}_{\mathrm{I}}$ relations, particularly in low $\mathrm{V}$ ranges and also when creep is involved.

- Improve techniques for strength measurements to insure both precise fracture-stress values and that variability reflects only the effects of natural flaws. 
With respect to $\mathrm{Si}_{3} \mathrm{~N}_{4}$ and $\mathrm{SiC}$ ceramics, research on the following is recommended for support:

- Determination of the basic reasons for service-incurred changes in the flaw populations in structural ceramics.

- Development of a design methodology for evaluating long-term life when flaw populations vary with time.

- Investigation of the role of oxide formation in creep, crack propagation, erosion, and friction and wear.

- Collection of real-time, long-term data on the strength of turbine materials in realistic environments, such data to be used as a standard for understanding lifetime prediction schemes developed for structural ceramics. 
1. Rudnick, A., Marscha11, C.W., and Duckworth, W. H., "The Evaluation and Interpretation of Mechanical Properties of Ceramic Materials," AFML Technical Report, AFML-TR-67-316, Apri1 1968.

2. Palaniswami, K., and Knauss, W. G., in Mechanics Today, Vol. 4, S. Nemat-Nasser, ed., Pergamon Press, 1978.

3. Petrovic, J. J. and Mendiratta, M. G., J. Amer. Ceram. Soc., 59, 163, 1976.

4. Petrovic, J. J. and Mendiratta, M. G., J. Amer. Ceram. Soc., 60, $463,1977$.

5. Hoagland, R. G., Hahn, G. T., and Rosenfield, A. R., Rock Mechanics, $\underline{5}, 77,1973$.

6. (a) Hubner, H. and Jillek, W., J. Mater. Sci., 12, 117, 1977.

(b) Bansal, G. and Duckworth, W., Ibid, 13, 215, 1978.

7. Frieman, S. W., Mecholsky, J. J.; and Rice, R. W., in Ceramic Microstructures '76, Fulrath and Pask, eds., Westview Press, Boulder, Colorado, 324, 1977.

8. Bansa1, G. K., "On Fracture Mirror Formation in Glass and Polycrystalline Ceramics," Philos. Mag., 35, 935, 1977.

9. Bansal, G. K., "Effect of Flaw Shape on Strength of Ceramics," J. Amer. Ceram. Soc., 59, 87, 1976.

10. Bansal, G. K., Duckworth, W. H., and Niesz, D. E., "Strength-Size Relations in Ceramic Materials: Investigation of an Alumina Ceramic," J. Amer. Ceram. Soc., 59, 472, 1976.

11. Johnson, C. A. and Prochazka, S., "Investigation of Ceramics for High-Temperature Components," General Electric Company, Quarterly Report No. 3, Navy Contract N62269-76-C-0243, January 1977.

12. Bansa1, G. K., Duckworth, W. H., and Niesz, D. E., "Strength-Size Relations in Ceramic Materials: Investigation of a Commercial Glass-Ceramic," Bul1. Amer. Ceram. Soc., 55, 289, 1976. 
13. Hoagland, R. G., Marscha11, C. W., and Duckworth, W. H., "Reduction of Errors in Ceramic Bend Tests," J. Amer. Ceram. Soc., 59, 189, 1976.

14. Gulbransen, E. Q., Andrew, K. F., and Brassart, F. A., "The Oxidation of Silicon Carbide at $1150^{\circ}$ to $1400^{\circ} \mathrm{C}$ and at $9 \times 10^{3}$ to $5 \times 10^{-1}$ Torr 0xygen Pressure," J. Electrochem. Soc., Vol. 113, No. 12, 1966, pp. 1311-1314.

15. Singhal, S. C., "Oxidation of Silicon-Based Structural Ceramics," in Properties of High Temperature Alloys, Z. A. Foroulis and F. S. Pettit, eds., The Electrochemica1 Society, Inc., New York, 1976.

16. Richerson, D. W. and Yonushonis, T. M., "Environmental Effects on the Strength of Silicon Nitride Materials," in Proceedings of the 1977 DARPA/NAVSEA Ceramic Gas Turbine Demonstration Engine Program Review, MCIC-78-36, 1978, pp. 247-271.

17. AiResearch Report No. 76-212188(1), Ceramic Gas Turbine Engine Demonstration Program, Interim Report No. 1, prepared under contract N00024-76-C-5352, June 1976.

18. Tripp, W. C. and Graham, H. C., "Oxidation of $\mathrm{Si}_{3} \mathrm{~N}_{4}$ in the Range $1300-1500^{\circ} \mathrm{C}$," J. Amer. Ceram. Soc., Vo1. 59, No. 9-10, 1976, pp. 399-403.

19. Mange1s, J. A., "High Temperature, Time Dependent Physical Property Characterization of Reaction-Sintered $\mathrm{Si}_{3} \mathrm{~N}_{4}$," in Nitrogen Ceramics, F. L. Riley, ed., Noordhoff, 1977, pp. 589-593.

20. Godfrey, D. J. and Pitman, K. C., "Mechanical Properties of $\mathrm{Si}_{3} \mathrm{~N}_{4}$ Ceramics," in Ceramics for High Performance Applications, J.. J. Burke, A. E. Gorum, and R. N. Katz, eds., Brook Hill Publishing Company, Chestnut Hill, Massachusetts, 1974, pp. 425-455.

21. (a) Wiederhorn, S. M. and Tighe, N. J., "Effect of Flaw Generation on Proof Testing," in Proceedings of the 1977 DARPA/NAVSEA Ceramic Gas Turbine Demonstration Engine Program Review, J. W. Fairbanks and R. W. Rice, eds., MCIC-78-36, pp. 689-700.

(b) Widerhorn, S. M. and Tighe, N. J., "Proof Testing of Hot-Pressed Silicon Nitride," J. Mater. Sci., 13, 1781-1793, 1978.

22. Singha1, S. C., "Corrosion Behavior of Silicon Nitride and Silicon Carbide in Turbine Atmospheres," Proceedings of the 1972 Tri-Service Conference on Corrosion, MCIC73-19, 1973, pp. 245-250. 
23. Miller, K. G., Andersson, C. A., Singhal, S. C., Lange, F. F., Diaz, E. S., Kossowsky, E. S., and Bratton, R. J., "Brittle Materials Design High Temperature Gas Turbine - Materials Technology," AMMRC CTR-76-32, Vo1. 4, 1976.

24. McKee, D. W. and Chatterji, D., "Corrosion of Silicon Carbide in Gases and Alkaline Melts," J. Am. Ceram. Soc., 59, 9-10, 1976, pp. 441-444.

25. Metcalfe, A. G., "Ceramic in Radial Flow Gas Turbines at Solar," in Ceramics for High Performance Applications, J. J. Burke, A. E. Gorum and R. N. Katz, eds., Brook Hill Publishing Company, Chestnut Hill, Massachusetts, 1974, pp. 739-747.

26. Pettit, F. S., DoE, EPRI, GRI, NBS Third Annual Conference on Materials for Coal Conversion and Utilization, Conf.-781018, October 10-12, 1978, available from MTIS.

27. Ives, L. K., "Erosion of 310 Stainless Steel at $970^{\circ} \mathrm{C}$ in Combustion Gas Atmospheres," J. Eng. Mater. Techno1., Trans ASME, 99, 126, 1977.

28. Hockey, B. J., Wiederhorn, S. M., and Johnson, H., in Fracture Mechanics of Ceramics,", R. C. Bradt, D. P. H. Hasselman and F. F. Lange, eds., Vo1. 3, Plenum Press, New York, 1978.

29. Evans, A. G., Gulden, M. E., and Rosenblatt, M., Proc. Roy. Soc., London, $\mathrm{A} 361,343,1978$.

30. Evans, A. G., Chapter 1 in Erosion, C. M. Preece, ed., Academic Press, to be published.

31. Ruff, A. W. and Wiederhorn, S. M., Chapter 2 in Erosion, C. M. Preece, ed., Academic Press, to be published.

32. Gulden, M. E., in Erosion: Prevention and Useful Applications," STP665, to be published.

33. McLean, A. F., Fisher, E. A., and Bratton, R. J., "Brittle Materials Design, High Temperature Gas Turbine," AMMRC CTR 72-19, September 1972, pp. 109-117.

34. Godfrey, D. J., "Silicon Nitride Ceramics for Engineering Applications," SAE Paper 740238, February 1974.

35. Yonushonis, T. M. and Hofer, K. E., "Cyclic Fatigue of Silicon Nitride Materials," in Proceedings of the 1977 DARPA/NAVSEA Ceramic Gas Turbine Engine Demonstration Program Review, MCIC-78-36, 1978, pp. 235-245. 
36. AiResearch Report No. 76-2121 88 (10), Ceramic Gas Turbine Engine Demonstration Program, Interim Report No. 10, prepared under Contract N00024-76-C-5352, August 1978.

37. AiResearch Report No. 76-212188(7), Ceramic Gas Turbine Engine Demonstration Program, Interim Report No. 7, prepared under Contract N00024-76-C5352, November 1977.

38. Arnon, N., Havstad, P. H., and Trela, W., "2500\% F Testing - Rig Development and Ceramic Gas Turbine Components Test Results," in Ceramics for High Performance Applications - II, J. J. Burke, E. N. Lenoe, and R. N. Katz, eds., Brook Hill Publishing Company, Chestnut Hil1, Massachusetts, 1978, pp. 317-334.

39. AiResearch Report No. 76-2121 88(11), Ceramic Gas Turbine Fngine Demonstration Program, Interim Report No. 11, prepared under Contract N00024-76-C-5352, November 1978.

40. Helms, H. E. and Rockwood, F. A., "Heavy Duty Gas Turbine Engine Program Progress Report for Period 1 July 1976 to January 1978, Report No. DDA EDR 9346, prepared under NASA Contract NAS3-20064, February 1978.

41. Lawn, B. R. and Marshall, D. B., in Fracture Mechanics of Ceramics, Vo1. e, R. C. Bradt, D. P. H. Hasselman, and F. F. Lange, eds., Plenum Press, New York, 1978, pp. 205-299.

42. Rabinowicz, E., Friction and Wear of Materials, John Wiley and Sons, Inc., New York, 1966.

43. Bowdon, F. P. and Tabor, D., The Friction and Lubrication of Solids, C1arendon Press, Oxford, Part 1 (1954), Part 1 (1964).

44. Enge1, P. A., Impact Wear of Materials, Elsevier Scientific Publishing Company, New York, 1976.

45. Swain, M. V., in Fracture Mechanics of Ceramics, Vo1. 3, R. C. Bradt, D. P. H. Hasselman, and F. F. Lange, eds., Plenum Press, New York, 1978, pp. 257-272.

46. Veldkamp, J. D. B., Hattie, N., and Snÿders, V. A. C., in Fracture Mechanics of Ceramics, Vol. 3, R. C. Bradt, D. P. H. Hasselman, and F. F. Lange, eds., Plenum Press, New York, 1978, pp. 273-301.

47. Rabinowicz, E. and Imai, M. M., "Basic Oxide as a High Temperature Lubricant," Paper No. 61-LUBS-17, Lubrication Symposium, Miami, Florida, May 8-9, 1961, American Society of Mechanical Engineers. 
48. Miller, D. G., Andersson, C. A., Singhal, S. C., Lange, F. F., Diaz, E. S., and Kossowsky, R., Brittle Materials Design, High Temperature Gas Turbine Material Technology, Vol. IV, Army Materials and Mechanics Research Center Report No. AMMRC CTR $76-32$.

49. Evans, A. G. and Langdon, T. G., "Structural Ceramics," Prog. Mater. Sci., 21, 171-441, 1976; see especially pp. 320-331.

50. Lange, F. F., "Interrelation Between Creep and Slow Crack Growth for Tensile Loading Conditions," Int. J. Fract., 12, 739-744, 1976.

5i. Hasselman, D. P. H., "Thermal Stress Resistance Parameters for Brittle Refractory Ceramics: A Compendium," Bull. Amer. Ceram. Soc., Vo1. 49, No. 12, 1970, pp. 1033-1037.

52. Hasselman, D. P. H., "Unified Theory of Thermal Shock Fracture. Initiation and Crack Propagation in Brittle Ceramics," J. Am. Ceram. Soc., 52, 11, 1969, pp. 600-604.

53. Gupta, T. K., "Strength Degradation and Crack Propagation in Thermally Shocked $\mathrm{Al}_{2} \mathrm{O}_{3}$," J. Am. Ceram. Soc., 55, 5, 1972 , pp. 249-253.

54. Badaliance, R., Kroh, D. A., and Hasselman, D. P. H., "Effect of Slow Crack Growth on the Thermal-Stress Resistance of an $\mathrm{Na}_{2} \mathrm{O}-\mathrm{CaO}-\mathrm{SiO}_{2}$ Glass," J. Am. Ceram. Soc., 57, 10, 1974. 
Chapter 5

QUALITY ASSURANCE

\subsection{Introduction}

Quality assurance of a component usually can be achieved prior to service by nondestructive evaluation and/or overload proof testing. Fracture models, which pertain to crack size/strength relations and crack growth/stress relations, are required to use either method. Thus quality assurance relies not only on inspecting and testing components, but also on confidence in the fracture models. The following section will review our current understanding of nondestructive evaluation, proof testing, fracture models, and lifetime prediction methodology.

\subsection{Nondestructive Evaluation}

In view of the fact that cracks, solid inclusions, and voids are sources of failure in ceramics, nondestructive evaluation (NDE) techniques are being developed to detect these flaws and measure their size and severity, so that the reliability of ceramics containing these sources of failure can be predicted. The ultimate goals of NDE are to: (a) scan a component of complex shape by automated methods to determine the size, shape, and type of flaws greater than a given size; (b) combine the stress distribution of the component with the flaw distribution to determine the correct stress intensity factor to be used for lifetime predictions; and (c) accept or reject the component based on these predictions. Since powders normally are used to fabricate ceramics, it is important that NDE begin prior to the densification and shaping of the component.

Until the DARPA Ford/Westinghouse Gas Turbine Program was initiated in 1971, NDE rarely was used for ceramics. During this program, commercial NDE tools (x-radiography and ultrasonics) used to examine metallic components were evaluated for applicability to ceramic materials. As expected, conventional techniques were limited to detecting very large surface cracks and gross processing flaws. Further developments were required to detect and classify the flaws that govern the reliability of a well processed ceramic component. $(1,2)$

Subsequently, the limits of resolution of x-radiography and ultrasonics have been improved, and new techniques are under development. It 
is the purpose here to discuss the current limitations of the conventional techniques and indicate the direction being taken to solve the NDE problem for ceramics.

\subsubsection{Current NDE Tools for Ceramics}

The NDE techniques used in current ceramic, heat-engine programs are visual inspection $(\sim 20 \mathrm{x})$, dye penetrants, $\mathrm{x}$-radiography, and ultrasonic mapping. Table 5-1 indicates their limits of resolution. These limits were determined by examining $\frac{1}{4}-i$. thick billets of hot-pressed (HP) and reaction bonded (RB) $\mathrm{Si}_{3} \mathrm{~N}_{4}$, seeded with known inclusions, under relatively ideal conditions. (3)

$\mathrm{X}$-radiography is a well developed, relatively automated technique. Resolution and image contrasts are both important for generating defect images on radiographs. The development and use of microfocused units (of the Cosslett-Nixon type) ${ }^{(4)}$ has increased resolution to defect sizes required for ceramics. In most applications, image contrast can present a serious limitation. The contrast on the film depends in part on the differential $x$-ray absorption coefficient of the defect/matrix couple and on the defect thickness. Automated techniques developed for space exploration can be used to enhance images on radiographs. (5) Studies with $\mathrm{Si}_{3} \mathrm{~N}_{4}$ show that inclusions with high atomic number (e.g., $\mathrm{W}, \mathrm{Fe}$ ) are readily detected using microfocused systems, but that sma11 isolated voids $(>300 \mu \mathrm{m})$, small cracks and defect/matrix couples of comparable atomic number (e.g., $\mathrm{Si} / \mathrm{Si}_{3} \mathrm{~N}_{4}, \mathrm{SiC} / \mathrm{Si}_{3} \mathrm{~N}_{4}$ ) cannot be imaged. In addition, image contrast decreases with incrasing component thickness. The ability of radiography to locate the defect's position accurately (in 3-D space) and to determine its shape is undefined. Current methods attempt to triangulate the defect using several radiographs taken at different angles. It is expected that the sensitivity of locating and defining the shape of the defect will thus depend on the component's shape and thickness.

Principal advantages of $x$-radiographs are: (a) ability to examine complex shapes without the need for contact, (b) suitability for both porous and dense materials, and (c) suitability for examining green ware at different processing steps. The disadvantages are (a) image contrast appears to have been developed to its intrinsic limit, which is inadequate for small cracks, low density inclusions, and defect/matrix couples of similar atomic number; (b) defect type cannot be determined; and (c) intrinsically poor accuracy in defect position/shape definition. The possible developments are: (a) enhancement of surface cracks by penetrants containing heavy elements; (6) (b) tomographic (3-D) developments will aide in defect position/shape definition.

Automated ultrasonics requires rastering a focused (focal length: 2-6 in.) transducer across the component and detecting power scattered 
TABLE 5-1 Ceramic NDE Status -- Conventional Methods

\begin{tabular}{|c|c|c|c|c|}
\hline $\begin{array}{l}\text { NDE } \\
\text { Method }\end{array}$ & $\begin{array}{l}\text { Material* } \\
\text { System }\end{array}$ & $\begin{array}{l}\text { Defect } \\
\text { Type }\end{array}$ & $\begin{array}{l}\text { Defect } \\
\text { Size } \\
\text { (Micron) }\end{array}$ & $\begin{array}{l}\text { Current } \\
\text { Limitations }\end{array}$ \\
\hline \multirow[t]{2}{*}{$\begin{array}{l}\text { Microfocus X-Ray with } \\
\text { Image Enhancement }\end{array}$} & $\operatorname{HP} \mathrm{Si}_{3} \mathrm{~N}_{4}$ & $\begin{array}{l}\text { Inclusions } \\
\text { - High Density } \\
\text { - Low Density }\end{array}$ & $\begin{array}{r}25 \\
250\end{array}$ & $\begin{array}{l}\text { - Sensitivity } \\
\text { - Material Thickness } \\
\text { Greater than } 0.250 \text { in. }\end{array}$ \\
\hline & $\mathrm{RB} \mathrm{Si}_{3} \mathrm{~N}_{4}$ & $\begin{array}{l}\text { Inclusions } \\
\text { - High Density } \\
\text { - Low Density }\end{array}$ & $\begin{array}{l}125 \\
250\end{array}$ & $\begin{array}{l}\text { Low Density } \\
\text { Inclusions }\end{array}$ \\
\hline \multirow{2}{*}{$\begin{array}{l}\text { Ultrasonics } \\
(45 \mathrm{MHz})\end{array}$} & $\mathrm{HP} \mathrm{Si}_{3} \mathrm{~N}_{4}$ & $\begin{array}{l}\text { Inclusions } \\
\text { - High Density } \\
\text { - Low Density }\end{array}$ & $\begin{array}{l}\sim 50 \\
\sim 50\end{array}$ & - Component Geometry \\
\hline & $\mathrm{RB} \quad \mathrm{Si}_{3} \mathrm{~N}_{4}$ & $\begin{array}{l}\text { Inclusions } \\
\text { - High Density } \\
\text { - Low Density }\end{array}$ & $\begin{array}{l}125 \\
125\end{array}$ & $\begin{array}{l}\text { - Component Geometry } \\
\left.\text { - Attenuation (RB Si }{ }_{3} \mathrm{~N}_{4}\right)\end{array}$ \\
\hline Dye Penetrants & $\begin{array}{l}\mathrm{HP} \mathrm{Si}_{3} \mathrm{~N}_{4} \\
\text { Siliconized } \\
\text { SiC } \\
\text { Sintered } \\
\text { SiC }\end{array}$ & Surface & $\begin{array}{c}\sim 250 \\
250-500 \\
\ldots . .\end{array}$ & $\begin{array}{l}\text { - Sensitivity } \\
\text { - Surface Conditions }\end{array}$ \\
\hline $\begin{array}{l}\text { * } \frac{1}{4} \text { in. thick billets } \\
\text { sides midplane detec }\end{array}$ & $\begin{array}{l}\text { round, para } \\
\text { locations. }\end{array}$ & Ilel & $\begin{array}{l}\mathrm{HP}= \\
\mathrm{RB}=\end{array}$ & $\begin{array}{l}\text { t-Pressed } \\
\text { action Bonded }\end{array}$ \\
\hline
\end{tabular}


from defects by a pulse-echo technique to map the defect's dimensions and position it in 3-D space. Water, which is used as a transmission/ acoustic coupling medium, presents several problems. First, attenuation by the water limits the frequency (because of attenuation/frequency dependence) that can be used and thus limits the defect size resolution; current, focused systems appear to be limited to $<45 \mathrm{MHz}$. Attenuation also limits transmission of power into the component and thus limits sensitivity. Second, the strong reflection of the water/component interface caused by the acoustic impedance mismatch produces near-surface dead spaces where small defects cannot be detected. Third, differential water/component acoustic velocities produce focusing aberrations, which reduces sensitivity. Under good conditions ( $\frac{1}{4} \mathrm{in}$. thick rectangular bililets with centerline defects; machined, parallel surfaces) TRW/AiResearch has detected seeded inclusions of all types with resolutions shown in Table 5-1.(3) Flaw detection limitations in complex shapes have yet to be demonstrated.

The advantages of ultrasonics are: (a) small inclusions can be detected; (b) higher resolution and much better definition of defect location relative to radiography. The disadvantages are: (a) defect type cannot be determined; (b) small surface cracks near surface inclusions are difficult to detect; and (c) attenuation in porous materials limits frequency and hence resolution and sensitivity. Developments being considered are: (a) high frequency ultrasonic, which will yield defect type, size, and shape information; (b) direct component/transducer contact to match acoustic impedance and wave velócity, which potentially could overcome complex-shape and near-surface problems; and (c) development of surface-wave ultrasonic NDE for detection of small surface cracks in complex shapes.

\subsubsection{Status of Emerging Developments}

High frequency ultrasonics has received more attention and currently appears to have the greatest potential for NDE. High frequencies are required to resolve small defects in ceramics. The maximum amplitude of scattered power occurs when $2 \pi c_{o} / \lambda=1$, and most of the frequency/ amplitude information required to determine defect size, shape, and type occurs between $0.3<\pi c_{0} / \lambda<3$ ( $\lambda$ is the wavelength of the transmitted signal, and $c_{o}$ is the flaw size). Frequencies centered around $200 \mathrm{MHz}$ are being used because of transducer developments in this frequency range. (7)

Attenuation at these high frequencies presents two problems. First, attenuation essentially eliminates porous and coarse-grained ceramics from the scope of high resolution ultrasonics. (8) [Fortunately, attenuation in dense, fine-grained structural ceramics $\left(\mathrm{Si}_{3} \mathrm{~N}_{4}\right.$ and $\mathrm{SiC}$ ) does not present a serious problem. ${ }^{(8)}$ ] Second, water (or other liquids) cannot be used as a transmission medium because of the high attenuation in the path length; thus direct component/transducer contact methods 
must be employed, e.g., through suitable buffer material configurations. Engineering solutions to this second problem must be implemented before high frequency ultrasonics becomes a viable NDE tool.

Table 5-2 1ists a few of the more promising NDE techniques under development. (3)

The current status of high frequency ultrasonics as applied to ceramics is as follows. Experiments with seeded hot-pressed $\mathrm{Si}_{3} \mathrm{~N}_{4}$ billets have shown that all important bulk defects can be detected to sizes of about $25 \mathrm{\mu m}$. (7) Amplitude/time domain signals have identified the difference between voids and solid inclusions, which was independently predicted by theory. (9) This advance required a special filter to subtract the frequency response of the transducer. Although it has yet to be shown that high frequency ultrasonics can unambiguously identify the inclusion type and shape, an attempt is now in progress to use spectroscopy and angular dependencies, which are potentially powerful tools, to solve this problem.

An acoustic surface-wave technique for detecting surface cracks in hot-pressed $\mathrm{Si}_{3} \mathrm{~N}_{4}$ has been devised. (10) The technique has been shown to detect cracks at least as small as $60 \mu \mathrm{m}$ deep on polished specimens and $120 \mu \mathrm{m}$ deep on roughly ground specimens. The amplitude of the scattered background is attributed to surface microcracks produced during grinding.

\subsubsection{Summary of NDE Capabilities}

of all current NDE techniques, ultrasonics appears in principle to be able to satisfy most requirements for defect detection in dense, fine-grained structural ceramics. None of the high frequency ultrasonic techniques is advanced enough to be used as an engineering tool. Experiments have shown that important defects can be located, and limited experiments have shown that voids and solid inclusions can be differentiated. Further work is required to determine defect type and shape unambiguously for correlation with a fracture model. None of the high frequency techniques, to date, is automated. Automation requires in part a surface coupling method for reducing the ultrasonic technique to engineering practice.

Despite inherent limitations, x-radiography will be an important NDE tool. Today, this tool is more automated than others, and it can be used on materials (porous and large-grained) where ultrasonics cannot.

Other NDE techniques (e.g., penetrants), which may not be as sensitive to small.cracks and flaws, will find important applications in screening components prior to critical evaluation. 
TABLE 5-2 Ceramic NDE Status -- Emerging Development

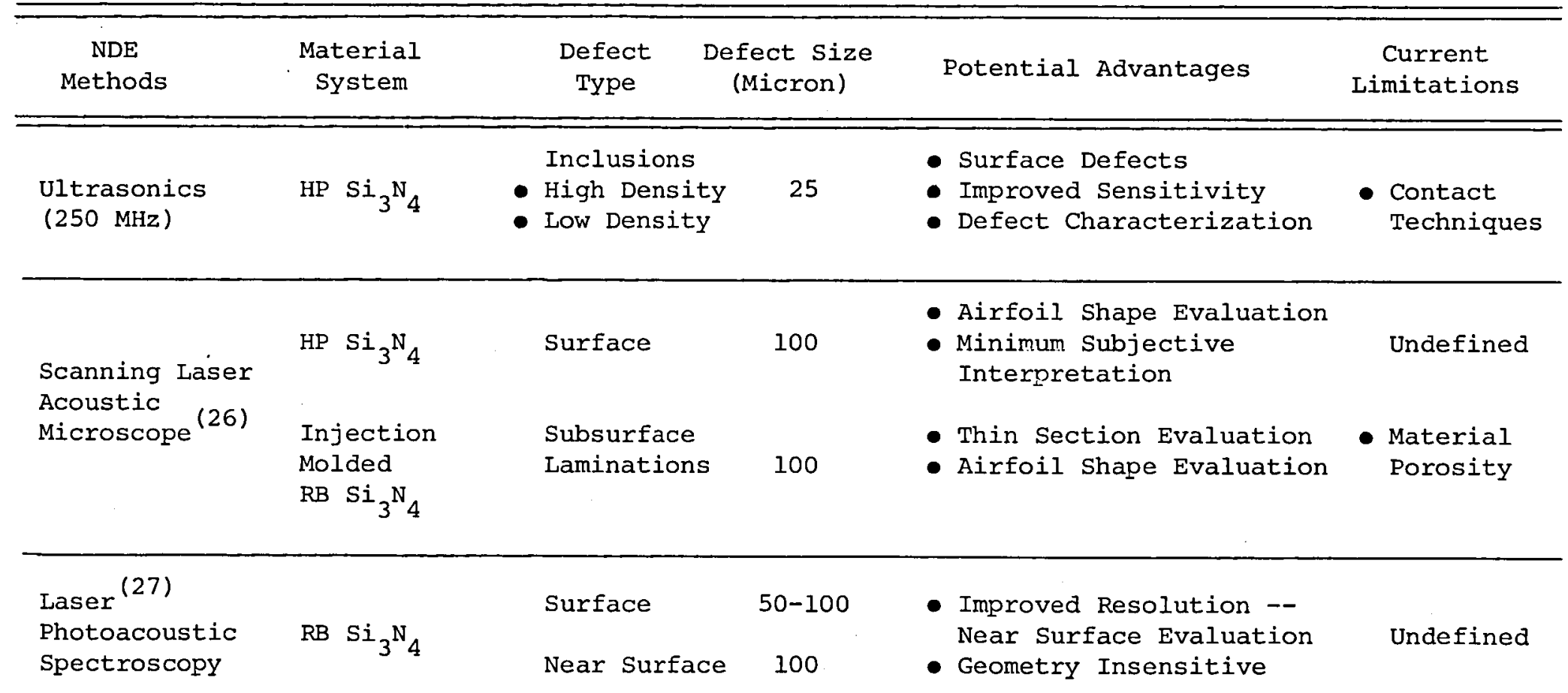




\subsubsection{Acceptance/Rejection Criteria}

Although current suppliers and users of structural ceramics routinely use $x$-radiography (and, in some cases, conventional ultrasonics) to detect defects, the present criteria for rejecting either a billet or a component are ambiguous at best. In general, components (e.g., reaction-sintered vanes) containing large detectable fabrication voids and cracks are rejected, whereas judgments concerning smaller defects are less definitive. It is obvious that acceptance/rejection criteria must be developed concurrently with NDE tools. That is, as NDE tools are developed to locate and identify cracks and inclusions, a concurrent effort must be made to identify the effect of each type of flaw on strength in order to develop sound acceptance/rejection criteria.

As shown in Figure 5-1, studies have been initiated to evaluate the effect of defect size on the strength of hot-pressed silicon nitride containing silicon, carbon, tungsten carbide, and iron silicide inclusions. (11) Additional experimental and theoretical approaches are necessary to determine, for each type of defect, the relations among specimen strength, defect size, and defect shape. Nondestructive evaluation techniques should be used to measure the size of defects introduced intentionally into specimens intended for strength measurements. The defect size estimated from NDE can then be compared with that determined from fractographic analyses of the specimens after they have been broken, so that the accuracy of the nondestructive techniques can be evaluated. Finally, the severity of the defect should be determined by comparing the strength calculated from the defect size (measured by fractography) with that determined in the strength test. Once the severity of the defect and the accuracy of the nondestructive techniques have been evaluated, they can be combined with information on defect location and stress distribution to accept or reject a component that contains a defect.

In practice, both fracture models and NDE techniques will contain certain errors which will result in some components being either falsely accepted or falsely rejected. Since both false-accept and false-reject will have adverse economic, political, and social results, proper acceptance/rejection criteria must be developed to minimize these problems. One approach involves probability theory, (7) which indicates that three probability functions must be defined: one covering the fracture model for a defect of a given dimension/shape; one covering the NDE estimate of the defect dimension/shape; and one covering the defect size range expected. Knowledge of these three functions can define the inspection level required for a given defect/stress and determine the probabilities that the component has been either falsely accepted or rejected.

This area has received little attention except for the formalization of the theory and preliminary fracture models for pertinent types of defects. Effort is required to define the three probability functions 


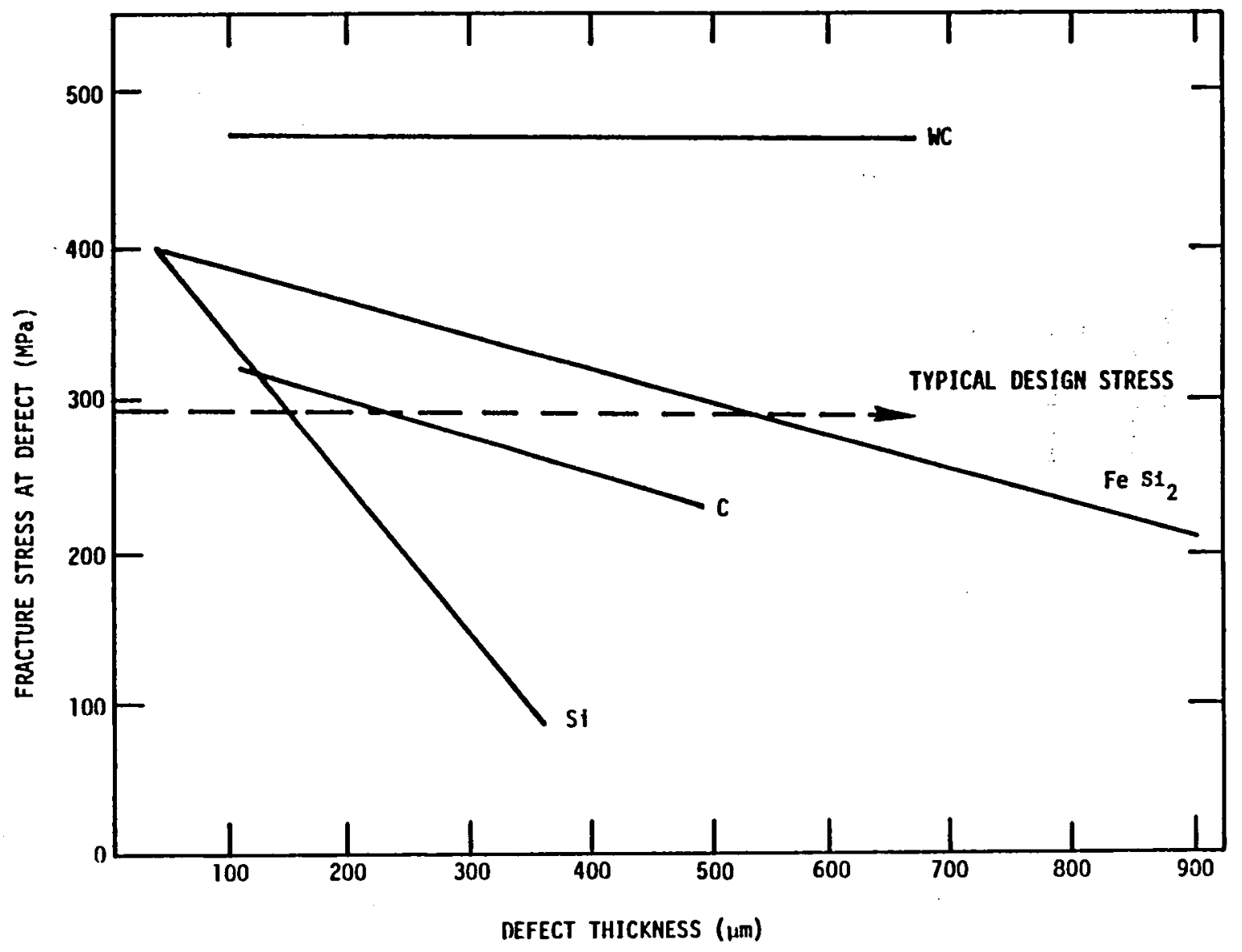

FIGURE 5-1 Flexural Strength of Hot-Pressed $\mathrm{Si}_{3} \mathrm{~N}_{4}$ Seeded with Different Types of Inclusions vs. the Size of the Inclusion 
experimentally for each defect type and to test the theoretical model for practical application.

\subsection{Proof Testing}

In proof testing, ceramic components are subjected to stresses greater than those expected in service in order to break the weak components and thus truncate the low end of the strength distribution. Weak components are eliminated before they can be placed in service. To ensure the validity of proof esting, certain precautions must be followed. (12) For the proof test to be most effective, it should be conducted in a relatively inert environment, and rapid unloading rates should be used. Also, the proof test must duplicate the actual state of stress in the component as expected in service. After proof testing, the component must be protected from any subsequent damage. If these precautions are followed, proof testing can be a practical method for assuring the mechanical reliability of ceramics. Proof testing has been applied to spacecraft windows, (13) electrical porcelain insulators, (14) vitrified grinding wheels, (15) and optical glass fibers. (16)

Evans, Wiederhorn, and Fuller $(17,18)$ have provided a mathematical foundation for the selection of proof-test stresses and the establishment of proof-test conditions. Their analysis is based on the assumption that ceramics fail because of the growth of preexisting flaws. By characterizing this crack growth, and coupling crack growth kinetic parameters with proof testing, they derive the strength after proof testing, assuming flaw growth during the proof-stress, load-unload cycle. The resulting theory indicates that crack growth must be minimized to have effective proof testing. This can be achieved by rapid unloading from the proof stress and good environmental control during the proof test. When this is done, crack growth on unloading from the proof stress is minimized (or eliminated), and the minimum fast-fracture strength after proof testing is the proof stress $\sigma_{p}$. Thus, the corresponding minimum lifetime after proof testing $\left(t_{m i n}\right)$ at an applied stress $\left(\sigma_{a}\right)$

$$
t_{\min }=B \sigma_{p}^{n-2 \sigma} a^{-n}
$$

where $\mathrm{B}$ and $\mathrm{n}$ are measured parameters related to the crack growth kinetics and fracture model.

Ritter et al. (20) recently have studied the effectiveness of proof testing extensively by comparing the fast-fracture strength distributions of soda-lime silicate glass before and after proof testing. The effects of unloading rate from the proof stress, hold time at the proof stress, and proof-test environment were examined. The results indicated that when good proof-test controls -- rapid unloading and good environmental control -- were used, proof testing was effective and the after-proof 
strength distributions could be predicted from theory (Figure 5-2). On the other hand, with poor proof-test controls -- relatively slow unloading rates and/or moist environment (which increases crack growth kinetics in glass) -- the after-proof strength distributions either did not differ significantly from the initial (Figure 5-3) or were weaker than the initial (Figure 5-4). Also, these after-proof distributions could not be accounted for by theory.

\subsubsection{Summary of Proof Testing}

The above proof testing results have important implications. First, good proof-test conditions (relatively inert environment and rapid unloading) must be used to help assure effective proof testing. Secondly, it is important to demonstrate experimentally that proof testing is effective for a given set of conditions by comparing the after-proof strength distribution with the initial distribution. Only in this way can one be assured that proof testing under a given set of conditions is eliminating the weak components, thereby truncating the low end of the strength distribution. Thirdly, to minimize any uncertainty in proof testing, some means, such as acoustic emission, should be used to insure that no crack growth occurs in unloading. Finally, the above results show that the theoretical analysis of the effects of proof testing must be further developed.

\subsection{Fracture Models}

\subsubsection{Crack Size Responsible for Failure}

Cracks in some materials in specific environments -- e.g., high temperature, water vapor, hydrogen -- are prone to grow slowly, so failure may not occur for some time after the stress has been applied. During this period, the crack will have grown from its initial radius, $c_{o}$, to its critical radius, $c_{f}$, at which point failure occurs by catastrophic crack growth. The kinetics of crack growth in the stable, slow growth regime can be measured experimentally. For many materials, the crack's velocity, $\mathrm{v},(\mathrm{dc} / \mathrm{dt})$ in the stable regime is related to the stress intensity factor, $\mathrm{K}$, (a parameter which defines the intensity of the stress at the crack tip in terms of the applied stress and crack size, i.e. $\mathrm{K}=\sigma_{\mathrm{a}} \mathrm{Y} \sqrt{\mathrm{c}}$ ) by the empirical relation $(21)$

$$
\mathrm{v}=\mathrm{AK}^{\mathrm{n}} \text {. }
$$

where $A$ and $n$ are empirical constants that depend on the material, the test environment, and temperature. The crack size required for catastrophic growth and fracture is given by the well estabished GriffithIrwin relation: 


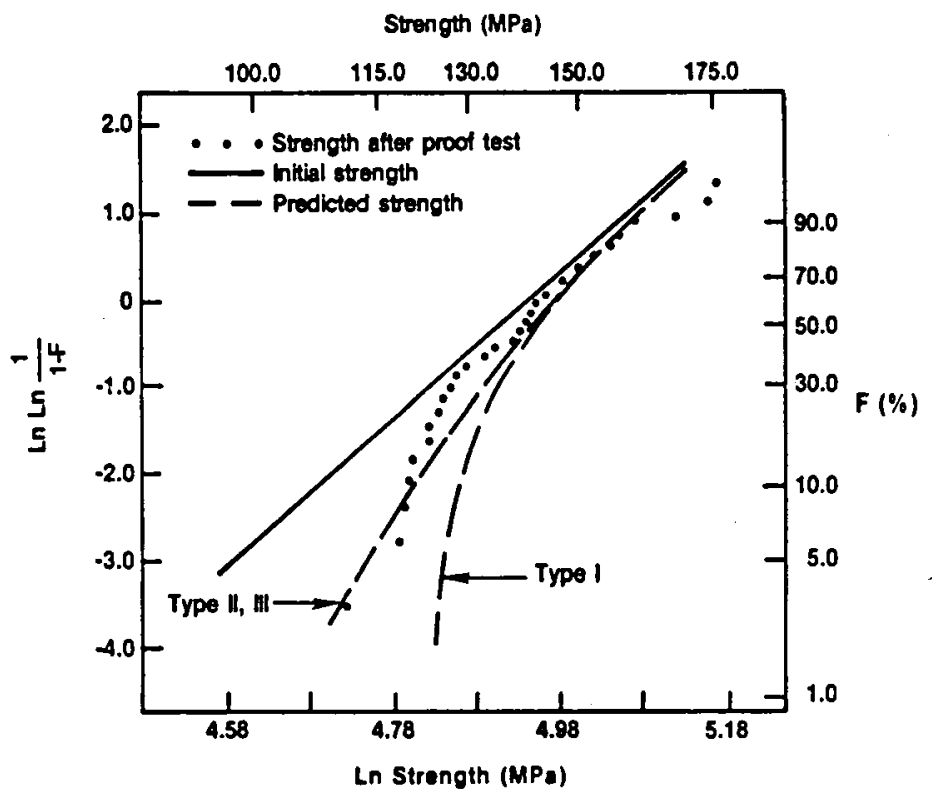

FIGURE 5-2 Comparison of Strength Data for Soda-Lime Glass Before and After Proof Testing in Air Using Very Rapid Unloading Rate.

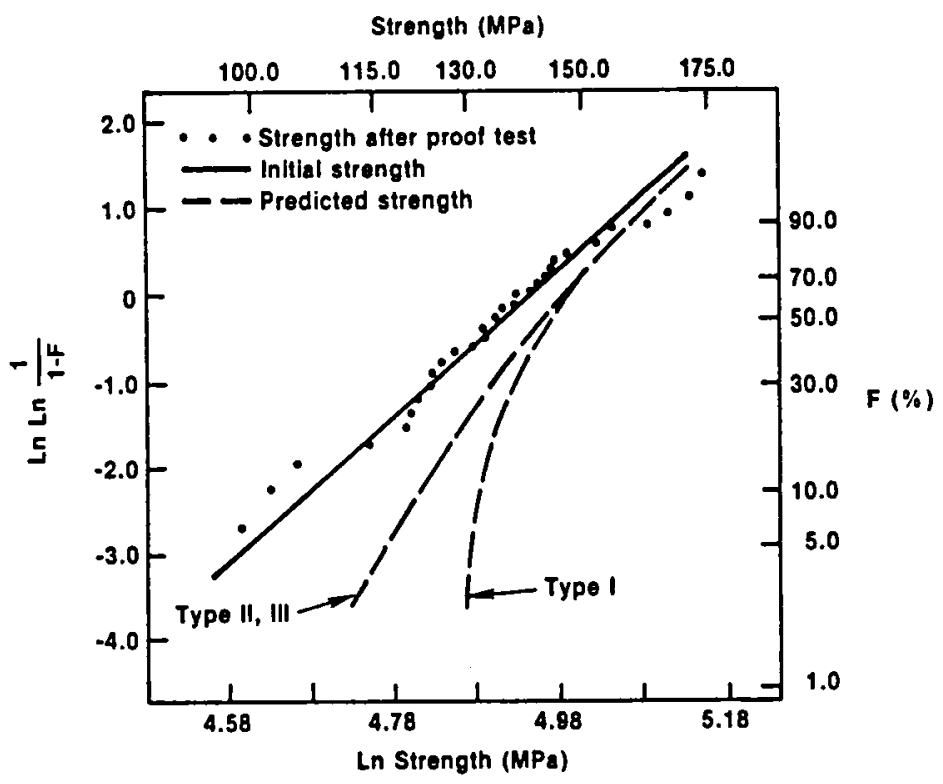

FIGURE 5-3 Comparison of Strength Data for Soda-Lime Glass Before and After Proof Testing in Moist Environment Using Rapid Unloading Rate. 


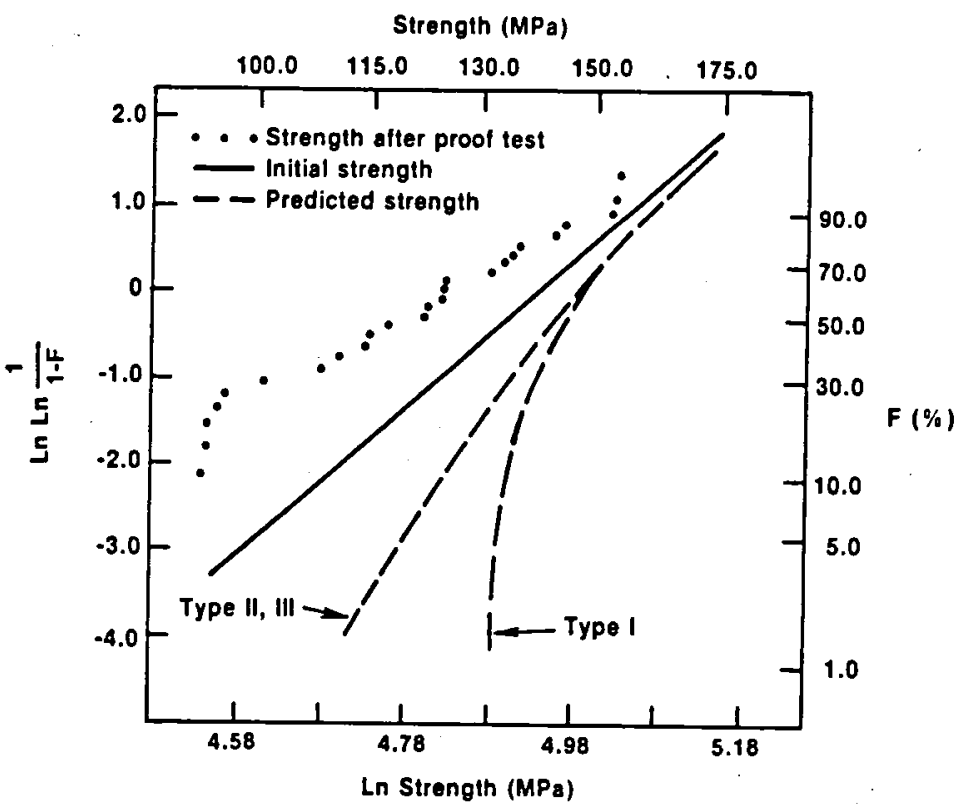

FIGURE 5-4 Comparison of Strength Data for Soda-Lime Glass Before and After Proof Testing In Air Using Slow Unloading Rate. 


$$
c_{f}=\left(\frac{K_{c}}{\sigma_{a} Y}\right)^{2}
$$

where $\mathrm{K}_{\mathrm{C}}$, the critical stress intensity factor, is a material parameter, and $Y$ is a numerical factor which depends on the location of the crack, the shape of the crack, and boundary conditions associated with the cracked body and load application. By integrating Eq. (2) and making the appropriate substitution of $\mathrm{Eq}$. (3), it can be shown that the initial crack radius responsible for failure after a time, $t_{f}$, during which the crack has been subjected to a normal applied tensile stress, $\sigma_{a}$, is given by

$$
c_{o}=\left(\frac{K_{c}}{\sigma_{a} Y}\right)^{2}\left(\frac{2}{2+k_{c}^{n-2} A t_{f} \sigma_{a}^{2}(n-2) Y^{2}}\right)^{2 /(n-2)}
$$

For environmental conditions where subcritical crack growth is negligibie $(\mathrm{n}>50)$

$$
c_{o} \simeq c_{f}=\left(\frac{\mathrm{K}_{\mathrm{c}}}{\sigma_{\mathrm{a}} \mathrm{Y}}\right)^{2}
$$

Thus, in general, Eq. (4) shows that the size of the preexisting crack responsible for failure at time $t_{f}$ depends on the applied tensile stress $\left(\sigma_{a}\right)$ resolved normal to the crack plane, the numerical factor $Y$, and the fracture-mechanic parameters $K_{c}, A$, and $n$. Knowledge of these parameters can be used to estimate the smallest crack that must be sought using NDE tools to insure the reliability of an engineering component for a given period under an applied tensile stress.

Estimates for the crack size $\left(2 c_{0}\right)$ that must be identifiable to insure reliability for $10,000 \mathrm{~h}$ have been calculated for several candidate high-temperature structural ceramics. (7) This information indicates that crack sizes of 20 to $200 \mu \mathrm{m}$ must be detectable to maintain a reliable component for extended periods for applied stresses up to $300 \mathrm{MPa}$ (40,000 psi). 


\subsubsection{Effect of Crack Location}

Since the location of a crack is important to its detectability with NDE tools, it is of interest to examine the effect of crack location on strength. Calculated stress intensity factors for circular interior cracks, (22) semicircular surface cracks, (23) and quarter-circular corner cracks, (24) can be used to calculate a normalized strength (Table 5-3). The table illustrates that corners are the worst locations for cracks.

\begin{tabular}{|c|c|}
\hline & $5-3$ \\
\hline $\begin{array}{l}\text { Crack Type, } \\
\text { Radius c }\end{array}$ & $\begin{array}{l}\text { Strength Normalized } \\
\text { to Interior Crack }\end{array}$ \\
\hline Interior ${ }^{(22)}$ & 1.0 \\
\hline Surface (23) & 0.80 \\
\hline Corner (24) & 0.75 \\
\hline
\end{tabular}

\subsubsection{Crack Shape and Orientation}

Stress intensity solutions for elliptical cracks are available for interior, ${ }^{25)}$ surface, (25) subsurface, $(25)$ and corner (24) locations. Solutions for other shapes are not available. Budiansky and Rice(26) have shown recently that the maximum value of $\mathrm{K}$ for an elliptical crack is nearly equivalent to that for a circular crack of the same area. This important result indicates that only the area of the crack need be known. Solutions for cracks inclined to the surface are not yet available, but approximations could be obtained experimentally by using cracks produced by a knoop indenter.

\subsubsection{Flaws as Stress Concentrators}

It is well known that voids and solid inclusions concentrate stress; in addition, residual stresses can develop within and around solid inclusions because of differential thermal expansion and/or phase changes. Reaction zones and porosity also can be associated with solid inclusions.

Voids and solid inclusions originate during powder processing and fabrication. Their identification in relation to the processing and 
fabrication parameters is thus critical for directing changes that eliminate them or minimize their effect on strength. For example, powder classification techniques can minimize large or dense contaminant particles introduced during milling.

It should be noted, in relating inclusion size to strength, that some inclusions are more severe than others and less severe than a crack of equivalent size. Inclusions that generate microcracks, due to thermomechanical stresses which arise during fabrication, are the most severe.

General solutions for thermomechanical stresses near arbitrarilyshaped inclusions are not available, but some solutions exist for spherical $(27,28)$ and ellipisoidal $(28)$ inclusions. These solutions can be used to classify the severity of the inclusion/matrix couple in terms of their thermal expansion $(\alpha)$ and elastic modulus (E) (Table 5-4 -$i=$ inclusion, $m=$ matrix.)

\begin{tabular}{|ccc|}
\hline & TABLE 5-4 & \\
\hline Most Severe & Moderately Severe & Least Severe \\
$\alpha_{i}<\alpha_{m}$ & $\alpha_{i}>\alpha_{m}$ & $\alpha_{i}=\alpha_{m}$ \\
$E_{i}<E_{m}$ & $E_{i}>E_{m}$ & $E_{i}, v_{i}=E_{m}, v_{m}$ \\
\hline
\end{tabular}

Experimental observations have shown that crack extension in the highly localized thermoelastic stress field associated with inclusions depends not only on the magnitude of the maximum tensile stress $\left(\sigma_{m}\right)$, but also on the inclusion size (2R). (29) Thermodynamic and stress intensity theories have substantiated these observations to show that cracks will be observed only when $\sigma_{\max } R>$ constant, where the constant involves material properties and the strain energy release rate for the crack of interest. (29) Although these solutions are not adequate at present to predict the size of the crack produced, they do show that cracks will only be present for inclusions that exceed a critical size, given by

$$
R_{c}=\frac{\text { constant }}{\sigma_{\max }{ }^{2}}
$$


Therefore, depending on both $\sigma_{\max }$ and $\mathrm{R}$, preexisting cracks may be associated with the solid inclusions due to thermal-mechanical stresses. When cracking is avoided, undesirable localized residual stresses will be associated with the inclusion. The combined action of these residual stresses with an applied stress can lead to crack extension and failure. Adequate stress intensity solutions do not exist for this combined stress state. It is expected that these solutions will not only depend on the magnitudes of the applied stress and the residual stress, but also on the size of the inclusion. Acoustic emission experiments are needed to help define the applied stress level where microcracking is observed.

\section{4 .5 Pores}

Theory shows that the stress concentration factor associated with a pore depends only on its shape, e.g., increasing from 2 as the shape changes from a sphere to an ellipsoid.(30) Models for determining the effect of pore size on strength rely on the assumption that a small crack resides on the pore's surface which makes it more like a crack. $(31,32)$ This idea may be valid for polycrystalline materials, but it may not be applicable to glasses. Further experimental work in this area is required.

\subsubsection{Experimenta1 Data for $\mathrm{Si}_{3} \mathrm{~N}_{4} /$ Inclusion Couples}

As indicated above, pertinent fracture models depend on the specific inclusion/matrix combination. Strength-size relations for specific inclusion types purposely introduced into hot-pressed $\mathrm{Si}_{3} \mathrm{~N}_{4}$ specimens which were subsequently fractured are shown in Figure 5-1 (11) Figure 5-1 illustrates the current results for $\mathrm{Si}, \mathrm{WC}, \mathrm{FeSi}_{2}$, and $\mathrm{C}$ inclusions. As shown, $\mathrm{Si}$ inclusions have a strong influence on strength, whereas WC inclusions have minimal effect. The strength/size relation for the Si inclusions indicates a direct correspondence to an equivalent crack size, i.e., the Si inclusion can be considered a crack of similar dimension. Analysis of these experimental effects is under way.

\subsubsection{Oxidation-Flaw Generation}

NDE and proof testing are of value only if the flaws detected during the test are, in fact, the flaws that will cause failure during service. Modification of the flaw population by oxidation can invalidate NDE and proof testing procedures by eliminating the machining flaws that cause failure at room temperature, by changing their severity, or by creating a new flaw population. Recent research $(32-34)$ has shown that high temperature $\left(1200^{\circ} \mathrm{C}\right)$ during bend testing modifies the flaw population enough so that truncation (proof testing) of the normal flaw population (due to machining) is no longer observed after exposure times as short as $\frac{1}{2} \mathrm{~h}$ (Figure 5-5). Therefore, although the small flaws that result 


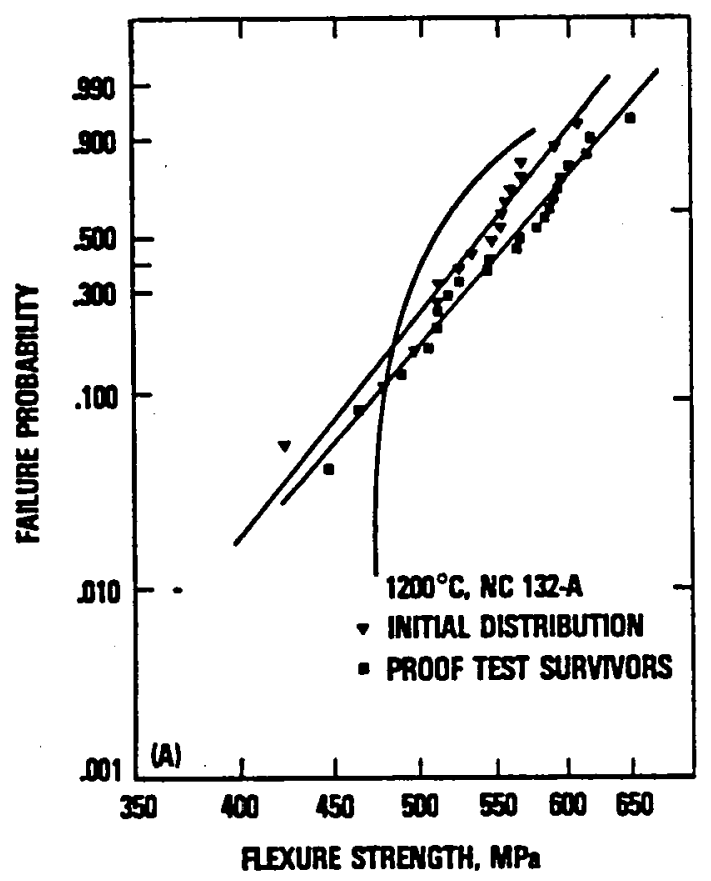

FIGURE 5-5 The Effect of a Room Temperature Proof Test on the High Temperature Strength of Hot-Pressed Silicon Nitride. The solid curve gives the expected theoretical distribution for the high temperature strengths after proof testing. (22) 
from machining can be truncated by proof testing, truncation will serve little practical value since these flaws probably are not the ones that cause failure after high temperature exposure. Thus, a need clearly exists to develop a failure prediction scheme accounting for flaw generation while a component is in long-term service. Before a failure prediction methodology can be developed fully, the effect of stress on the oxidation/ flaw generation phenomenon must be understood.

\subsubsection{Summary of Fracture Models}

The initial crack size that controls long term reliability depends on the state of stress, the critical stress intensity factor, and fracture-mechanics parameters that describe slow crack growth kinetics. Improved experimental techniques and methods of analysis are needed to better characterize slow crack growth kinetics to obtain better reliability predictions for extended periods. Current data and analysis indicate that cracks in the size range of 20 to $200 \mu \mathrm{m}$ must be detectable for current structural materials/applications.

Stress intensity factor solutions for real cracks have received most attention and are, therefore, most developed. The locations of cracks in descending order of severity are: corner, surface, subsurface, and interior. Solutions for inclined corner, surface, and subsurface cracks are still required. Tentative correlations between maximum stress-intensity factor and crack area appear encouraging and indicate that the stress intensity factor for an arbitrarily-shaped crack can be obtained with knowledge of the crack's surface area. Further work in this area will be significant. Effects of triaxial stress states have not been explored. Flaw populations generated during service (e.g., during oxidation) need to be identified and characterized.

\subsection{Status of Life Prediction}

\subsubsection{Crack Growth Kinetics}

Schemes for predicting the life of a ceramic component not only require knowledge of the flaw size (as determined through NDE and proof testing) and flaw size/strength relations, as emphasized in previous sections, but also need to incorporate knowledge of crack growth kinetics. Confidence in life prediction thus reduces to the confidence in using crack growth kinetics.

Although the relation between crack growth rate, $v$, and the applied stress intensity factor, $\mathrm{K}$, can be complicated, it has been observed that at the low velocities that determine lifetime these two parameters are given by Eq. (2). If it is assumed that time dependent failure of 
ceramics occurs only by subcritical crack growth, ${ }^{(17)}$ then the following equation is determined for the time-to-failure at a constant applied load, $\sigma_{\mathrm{a}}(19)$ :

$$
t_{f}=B s_{i}^{n-2} \sigma_{a}^{-n}
$$

where $\mathrm{B}\left(=2 /(\mathrm{n}-\mathrm{n}) \mathrm{AY}^{2} \mathrm{~K}_{\left.\mathrm{C}^{n-2}\right)}\right.$ can be defined in terms of fracture mechanics parameters and ${ }^{C} S_{i}$ is the fast-fracture strength. Once $B$ is known, the failure time for a given application can be evaluated.

It is seen that lifetime predictions for ceramics depend on the crack growth parameters A (or B) and $n$. To be relevant for lifetime prediction purposes, these parameters must be measured in the service environment. They can be determined through either crack-velocity, stress-rupture, or stressing-rate experiments. Regardless of which technique is used, the same values should be obtained for a given material and environment. Experimental studies show that the same values can be obtained from the different measurements for some materials, but not for others. From the discussion, it will become clear that additional experimentation is needed to evaluate fully the limits of the theory and to identify those materials for which the theory is applicable.

\subsubsection{Techniques for Characterizing Crack Growth Kinetics}

Subcritical crack velocity can be measured as a function of the stress intensity factor on specimens specifically designed for fracture. mechanics experiments. These specimens contain macroscopic cracks that allow accurate measurement of the crack velocity and the stress intensity factor. A regression analysis of such data, using Eq. (2), gives A and $n$ their variances and their covariance. By determining $\mathrm{K}_{\mathrm{C}}$ in a separate experiment, B can be determined from its definition (Eq. 7). Predictions of lifetime can then be made using Eq. (7). Errors in the lifetime prediction resulting from uncertainties in $A, n$, and $\mathrm{K}_{C}$ can be determined by standard statistical thechniques using either the Monte Carlo method. of error prediction, 35 or the normal statistical method of error propagation. (36)

A second method of evaluating $B$ and $n$ is by measurement of time-tofailure as a function of applied load. Stress rupture measurements of this type are made on a large number of samples at several constant applied stresses. From these data the median value of the failure time $\left(t_{f}\right)$ is determined as a function of the applied stress. By measuring the median fast-fracture strength $\left(S_{i}\right)$ on a group of samples statistically identical to those used in the stress rupture test, $B$ and $n$ can be determined from:(19)

$$
\ln t=\ln B+(n-2) \ln S_{i}-n \ln \sigma_{a}
$$


A linear regression analysis of $\ln t$ versus $\ln \sigma_{a}$ allows $n$ and $B$ and their related statistical quantities to be determined. Again, standard statistical techniques can be used to evaluate errors in the predicted failure time which result from experimental uncertainties in $S_{i}, B$, and $n$.

The third technique for evaluating delayed failure in a ceramic involves measuring the strength as a function of stressing rate. The analysis of these data is similar to that used with stress rupture data, since the median strength $(S)$ is related to stressing rate $(\sigma)$ by: (19)

$$
\ln S=\frac{1}{n+1}\left[\ln B+(n-2) \ln S_{i}+\ln \sigma\right]
$$

From a regression analysis of $\ln \mathrm{S}$ on $\ln \sigma, \mathrm{n}$ and $\mathrm{B}$ and their statistical variates can be determined. The failure time and its uncertainty can then be predicted as before.

Although the analysis of stress rupture and stressing rate data based on median values is straightforward, it does not make most efficient use of the data. Alternate procedures that use all of the data in the regression analysis have been developed for analyzing this type of data. The reader is referred to reference 37 for further discussions of this point.

Each of three experimental techniques for evaluating the parameters $\mathrm{n}$ and $\mathrm{B}$ has its advantages and limitations. Crack velocity measurements have been widely used to determine the static fatigue behavior of ceramics. The experimental techniques are relatively simple, and relatively few samples are needed to collect large quantities of data. Because the behavior of cracks is observed directly, the technique has been used to generate much fundamental data on subcritical crack growth. This fundamental information is often missed when strength techniques are used to evaluate delayed failure, because only the average crack propagation behavior can be inferred from the data. On the other hand, strength techniques use specimens that more closely resemble structural parts, so that failure results from microscopic rather than macroscopic cracks. Thus, cracks in strength specimens are likely to behave in the same way as those in structural components. The same cannot always be said for the macroscopic cracks used in fracture mechanics tests. In fact, recent evidence (to be discussed below) indicates real differences in lifetime predictions for some materials, depending on which technique is used for the prediction. Obviously, when such differences occur, lifetime estimates made from strength data are to be preferred over those made from fracture mechanics data. 


\subsubsection{Data Extrapolation for Long-Term Lifetime Predictions}

For many applications, structural reliability is required for periods that range from 1,000 to $50,000 \mathrm{~h}$. Because of the cost of long-term mechanical strength testing, it would be valuable if long-term lifetime predictions could be made from relatively short-term tests. The fracturemechanics-based theory discussed here offers a framework for making these predictions. Aside form the expected problem of error propagation because of experimental uncertainties in the values of $n, B$, and $s_{i}$, two additional factors must be considered in predicting long-term lifetimes: one factor involves the assumed relation between $\mathrm{K}$ and $\mathrm{V}$ (Eq. 2); the other involves the efficiency of obtaining delayed failure data for lifetime predictions.

Equation (2) assumes that crack velocity can be expressed as a power function of the applied stress intensity factor. This equation was selected because it fits experimental data over a wide range of: crack velocities and because it permits other equations for reliability predictions to be handled by relatively simple mathematics. However, because of the strong dependence of crack velocity on stress intensity factor, other equations can be shown to fit the crack propagation data equally well. Similarly, with both stress rupture and stressing rate data, a number of analytic expressions may be used with apparently equal accuracy to represent the strength properties of ceramic materials. If failure predictions are made within the range of experimental data, all of the possible equations predict similar lifetimes. However, if the strength or crack propagation data must be extrapolated beyond the period over which the data were collected, large differences can occur in predicted failure time.

The effect of the form of the crack propagation equation on the predicted failure time has been demonstrated for glass. (38) Minimum lifetime predictions based on crack propagation data obtained on an ultralow expansion glass $\left(92.5 \mathrm{w} / 0 \mathrm{SiO}_{2} ; 7.5 \mathrm{w} / \mathrm{o} \mathrm{TiO}_{2}\right.$ ) are plotted in Figure 5-6 for three different representations of the crack propagation equation. The vertical line on this graph marks the lower velocity limit of the crack propagation data. Points to the left of this line reflect crack propagation data taken in the laboratory; points to the right of the line reflect extrapolation of the crack propagation data to long-term failure conditions. Note that to the left of the vertical line, all three representations of the crack propagation data give equivalent predictions of failure time -- that is, the data are represented equivalently by the three equations. To the right of the vertical line, however, the three predictions of fallure time diverge, indicating the danger in extrapolating data.

Accurate, long-term lifetime predictions require the collection of data on slowly moving cracks, since it is these cracks that cause failure after they have been subjected to loads for extended periods. Data can be collected by any of the three methods discussed earlier. Crack velocity 


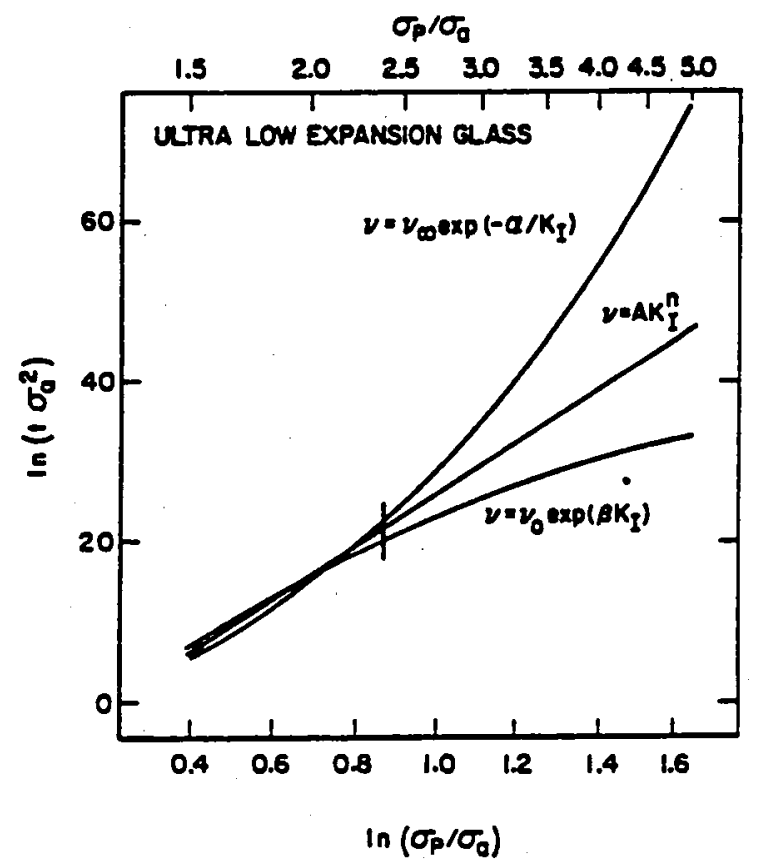

FIGURE 5-6 Proof Test Diagram Comparing Three Representations of Crack Propagation Data from an U1tralow Expansion Glass. 
techniques require measurements at very low crack velocities; stressing rate measurements require the use of very low stressing rates; stress rupture measurements require relatively low stresses and correspondingly long failure times. Regardless of which technique is used, the times involved in collecting the data will be long, so some consideration must be given to which of the three techniques is most time-efficient. This subject has been considered by Wiederhorn and Ritter, (39) who conclude that data for long term life prediction are obtained most quickly by using stress rupture techniques. (40)

\subsubsection{Experimental Verification of the Basic Equations}

In previous sections we have developed and discussed a theory of predicting the lifetime of structural ceramics. The theory is based on fracture mechanics and takes into account both the initial flaw. size and the rate at which the flaw will grow under stress. Since the theory predicts failure time quantitatively as a function applied stress, it can be checked in the laboratory on model systems that cover a wide range of materials and microstructures. In this section the theory will be compared with experimental data to determine its validity and limitations. Particular attention will be paid to the three experimental techniques for determining the delayed failure behavior of the material.

Glass is one material/environment system for which several techniques have been used to characterize time-dependent parameters. The results of these studies have varied somewhat: sometimes excellent agreement is obtained among the three test procedures, while at other times agreement is less than satisfactory. Soda-lime-silicate glass seems to give consistent results regardless of which technique is used to evaluate the fatigue parameters of the glass. (19) Figure 5-7 illustrates minimum lifetime predictions for soda-lime-silicate glass based on Eq. (7). The upper limits of the experimental data are indicated by vertical lines. We see that the three techniques are represented by parallel lines, corresponding to the fact that the slopes $(n)$ of the fatigue-data curves are nearly the same for the three techniques. For a lifetime of one year at an applied stress of $10 \mathrm{MPa}(\sim 1,400 \mathrm{psi})$, the ratio $\sigma_{\mathrm{p}} / \sigma_{\mathrm{a}}$ to obtain this lifetime ranges from 4 to 5 , which is satisfactory considering the fact that this prediction is made from an extrapolation that extends well beyond the range of a11 the data. A similar study(13) comparing stressing rate and crack velocity data on a low expansion glass gave closer predictions of $\sigma_{\mathrm{p}} / \sigma_{\mathrm{a}}$, ranging from 2.4 to 2.6 , for the same lifetime and stress (Figure 5-8). For this glass, the slopes of the curves differ more than for the soda-lime glass, but because the data overlap in the region where they were collected, excellent lifetime predictions are obtained.

Stress rupture and stressing rate data ${ }^{(40)}$ collected in a moist environment on the same grade of aluminum oxide are compared in 


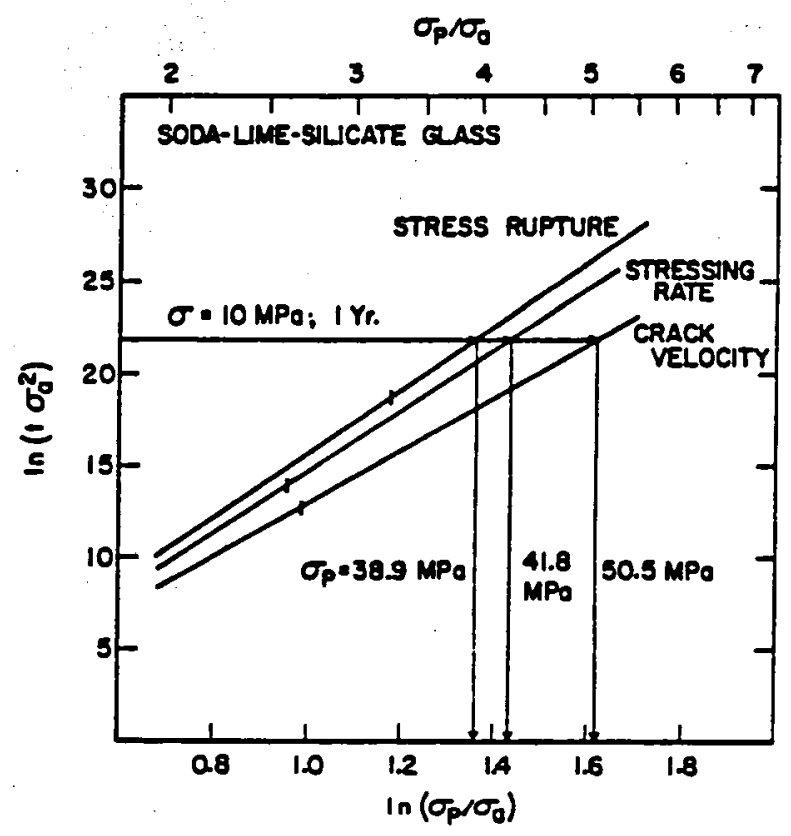

FIGURE 5-7 Proof Test Diagram Comparing Crack Velocity, Stress Rupture, and Stressing Rate Techniques Used In Determining Crack Growth Constants for Soda-Lime-Silicate Glass. 


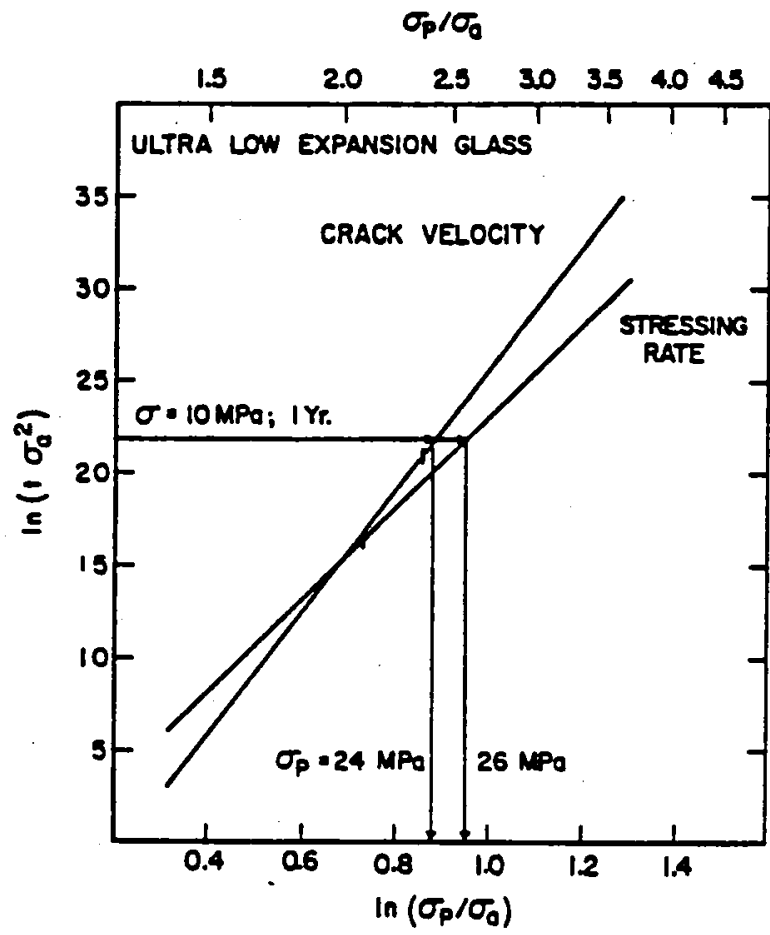

FIGURE 5-8 Proof Test Diagram Comparing Crack Velocity and Stressing Rate Techniques Used in Determining Crack Growth Constants for an U1tralow Expansion Glass. 
Figure 5-9 with crack growth data ${ }^{(41)}$ collected on a similar but not identical grade of aluminum oxide tested in water. For a lifetime of one year at a stress of $100 \mathrm{MPa}(\sim 14,000 \mathrm{psi})$, the value of $\sigma_{\mathrm{p}} / \sigma_{\mathrm{a}}$ ranges from 2.2 to 2.3 . Therefore, the agreement between the three methods is better than for glass.

Based on the above results it can be concluded that soda-lime glass and aluminum oxide fail by subcritical crack growth from preexisting flaws in moist environments, and that this crack growth can be characterized by crack velocity, stress rupture, or stressing rate experiments. Unfortunately, crack growth parameters determined by the various techniques are not always self consistent. Figure 5-10 compares strength data on pristine silica fibers ${ }^{42}$ with crack velocity data of the same material. (39) The figure shows that the crack growth parameters determined from strength experiments differ significantly from those obtained from crack velocity experiments. This lack of agreement probably results from the extreme difference in size between the cracks in the fibers $(\sim 3 \mathrm{~nm})$ and those in the crack velocity specimens $(\sim 1 \mathrm{~cm})$. In addition, the chemical environment at the crack tips in the two types of specimens probably differs, resulting in different crack growth behavior. Furthermore, one must question the underlying assumption of an elastic continuum for cracks as sma1l as $30 \mathrm{~nm}$.

Recently, it has also been shown that crack growth parameters can depend on microstructure and the test technique. (39, 44-46) For example, for various grades of alumina the crack growth parameters obtained from crack velocity tests range from 20 to 40, whereas $n$ obtained from dynamic fatigue experiments varied from 30 to 70 .(39) Similar results were obtained on various glass-ceramic materials, $(44)$ where the differences in $\mathrm{n}$ were attributed to interactions between the microstructure and the propagating cracks that were dependent on crack size. Other recent studies $(45,46)$ indicate that the crack propagation parameter, $n$, depends not only on the test technique (strength vs. crack velocity), but also on the particular strength test used (flexure, biaxial, tension, or compression). Unfortunately, this area of research has not been explored sufficiently, so that the full implications of microstructure and test technique are not understood. However, an important conclusion to be drawn from this limited research is that when there are possible microstructural interactions, the test chosen to characterize subcritical crack growth should be one that most closely simulates the stress condition in service and therefore uses specimens that contain critical flaws which resemble those in an actual component.

\subsubsection{Summary of Life Prediction Theory}

To date, the life prediction theory has been tested experimentally with mixed results. For soda-lime-silicate glass and for one grade of aluminum oxide, the three methods of determining the crack propagation 


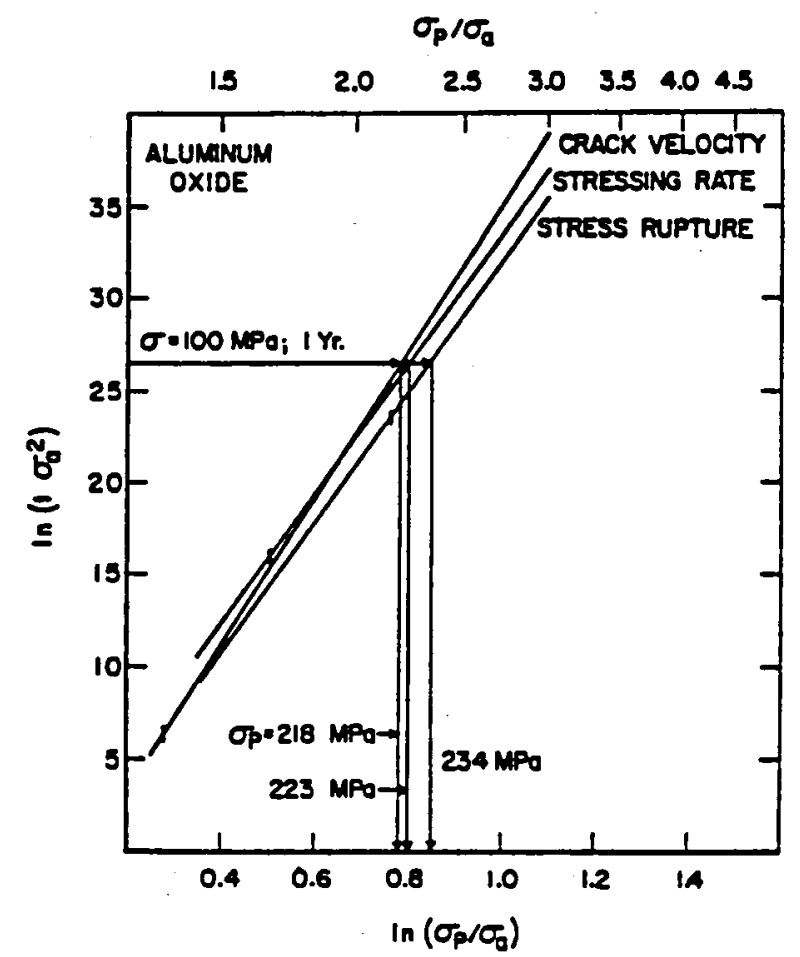

FIGURE 5-9 Proof Test Diagram Comparing Crack Velocity, Stress Rupture, and Stressing Rate Techniques Used In Determining Crack Growth Constants for $\mathrm{Al}_{2} \mathrm{O}_{3}$. 


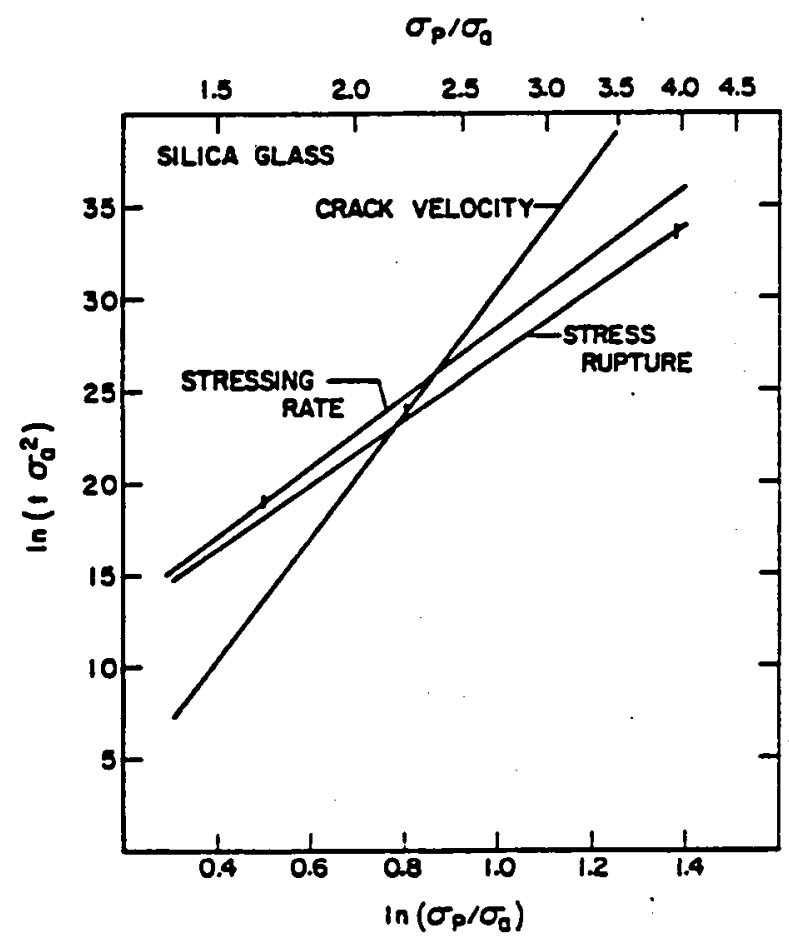

FIGURE 5-10 Proof Test Diagram Comparing Crack Velocity, Stress Rupture, and Stressing Rate Techniques Used in Determining Crack Growth Constants for Fused Silica. 
parameters gave self-consistent results. For other ceramics, the results were not self-consistent. Crack size and microstructure strongly influenced the values of the crack propagation parameters. In polycrystalline ceramics, microstructural parameters such as porosity and grain size can influence the crack propagation parameters, $n$ and $B$, for both fracture-mechanics and strength techniques. Furthermore, the type of stress field to which the test specimens are subjected has a significant effect on these parameters. Because of these discrepancies, additional experimentation is needed to evaluate fully the limits of the life prediction theory.

\subsection{Recommendations}

\subsubsection{Nondestructive Evaluation Techniques}

1. Extend the effort in developing high-frequency transducer technology leading to automated ultrasonic techniques.

2. Continue and expand present efforts in u1trasonic NDE of ceramics:

(a) Verify flaw locations in specimens with known flaw/matrix couples; extend work to unknown flaw/matrix couples.

(b) Extend work in ultrasonic spectroscopy to obtain signatures of known flaw/matrix couples as a function of flaw type, shape, and size.

(c) Verify spectroscopy results for ceramics with previously unknown defects.

3. Further develop ultrasonic techniques for surface flaw detection:

(a) Develop present technique into an automated method.

(b) Investigate resolution as a function of surface roughness.

4. Develop transducer technology to allow direct deposition of transducer arrays onto the component surface at reasonable cost.

5. Consolidate all NDE efforts for ceramics on a national level (e.g., a national NDE laboratory) to utilize each method consistent with its limitations. 
6. Extend probabilistic theory for acceptance/rejection criteria:

(a) Identify and measure errors involved in fracture models relating strength to flaw size and NDE evaluation of flaw size.

(b) Measure flaw size distributions in structural ceramics.

(c) Combine statistical information to determine failure probabilities based on NDE observations and fracture models.

7. Test acceptance/rejection criteria by proof testing.

8. Use theoretical and experimental results to determine level of inspection needed to minimize false-acceptance/falserejection components.

\subsubsection{Proof Testing}

1. Extend component verification of proof testing methodology from current, limited data base.

2. Develop proof tests that simulate transient thermal stresses and mechanical stresses.

\subsubsection{Fracture Mode1}

1. Develop experimental relations between strength (uniaxial and biaxia1) and defect (cracks, voids, and solid inclusions)/matrix couples.

2. Develop stress intensity factor solutions for solid inclusions as a function of defect size and shape and to include residual stress fields.

3. Identify sources of defects as related to fabrication processes.

4. Identify defects which can develop a new flaw population during service (e.g., as produced by oxidation). 


\subsubsection{Life Prediction}

1. Verify and/or modify life prediction methodology with component tests.

2. Obtain crack growth kinetic data for extended periods; data should be obtained for candidate structural ceramics.

3. Further develop fracture mechanics analysis for subcritical crack growth to account for the mechanics of the phenomenon and relations to microstructure.

4. Perform tensile stress-rupture experiments to obtain reliable, extended-period data to be used for fracture mechanics analysis. 


\section{REFERENCES}

1. Kossowsky, R., "Defect Detection in Hot-Pressed $\mathrm{Si}_{3} \mathrm{~N}_{4}$," in Ceramics for High Performance Applications, J. J. Burke, A. E. Gorum, and R. N. Katz, eds., Brook Hill Publishing Company, Chestnut Hil1, Massachusetts, 1974, p. 665.

2. McLean, A. F., Fisher, E. A., and Bratten, R. J., ARPA/AMRC Reports on Brittle Materials Design, High Temperature Gas Turbine, 1973-1976.

3. Schuldies, J. J., AiResearch, private communication, February 1978.

4. Cosslett, V. E. and Nixon, W. C., "Development of Microfocus X-ray," J. App1. Phys., 24, 616, 1953.

5. Schuldies, J. J. and Spaulding, W. H., "Radiography and Image Enhancement of Ceramics," presented at ARPA/NAVSEA-Garrett/AiResearch Ceramics Gas Turbine Engine Program Review, Maine Maritime Academy, August 1977.

6. Kupperman, D. S., Sather, A., Lapinski, N. P., and Dragel, G. M., "Nondestructive Evaluation Techniques for High-Temperature Ceramic Components," Quarterly Report, DoE Contract No. W-31-109-Eng-38, Argonne National Laboratory, ANL/MSD-78-2, December 1977.

7. Evans, A. G., Kino, G. S., Khuri-Yakub, P. T., and Tittmann, B. R., "Scattering Acoustic Waves in Solids," Mater. Eval., April 1977, p. 85 .

8. Evans, A. G., Tittmann, B. R., Ahlberg, L., Khuri-Yakub, B. T., and Kino, G. S., "U1trasonics Attenuation in Ceramics," J. App1. Phys., 49, 2669, 1978.

9. Murakama, Y., Khuri-Yakub, B. T., Kino, G. S., Richerson, J. M., and Evans, A. G., NBS Conference on NDE, July 1978, submitted to J. Appl. Phys.

10. Khuri-Yakub, B. T., Evans, A. G.; and Kino, G. S., "Acoustic Surface Wave Measurements of Surface Cracks in Ceramics," J. Amer. Ceram. Soc., 63, 65, 1980. 
11. Evans, A. G. and Baumgartner, H. R., "Strength as a Function of Flaw Size in Ceramics," submitted to J. Amer. Ceram. Soc.

12. Wiederhorn, S. M., "Reliability, Life Prediction and Proof Testing of Ceramics," in Ceramics for High Performance Applications, J. J. Burke, A. E. Gorum, and R. M. Katz, eds., Brook Hill Publishing Company, Chestnut Hil1, Massachusetts, 1974, pp 635-665.

13. Wiederhorn, S. M., "Application of Fracture Mechanics to SpaceShuttle Windows," J. Amer. Ceram. Soc., 57, 319-323, 1974.

14. Evans, A. G., "Proof Testing of Porcelain Insulators and Application of Acoustic Emission," Bu11. Amer. Ceram. Soc., 54, 576-581, 1975.

15. Ritter, J. E., Jr., and Wulf, S. A., "Evaluation of Proof Testing to Assure Against Delayed Failure," Bull. Amer. Ceram. Soc., 58, 186-189, 1978.

16. Tariya1, B. K., "Proof Testing of Long Length Optical Fibers for a Communication Cable," Bul1. Amer. Ceram. Soc., 56, 204-205, 1977.

17. Evans, A. G. and Wiederhorn, S. M., "Proof Testing of Ceramic Materials -- An Analytical Basis for Failure Prediction," Int. J. Fract., 10, 379-392, 1974.

18. Evans, A. G. and Fuller, E. R., "Proof Testing -- The Effects of Slow Crack Growth," Mater. Sci. Eng., 19, 69-77, 1975.

19. Ritter, J. E., Jr., "Engineering Design and Fatigue of Brittle Materials," in Fracture Mechanics of Ceramics, Vo1. 4, R. C. Bradt, D. P. H. Hasselman, and F. F. Lange, eds., Plenum Press, New York, 1978, pp. 667-686.

20. Ritter, J. E., Jr., Oates, P. B., Fuller, E. R., and Wiederhorn, S. M., "Proof Testing of Ceramics: I, Experiment," J. Mater. Sci., in press 1980.

21. Evans, A. G. and Langdon, T. G., "Structural Ceramics," in Progress in Materials Science 21, B. Chalmers, J. W. Christian, and T. B. Massalski, eds., Pergamon Press, Oxford, England, 1976, pp. 300-319.

22. Sack, R. A., Proceedings of the Physical Society, London, Vol. 58, 1946 , p. 729 .

23. Hartraught, R. J. and Sih, G. E., in Mechanics of Fracture I, G. C. Sih, ed., Nordhoff, ASTM, 1273, p. 225. 
24. Kobayashi, A. S. and Enetariga, A. N., "Stress Intensity Solutions for Near Surface Cracks," ASTM STP 590, 1976, p. 491.

25. Kobayash1, A. S., "Embedded E1l1pt1cal Crack at a Corner," Journal of Pressure Vessel Technology, Trans. ASME 100, 28, 1978.

26. Budlansk1, B. and Rice, J. R., Proceedings of Materlal Research Counc11, Summer Conference, La Jolla, California, 1977.

27. Selsing, J., "Interna1 Stresses in Ceramics," J. Amer. Ceram. Soc., 44, 419, 1961 .

28. Eshelby, J. D., "Determination of the Elastic Field of an E11ipsoidal Inclusion and Related Problems," Proceedings of the Royal Society, London, A241, 376, 1957.

29. Lange, F. F., "Fracture Mechanics in Microstructural Design," in Fracture Mechanics of Ceramics, Vol 4, R. C. Bradt, D. P. H. Hasselman, and F. F. Lange, eds., Plenum Press, New York, 1978, p. 799.

30. Neuber, H., Theory of Notch Stresses, Springer, Berlin, 1958, p. 149 .

31. Bowie, 0. L., "Analysis of an Infinite Plate Containing Radial Cracks Originating at the Boundary of an Internal Circular Hole," J. Math. Phys., 35, 60, 1956.

32. Wiederhorn, S. M. and Tighe, N. J., "Effect of Flaw Generation on Proof Testing," presented at ARPA/NAVSEA-Garrett/AiResearch Ceramic Gas Turbine Engine Program Review, Maine Maritime Academy, August 1977, pp. 689-700.

33. Wiederhorn, S. M. and Tighe, N. J., "Proof-Testing of Hot-Pressed Silicon Nitride," J. Mater. Sci., 13, 1781-1793, 1978.

34. Wiederhorn, S. M. and Tighe, N. J., "Application of Proof Testing to Silicon Nitride," Workshop on Ceramics for Advanced Heat Engines, ERDA Division of Conservation Research and Techriology, Or1ando, Florida, Jan. 24-26, 1977, CONF770110, pp. 247-258.

35. Jacobs, D. F. and Ritter, J. E., Jr., "Uncertainty in Minimum Lifetime Predictions," J. Amer. Ceram. Soc., 59, 481-187, 1976.

36. Wiederhorn, S. M., Fuller, E. R., Jr., Mande1, J., and Evans, A. G., "An Error Analysis of Failure Prediction Techniques Derived From Fracture Mechanics," J. Amer. Ceram. Soc., 59, 403-411, 1976.

37. Jakus, K., Coyne, D. C., and Ritter, J. E., Jr., "Analysis of Fatigue Data for Lifetime Predictions for Ceramic Materials," J. Mater. Sci., 13, 2071-2080, 1978 . 
38. Wiederhorn, S. M., "Dependence of Lifetime Predictions on the Form of the Crack Propagation Equation," in Fracture 1977, D. M. R. Taplin, ed., University of Waterloo Press, Waterloo, Canada, 1977, pp. 893-901.

39. Wiederhorn, S. M. and Ritter, J. E., Jr., "Fracture Mechanics Applied to Brittle Materials," ASTM STP 678, S. W. Freiman, ed., 1979, pp. 202-214.

40. Ritter, J. E., Jr. and Humenik, J. N., "Static and Dynamic Fatigue of Polycrystalline Alumina," J. Mater. Sci., 14, 626-632, 1979.

41. Bansa1, G. K., Duckworth, W. H., and Niesz, D. E., "Strength-Size Relations in Ceramic Materials: Investigation of an Alumina Ceramic," J. Amer. Ceram. Soc., 59, 472-478, 1976

42. Proctor, B. A., Whitney, I., and Johnson, W., Proceedings of the Royal Society, London, A297, 534-557, 1967.

43. Wiederhorn, S. M., Evans, A. G., and Roberts, D. E., "Fracture Mechanics Study of the Skylab Windows," in Fracture Mechanics of Ceramics, Vol. 2, R. C. Bradt, D. P. H. Hasselman, and F. F. Lange, eds., Plenum Press, New York, 1974, pp. 829-42.

44. Pletka, B. J. and Wiederhorn, S. M., "Subcritical Crack Growth in Glass Ceramics," in Fracture Mechanics of Ceramics, Vo1. 4, R. C. Bradt, D. P. H. Hasselman, and F. F. Lange, eds., Plenum Press, New York, 1978, pp. 745-759.

45. Conley, P. H., Chandan, H. C., and Bradt, R. C., "Dynamic Fatigue of Foam Glass," in Fracture Mechnics of Ceramics, Vol. 4, R. C. Bradt, D. P. H. Hasselman, and F. F. Lange, eds., Plenum Press, New York, 1978, pp. 761-772.

46. Gesing, A. J. and Bradt, R. C., "Effects of Porosity on Room Temperature $\left(\mathrm{K}_{\mathrm{I}} \mathrm{V}\right)$ Behavior of Polycrystalline $\mathrm{Al}_{2} \mathrm{O}_{3}$," Paper No. 141-B-77 presented at annual meeting of the American Ceramic Society, Chicago, 1977. 
This Page Intentionally Left Blank 
Chapter 6

CASE HISTORY OF AN ITERATIVE DESIGN

\subsection{Introduction}

Previous chapters have documented the state of the art and future technology requirements for enhancing the reliability of ceramic heat engine components in the areas of design, material development and manufacturing, materials characterizations, and quality assurance.

The introduction of advanced materials into engines requires the integration of these technologies via iterative development. Historically, all engine development has involved such iterative procedures. In the past this iterative development has proceeded rather informally over a long period. To attain the potential benefits of ceramics in heat engines, this iterative development procedure must be recognized more formally.

A recurring theme which the ceramic manufacturing community articulated to this committee was the need to close the feedback loop so that materials/manufacturing deficiencies identified in engine demonstration programs could be resolved and the resolution confirmed by engine or rig test. A similar frustration was expressed by engine designers, who felt that many current programs did not allow them enough design iterations after component test data were obtained to take advantage of lessons learned. The common message from both groups was that by the time problems were identified and solved, the program as originally scheduled was likely to have ended, making demonstration of an improved approach impossible. Aside from the personal frustrations of the technologists involved, this represents a situation where the government is not reaping the benefits of its investment. Formal inclusion of the iterative design approach in future programs (or at least in selected future programs) is thus deemed essential.

\subsection{Case History}

A limited number of ceramic engine development programs are operating in an iterative mode. The program first directed explicitly to operate in an iterative mode which therefore provides the best example of what may be expected from such programs, was the Ford portion of the DARPA "Brittle Materials Design" program. A detailed review of the program 
Is beyond the scope of this chapter, but 1t is important at least to look at a case history of the development of one major component. The clearest example of the success of the iterative design approach in the DARPA/Ford program is the development of the first-stage, reaction-bonded, sllicon nitride (RBSN) stator.

In service, the stator w111 be exposed to peak cycle temperature and to severe thermal transients that characterize vehicular gas turbine operation. These transient loadings along with aerodynamic performance requirements constitute the governing design criteria for the stator. The steady state thermal and mechanical loadings are negligible and will not affect reliability. The reliability requirements for the stator are the same as for the turbine rotor, since failure of a stator is likely to precipitate a rotor failure and consequently a total loss of power. A reliability goal of 99 percent at the 90 percent confidence level for the life of the component is considered representative for this application.

The initial goal was to demonstrate an uncooled RBSN stator in an all-ceramic engine. A representative duty cycle was used with turbine inlet temperature (TIT) varying between $1930^{\circ}$ and $2500^{\circ} \mathrm{F}$ for an aggregate of $200 \mathrm{~h}$. When it became apparent that the lack of a 200-h ceramic rotor capability would preclude engine demonstration within the funding of the existing program, the goal was redefined. The revised goal was to demonstrate the stator in a test rig over a representative engine duty cycle comprising $175 \mathrm{~h}$ at $1930^{\circ} \mathrm{F}$ and $25 \mathrm{~h}$ at $2500^{\circ} \mathrm{F}$.

The iterative development of an RBSN stator that would meet these goals proceeded for seven years. During this period, five major iterations (plus many more subiterations) were carried out. These included four iterations of design and three of material. Figure 6-1 sumarizes the stator's development.

The original design, $A$ in Figure 6-1, included an integral first stage rotor shroud and did not include an inner shroud. Individual vane segments were injection molded and bonded together with a silicon metal slip in the green state to form the full first stage stator. The vane segments attained a nitrided density of $2.2 \mathrm{~g} / \mathrm{cc}$, while the bond material had a somewhat lower density. During tests of this stator, the bonding material in the outer shroud often failed. More significantly, vane root thermal cracks were initiated during thermal transients. These led to loss of vanes on lightoff or shut down. Two-dimensional finite element stress analysis, supplemented with bench tests, was used to attempt to correct the thermal shock problem. This resulted in elimination of the integral rotor shroud and a thinning down of the outer stator shroud channel. Aerodynamic considerations led to the introduction of inner vane shrouds. This first iteration was Design B in Figure 6-1. Again, segments were injection molded 


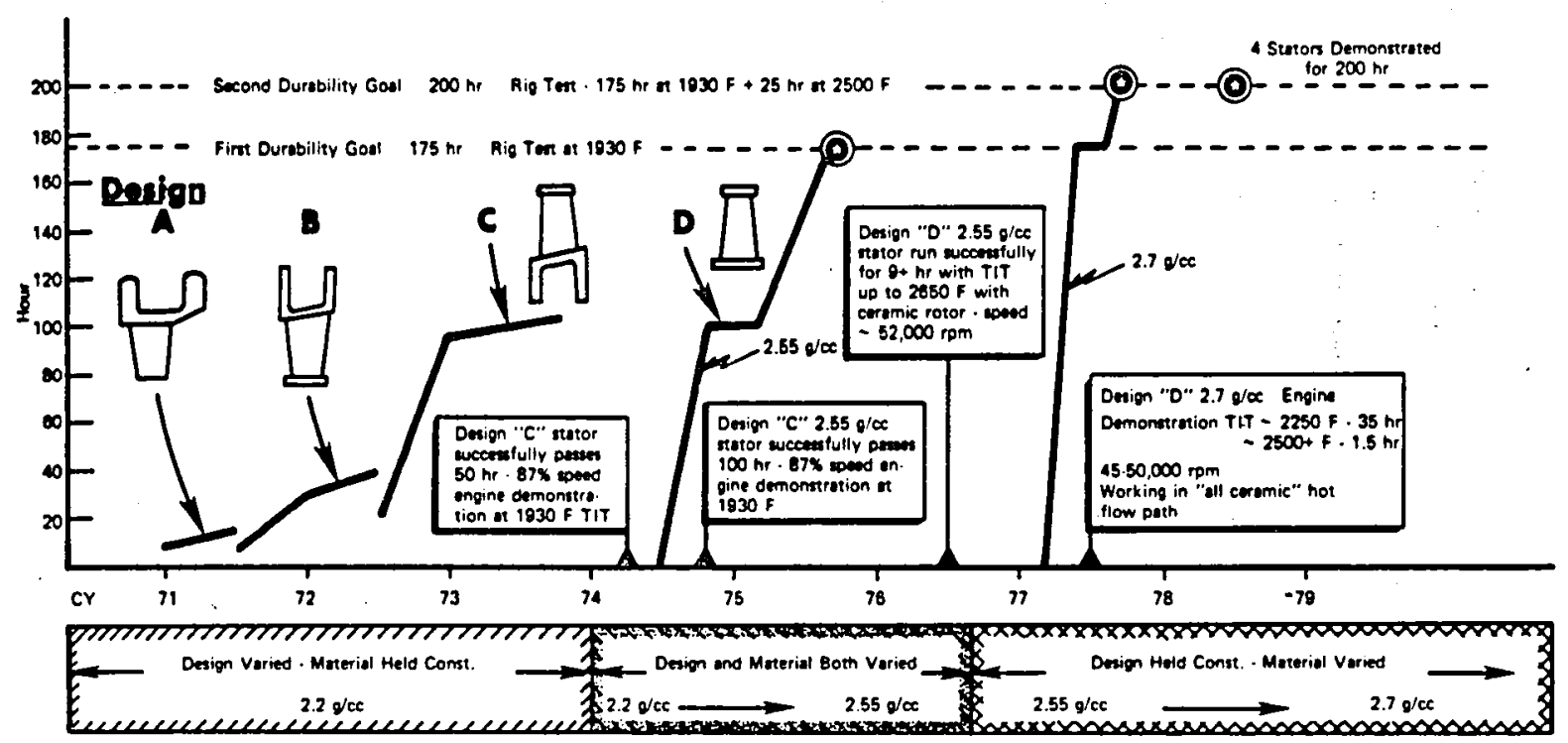

FIGURE 6-1 Engineering Development History -- First stage RBSN Stator DARPA/Ford Engine -- A Case study of Iterative, Brittle Materials Design 
individually, bonded together, and nitrided to $2.2 \mathrm{~g} / \mathrm{cc}$. Design B led to significantly longer test-rig life than Design A. An important factor in the improved performance was the better shroud-to-vane mass balance in Design $B$. The vane cracking, which was not predicted by the 2-D analysis, was moved to the midspan of the vane, and outer shroud cracking continued as before. A laboratory thermal shock rig was used to evaluate several modified vane profiles empirically. As a result, a second iteration, $C$, was defined in which Design $B$ vanes had their trailing edges cut back. Stators were still assembled from individual segments and nitrided to $2.2 \mathrm{~g} / \mathrm{cc}$. These design changes, with material held constant, increased maximum stator life from about $10 \mathrm{~h}$ to about $100 \mathrm{~h}$. It is significant to note that the Design $C$ stator was used in the first major engine demonstration -- $50 \mathrm{~h}$ at up to 87 percent design speed and $1930^{\circ} \mathrm{F}$. (Ful1 speed occurs at $2500^{\circ} \mathrm{F}$ and, therefore, required a ceramic rotor, which was unavailable.)

At this point, failures in the bond between the individual vane segments were recognized as being due to oxidation. A detailed 3-D analysis confirmed that, with the difference in thermal expansion of oxidized bond material and oxidized vane material (the two materials had different densities and thus oxidation rates), a one-piece stator would be required to meet the program goals. Tooling for a one-piece stator was procured in the third design iteration, D. This design had the same vane geometry as Design $\mathrm{C}$, but the outer shroud channels were not removed and the gaps in the inner shroud were precisely defined. Simultaneously with the introduction of Design $D$, the first materials iteration, $2.55 \mathrm{~g} / \mathrm{cc}$ RBSN, was incorporated. The combined effect of these iterations was the achievement of two important program goals: a 175-h rig durability demonstration, and a 100-h engine test demonstration.

Outer shroud cracking was still a problem, possibly related to oxidation of the RBSN, with the $2.55 \mathrm{~g} / \mathrm{cc}$ of Design $\mathrm{D}$. At this point it was concluded that the elimination of outer shroud cracking could be addressed most directly by materials improvement, so design of the stator was frozen. The final iteration was the introduction of $2.7 \mathrm{~g} / \mathrm{cc}$ material. This iteration carried the stator to a 200-h program demonstration as well as to several engine tests with ceramic rotors at up to $2650^{\circ} \mathrm{F}$. Thus, the demonstrated durability of the first stage stator increased from about $10 \mathrm{~h}$ in 1971 to $200 \mathrm{~h}$, reproducibly demonstrated, in 1977 .

Between 1976 and 1978, several empirically derived proof tests were developed which allowed prediction of a given stator's potential to survive the demonstration test. It is important to note the the predictive proof tests, especially one utilizing oxidative weight gain in a several-hour exposure, resulted from experience gained by working with the materials and components and could not have been anticipated in the absence of that experience. In the course of the iterative stator development, significant engine demonstrations were made which showed that the stators would perform for 35 to $100 \mathrm{~h}$ in a real engine 
environment. Table 6-1 provides a projected time table for the introduction of ceramics into production of turbine engines for airborne applications.

TABLE 6-1 Scenario for the Introduction of Ceramics into Airborne Engines

Bearings :

- Limited Life

- APU

- Man Rated

Thermal Barrier Coatings

- Limited Life and APU

combustors

transitions

vanes

blades

- Man Rated

combustors

transitions

vanes

blades

Monolithic Ceramics

- Limited Life and APU

vanes

blades

- Man Rated

vanes

blades

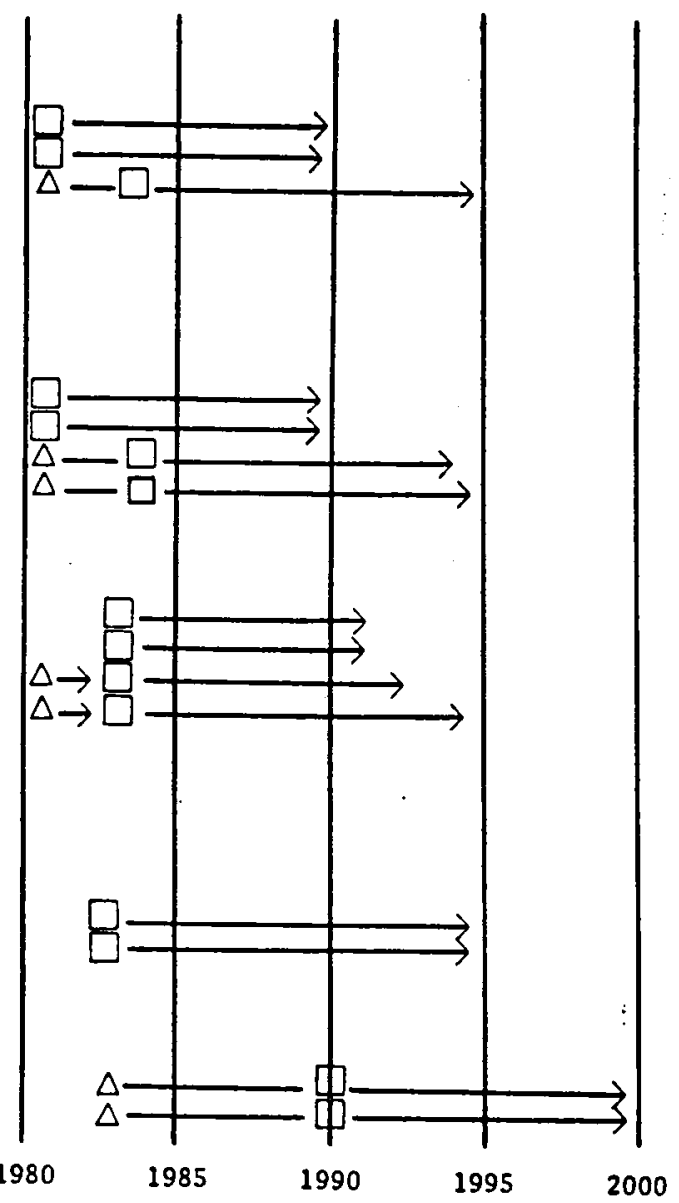

Key: $\triangle=$ Start RED

= Start Engineering Development for Specific Systems 


\subsection{Conclusions}

The iterative design approach, carried to the point of providing feedback to all required technologies and allowing for problem resolution, is recognized as crucial by the engine design and materials fabrication communities and by this committee. 


\section{Appendix}

CERAMICS FOR SMALL AIRBORNE ENGINE APPLICATIONS

The following paper is presented as a complement to the basic report on reliability of ceramics. It provides background regarding. systems requirements, supplements, and the achievements made in the use of structural ceramics; it also includes data on materials and the improvements that are required for their use in heat engine applications. 
This Page Intentionally Left Blank 
To be presented at the 49th Meeting of the Structures and Materials Panel of AGARD -

CERAMICS FOR TURBINE ENGINE APPLICATIONS - DFVLR, Porz-Wahn, Cologne, W. Germany, 8 Oct 79

CERAMICS FOR SMALL AIRBORNE ENGINE APPLICATIONS

R. Nathan Katz and Edward M. Lenoe

Army Materials and Mechanics Research Center

Watertown, MA 02172

ABSTRACT

An increasing number of successful demonstrations of ceramics as significant structural components In small land based heat engines, especially gas turbines, has drawn tho attention of small aircraft and misstle engine destgners to this class of materlals. The question which is being asked with increasing frequency 1s: "Do ceramics measure up to the criteria and requirements of alrborne engines?" This question obviously does not have a simple answer, mainly because of the wide range of systems requirements and duty cycles which exist amongst airborne engines themselves. In this paper the authors assess the likelihood for successful application of ceramics to several classes of atrborne engines with different duty cycles. The general design criteria and associated key materials and requirements for generic engines for. limited life, APU, and man-rated helicopter use will be addressed. Materials, processes, design approaches, and reliability considerations appropriate to each generic engine category will be briefly discussed. A scenario for a least risk strategy for the introduction of ceramics into airborne engines will be presented. Key issues in materials research and development will be identified.

\section{Introduction}

The energy crisis, environmental concerns, and critical materials supply considerations are the driving force behind the current emphasis on ceramic materials technology for gas turbine (GT) engines. Since the early 1970's the focus of this emphasis on ceramic technology exploitation has been for vehicular engines (1-5). As a consequence, an increasing number of successful demonstrations of ceramics as significant structural components in small terrestrially based heat engines, has drawn the attention of alrcraft and missile engine designers to this class of materials. For example, a study by Blankenship (6) has shown that for conventional take off and landing type of aircraft, the cost savings which can accrue by using ceramic vanes, would be $\$ 110$ million for 100 aircraft over 15 years of operation. The $\$ 110$ milition saving would require an investment of an $2 \$ 12 \mathrm{milli}$ ion for a cost/benefit ratio of about 10 (6). Table I lists the current experience on four terrestrially based, ceramic configured gas turbines (or components in G.T. test rigs). Given the fact that ceramics have now demonstrated feasibility for further development in terrestrially based applications it becomes appropriate to ask the question; "Do ceramics measure up to the requirements of small airborne engines?" This question obviously does not have a simple answer, mainly because of the wide range of systems requirements and duty cycles which exist amongst airborne engines themselves.

Table I.

SIGNIFICANT ACHIEVEMENTS IN CURRENT TERRESTIALYY BASED CERAMIC-GT PROCRAMS

\begin{tabular}{|c|c|c|}
\hline Program [Referencel & Type of Engine & Major Achievements \\
\hline \multirow[t]{3}{*}{$\begin{array}{l}\text { DARPAIFOC [I] } \\
\text { [n }\end{array}$} & $\begin{array}{l}-200 \mathrm{hp} \mathrm{Regenerated,} \mathrm{Axial} \\
\text { Single Shaft, } 2500 \mathrm{~F} \text { iIT }\end{array}$ & $\begin{array}{l}\text {-All Stationary Ceramic Components } \\
\text { in Reaction-Bonded Sijßs Demronstrated } \\
200 \text { hours life in Engine Rig to } 2500 \text { f }\end{array}$ \\
\hline & & $\begin{array}{l}\text { - Duo-Density } \mathrm{SizN}_{4} \text { Rotor Demonstr ated } \\
200 \text { hours } d-2200 \mathrm{~F} \text { III, 50,000 RPM }\end{array}$ \\
\hline & & $\begin{array}{l}\text {-First Stage Ceramic Hardware Run in } \\
\text { an Engine } 36.5 \text { hours } 2100-2500 \mathrm{~F} \text {. } \\
40,000-50,000 \mathrm{RPM}\end{array}$ \\
\hline \multirow[t]{3}{*}{ MERADCOM/Solar [8] } & $\begin{array}{l}-10 \mathrm{~km} \text { Turtogenerator, } \\
\text { Radial, =1700 F IIt }\end{array}$ & $\begin{array}{l}\text { - Run }-50 \text { hours with Ceramic Vanes, } \\
\text { Producing }-10 \mathrm{kw}\end{array}$ \\
\hline & & $\begin{array}{l}\text { - Run - } 40 \text { hours with all Ceramic } \\
\text { Nozzle Stage, Producing }-10 \mathrm{kw}\end{array}$ \\
\hline & & - Demonstration of Ceramic Bearing \\
\hline DARPA/AiResearch [9] & $\begin{array}{l}\text {-1000 np Simple Cycle } \\
\text { 3-5tage z200 F TIT }\end{array}$ & $\begin{array}{l}\text { - Integration of Over } 100 \text { Separate Ceramic } \\
\text { components in a High Pertermance } \\
\text { Engine. Run at Full Speed and Temperature } \\
\text { in Excess of } 2 \text { hours, Ineluodes } 2 \\
\text { Shutdowns and Starts. Ceramics } \\
\text { Demonstroted } 200+\text { hp Increase Over } \\
\text { Base Engine }\end{array}$ \\
\hline DDAIDOE IIO & $\begin{array}{l}\text {-350 hp Regenerated } \\
2 \text { Shan, } 2265 \mathrm{~F} \text { TIT }\end{array}$ & $\begin{array}{l}\text { - Ceramic Stators Run in Excess of } \\
\text { lo00 hours at } 1900 \text { f IIT. Ceramle } \\
\text { Vanes in vehicle on the Road for Over } \\
25 \text { hours }\end{array}$ \\
\hline
\end{tabular}

In this paper we will attempt to assess the likelihood for successful application of ceramics to several classes of airborne engines with different duty cycles. The general design criteria and associated key materials properties and requirements for generic engines of the APU, 1 imited life, and man-rated helicopter type will be addressed. The major focus of this paper will be on the materials and processes appropriate to the generic man-rated helicopter engine, as this represents the most rigorous duty cycle of the three classes of engines considered. Key issues in materials research and development will be discussed. A scenario for a least risk strategy for the introduction of ceramics into airborne engines will be presented. However, it is appropriate to first, briefly, review some aspects of the brittle materials design process.

\section{Brittle Materials Design Process}

Design with brittle materials requires a very precise definition of the state of stress at every point in the component. Brittle materials can, in fact, be quite strong, but generally manifest a wide scatter in strength and do not have the ability to redistribute high local stress concentration by yielding as in the case in metals. This in turn means that ceramics are extremely sensitive to high localized 
stress gradients due to notches or other sources. In this regard, Dukes (11) has pointed out that the most difficult aspect of high temperature design with brittle materials is the definition of, and subsequent minimization of thermal stresses. Thus, a realistic expectation of exploiting the potential of ceraics in capability to predict the thermal and stress environments from point to point in a component, and high temperature engineering materials with low thermal expansions in order to minimize thermal stresses. Advances in 2 and $3-D$ computerized finite element thermal and stress analysis techniques have provided the former, and the development to silicon nitrides and improved silicon carbides have provided the latter. Both of these developments reached a sufficient level of maturity in the late 1960's for various research programs for demonstration of ceramics in gas turbines to be initiated $(1-3)$.

While a low thermal expansion is necessary for a ceramic engine material, other properties must be considered. All of the materials properties and requirements listed in Table II must be adequate. In particular, the time, temperature, stress and environmental dependencies of the mechanical properties must be known (or predictable) for the entire engine duty cycle. As will be discussed latter in this paper the "virgin" materials properties are unlikely to be retained late in the engine's projected life time. Thus it is important to acquire design data on materials exposed to service environments for realistic times. One must also know the effects of processing method on these properties. of particular importance in brittle material design, where probabilistic versus deterministic design procedures are used $(11,12)$ is the trade-off between strength and Weibull Modulus with respect to calculated component probability of success. As shown in Fig. 1 an increase in Weibull Modulus " $m$ " is "worth more" than an increase in average strength (provided of course that the strength is at an acceptable level) in attaining a given level of component reliability. This point will be referred to latter when key issues for future materials $R \& D$ are discussed. Having the information just described, the designer is in a position to perform trade-off studies as in Fig. 2 and specify an optimum design/material/processing combination for a given component in the system under consideration. Once the design/material/process for a given component has been selected, validation by rig and/or engine tests usually requires several passes through

Table II.

GENERAL PROPERTIES REQUIRED OF A CERAMIC HEAT ENGINE COMPONENT

LEVEL I. IECHNICAL FEASIBILITY DEMONSTRATION

- THERMAL SHOCKITHERMAL FATIGUE RESISTANCE

- Necessary temperature capabILITy

- ADEQUATE STRENGTH AND CREEP BEHAVIOR AS A FUNCTION OF TEMPERATURE

- NECESSARY LONGIVITY IN THE ENGINE ENVIRONMENT

LEVEL II ENGINEERING FEASIBILITY DEMONSTATION

- CONSISTANCY OF ADEQUATE PROPERTIES IN AS FABRICATED COMPONENTS

- ADEQUATE LEVELS OF RELIABILITY ATTAINED

- adequate cost effective fabrication potential

LEVEL III IECHNOLOGY IMPLEMENTATION

- DEMONSTRATED BENEFIT/COST FOR THE TECHNOLOGY MUST BE SUFFICIENTLY HIGH TO WARRENT IMPLEMENTATION VERSUS EXISTING OR OTHER ALTERNATE TECHNOLOGIES

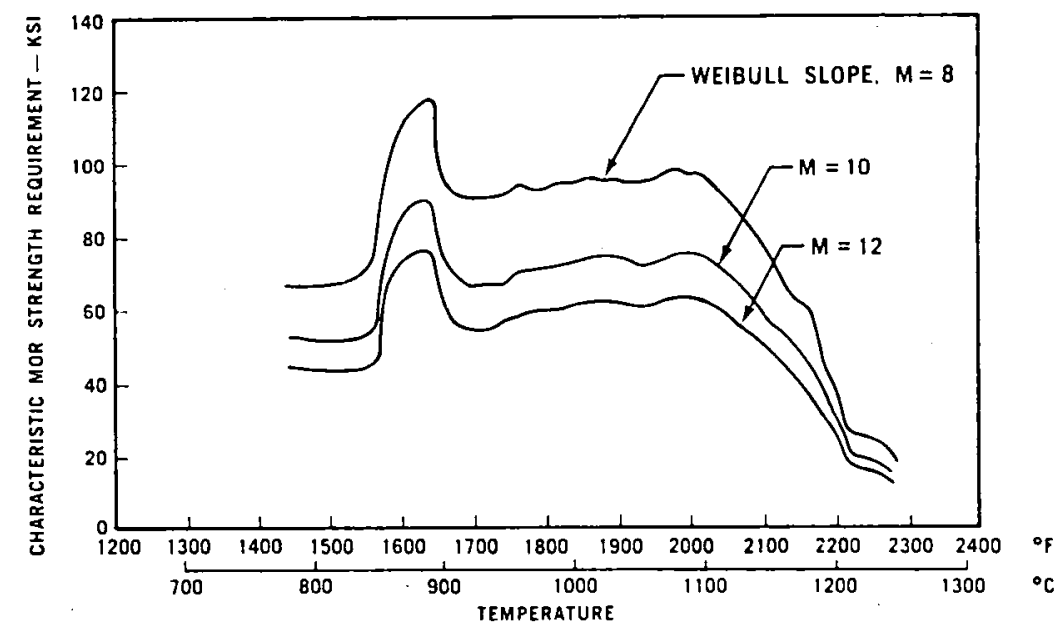

Figure 1. TRADE-OFF BETWEEN MOR AND WEIBULL MOOULUS IN BRITTLE MATERIAL DESIGN (Ref. 13) 
the iterative design scheme shown in Fig. 3. It is important to note that there is unlikely to be one optimum material/process that will satisfy a wide variety of systems requirements. Thus, the successful development of ceramic engine technology will require the existance of many materials and processing options. Similarly, a wide variety of innovative design concepts (particularly for attachment areas) will be required in order to develop compliant structures. This is essential, since brittle materials do not possess the capacity to redistribute over-stresses without failure, the structure must itself provide the means to redistribute stress (i.e., compliant structures). While the focus of this paper is on materials, the authors wish to point out their view that the development of compliant structures is currently a major pacing problem in high performance structural utilization of brittle materials.

\section{Systems Requirements}

As is clear from Fig. 2, the first step in defining materials requirements is an appropriate specification of systems requirements. The preceeding paper by Brooks \& Bellin, (14) has provided these for both limited life (LL) and man-rated generic engines. Similarly the paper of Napier \& Arnold (15) will partially provide this input for an APU type engine. However, it is worth while to reiterate in the broadest terms the systems requirements or goals for all these classes of engines, with special emphasis on Army goals. These are presented in Tables III thru V. Obviously, these general goals will take on appropriate numerical values and trade-off weights when a specific engine design study is initiated.

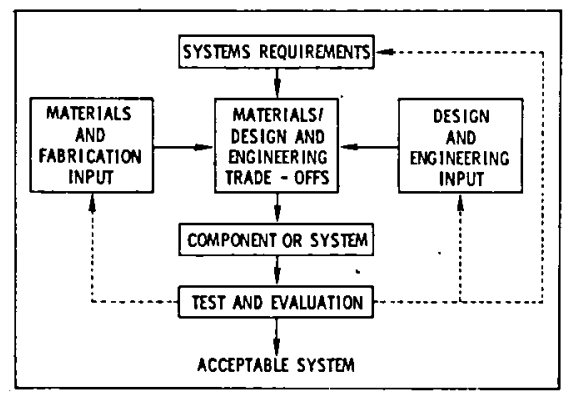

Figure 2. THE ENGINEERING TRADE-OFF LOGIC FOR INTRODUCING A NEW MATERIAL OR DESIGN INTO A SYSTEM

Table III.
REQUIREMENTS FOR ARMY AVIATION APU'S
- LONGER TBO/LESS MAINTENANCE
- HIGHER SPECIFIC POWER FROM CONSTANT
VOLUME PACKAGE
- LOWER SFC
-HIGH RELIABILITY (BUT LOWER THAN MAN-RATED
IS PERMISSIBLE)
- DUTY CYCLE - MODERATE WITH LOTS OF STARTS,
RELATIVELY FEW HOURS
-LOW COST (ACQUISITION AND LIFE CYCLE)

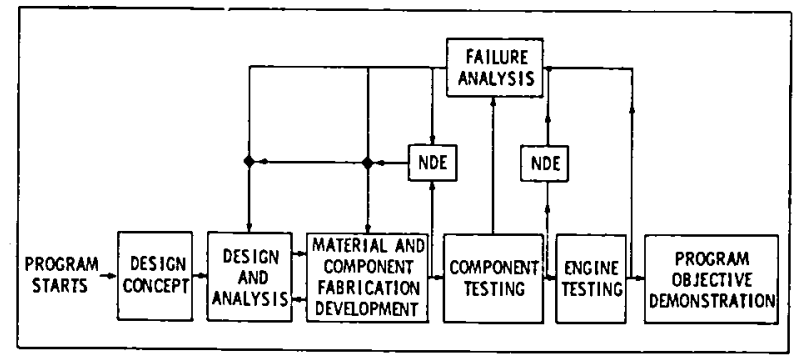

Figure 3. "BRITLLE MATERIALS DESIGN" ITERATIVE DESIGN SHCEME

\begin{tabular}{l} 
Table IV. \\
REQUIREMENTS FOR ARMY AVIAIION LIMITED LIFE ENGINES \\
\hline -5O HOURS - 50 STARTS AND/OR CYCLES \\
-NONCORRODINGINONBRINNELLING BEARINGS \\
-HIGHER THRUST/WEIGHT \\
-LOWER SFC \\
-HIGH RELIABILITY (BUT LOWER THAN MAN-RATED \\
IS PERMISSIBLE) \\
-MODERATE SEVERITY DUTY CYCLF \\
-LOW ACQUISITION COST \\
\hline
\end{tabular}

Table V.

GENERAL REQUIREMENTS FOR MAN-RATED ENGINES FOR ARMY HELICOPTERS

- 4000-hr COMPONENT LIFE

- HIGHER SPECIFIC POWER (HPIWT)

- Lower SFC

- LUBRICATION STARVATION TOLERANT BEARINGS

- VERY SEVERE DUTY CYCLE (LOTS OF ACCELDECEL)

- VERY HIGH RELIABILITY

- LOW LIFE CYCLE COSTS

\section{Requirements on Ceramics for Airborne Engine Applications}

To discuss the requirements on ceramic materials for the three classes of airborne engines in detail would require a major monograph rather than a brief paper. Therefore, the authors have elected to focus on the strength requirements for vanes and rotor blades for man-rated engines, since these represent the most demanding application. As shown in the previous paper (14) the design stresses in the vanes and blades in limited life and man-rated engines fall in the same range. Also despite differences in thermal and physical properties, the predicted stresses in vanes and blades of the various candidate ceramic materials will be similar due to design practices. 
Using the data of Brooks \& Bellin (14) as well as data from the literature (16-19) it is possible to identify the key stress-temperature combinations for the principal design points of vanes and blades for a generic helicopter or limited life engine with a TIT range of $2200-2500^{\circ} \mathrm{F}$. These are presented in Fig. 4 .

While vanes and blades are the most demanding of the high temperature applications, there is one important low temperature application, namely, bearings. Ceramic bearings offer important advantages in potential for lubrication starvation tolerance, high DN, and cooler running bearings. This subject will be reviewed in detail by Bersch $(20)$ in these proceedings. Therefore, we will not deal with the materials or requirements for ceramic airborne bearings. However, we will return to bearings in our recommendation for exploitation of ceramics in airborne engines.

Before proceeding to match the available ceramic properties with the generic design requirements we will introduce the various families of engineering nitride and carbide together with their fabrication processes.

\section{Families of Candidate Airborne GT Ceramics, Processing Routes and Some Properties}

Materials which are considered candidates for airborne G.T. application include state-of-the-art and developing materials, principally from two broad materials/process families; the silicon nitrides and the silicon carbides.* Typical properties of menbers of these two families of engineering ceramics are presented in Table VI. A brief description of each family of materials follows.

\section{Silicon Nitride Based Ceramics}

The silicon nitride families of ceramic materials include:

Hot Pressed Silicon Nitride (HPSN)

Reaction Bonded Silicon Nitride (RBSN)

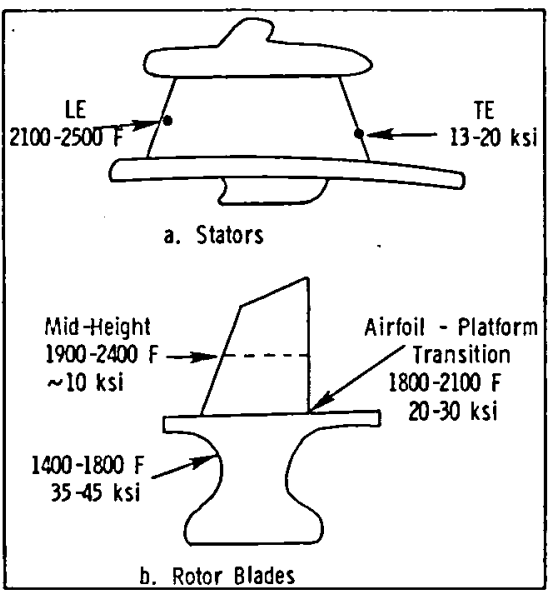

Figure 4. STRESS-TEMPERATURE RANGES AT DESIGN POINTS FOR GENERIC LIMITED LIFE AND HELICOPTER GAS TURBINE ENGINES $2100-2500 \mathrm{~F}$ TIT FIRST STAGE COMPONENTS

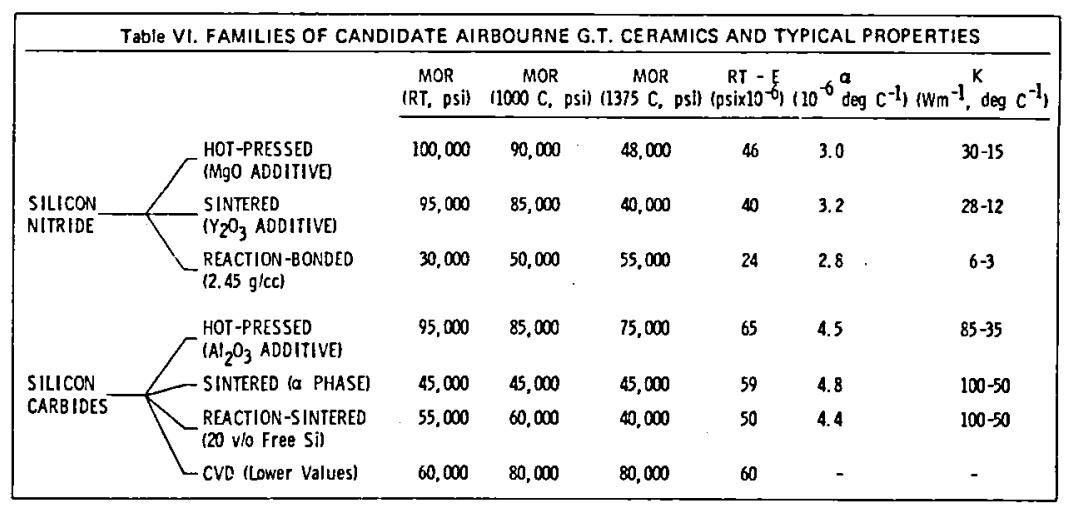

*Zirconia based thermal barrier coatings might also be appropriately included, however, this paper as well as these Proceedings, deals with monolithic ceramics. 


\author{
Sintered Silicon Nitride (SSN) \\ B' SIAION'S (SIMON) \\ Chemically Vapor Deposited Silicon Nitride (CVD-SN)
}

Hot Pressed Silicon Nitride can be produced by either conventional uniaxial (21) or hot isostatic

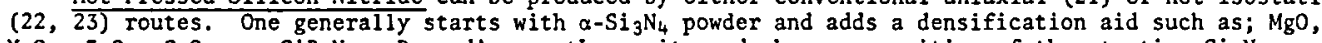
$\mathrm{Y}_{2} \mathrm{O}_{3}, \mathrm{ZrO}_{2}, \mathrm{CeO}_{2}$, or $\mathrm{SiBeN}_{2}$. Depending on the purity and phase composition of the starting $\mathrm{Si}_{3} \mathrm{~N}_{4}$ powder, the percentage and type of additive, milling and mixing procedures, and hot pressing parameters $(T, t)$ one can obtain a very wide range of strength, strength vs. temperature, creep, fracture toughness, or oxidation behaviors. Illustrative of such variety of behavior, the strength vs. temperature curves of HPSN's as a function of some of the foregoing processing variables, are shown in Fig. 5 . To make an important point, one cannot look at the data in Fig. 5 and make an arbitrary judgement that one material is "better" than another. The concept of "better" depends on the application requirement. The lower curve in Fig. 5 may be "better" for a given application than one of the higher curves, (i.e., it may have adequate strength, Weibull "m", creep, etc, and be cheaper and easier to fabricate).

Almost all HPSN's exhibit MOR values of 100,000 psi (690 MPa) or greater at RT and retain these values to $1000-1100^{\circ} \mathrm{C}$ (dependent on amount and type of additive), have high $\mathrm{K}_{\mathrm{IC}}\left(\sim 5-8 \mathrm{MN} / \mathrm{m}^{3 / 2}\right)$, high thermal shock resistance, and excellent erosion resistance.

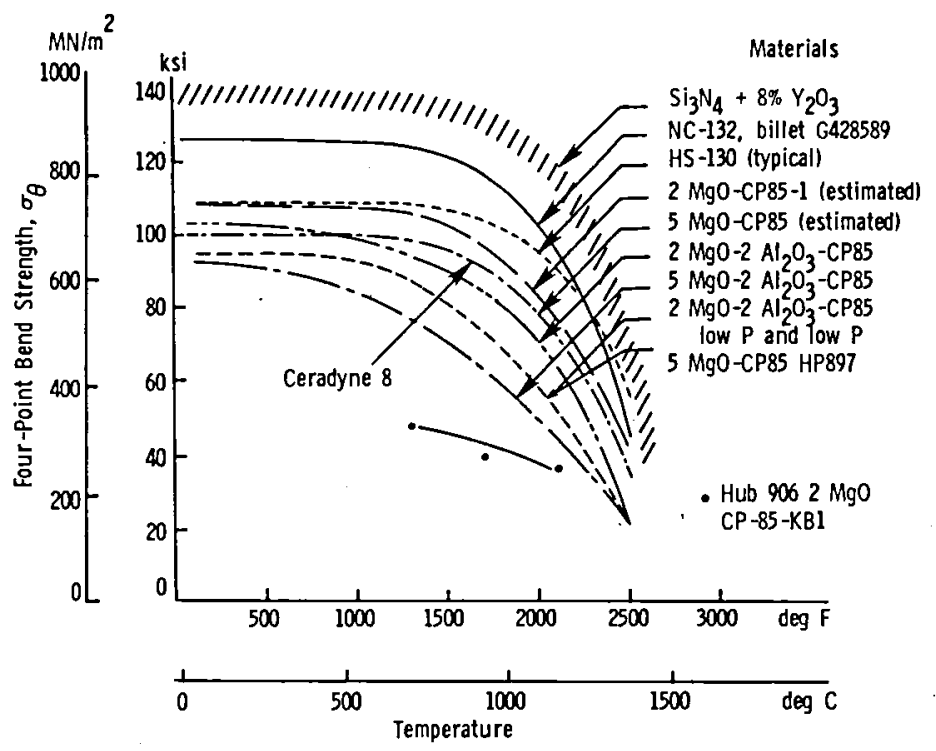

Figure 5. FLEXURAL STRENGTH OF VARIOUS TYPES OF HPSN

Hot pressed silicon nitride with $\mathrm{MgO}$ as an additive, typified by NC-132 material, most nearly approaches a mature engineering material. HPSN with $\mathrm{Y}_{2} \mathrm{O}_{3}$ additives typically have higher strengths at both room and elevated temperatures (see Fig. 5), as well as, better oxidation resistance and $K_{I C}$ and less slow crack growth than MgO containing HPSN. However, this material has been plagued with an intermediate temperature $\left(21000^{\circ} \mathrm{C}\right)$ oxidation problem. While $i t$ appears that the post-fabrication nitridation treatment demonstrated by Gazza, Knoch, and Quinn (25) can overcome this problem, more work needs to be carried out before HPSN with $\mathrm{Y}_{2} \mathrm{O}_{3}$ is as developed as the Mgo containing varieties. Very high strengths have been attained by Tsuge, et al, in Japan (26) with $\mathrm{Y}_{2} \mathrm{O}_{3}+\mathrm{AI}_{2} \mathrm{O}_{3}$ additive using the grain boundry crystallization approach. The high cost associated with diamond machining of HPSN from simple billets to complex geometry components, has led to research in near net shape hot pressing, in several laboratories. Significant progress in hot pressing $\mathrm{Si}_{3} \mathrm{~N}_{4}$ to near net shape has been demonstrated by Ford (27), AMMRC (28) and Annawerk (29). Such work has demonstrated the utility of hot pressing in engine development programs, and the costs may be acceptable for some airborne engine application.

Reaction Bonded Silicon Nitride, has been developed, largely to obtain a readily formable (little machining required), low cost material. In contrast to $\mathrm{HPSN}$, RBSN maintains its strength to temperatures beyond $1400^{\circ} \mathrm{C}$. RBSN can be made with creep rates significantly below HPSN (30). As a consequence of the reaction bonding process, RBSN is of necessity at least $10 \%$ porous which makes it less oxidation resistant than HPSN at intermediate temperatures (31), and limits its strength to less than $60 \mathrm{KSI}$ (415 MPa) or more typically to about $35 \mathrm{KSI}(245 \mathrm{MPa})$.

The fabrication of RBSN components begins with a silicon metal preform made by slip casting, dry pressing, flame spraying, injection molding or various other techniques. The preform is tinen nitrided in an atmosphere of pure $\mathrm{N}_{2}$ or $\mathrm{N}_{2}+\mathrm{H}_{2}$, at either a preselected temperature schedule (32) or now more usually using a nitrogen demand control cycle (33). The nitridation process of such a $S i$ preform is a remarkable, if still somewhat Imperfectly understood event. For $3 S i(s)+2 \mathrm{~N}_{2}(\mathrm{~g})+\mathrm{Si}_{3} \mathrm{~N}_{4}(\mathrm{~s})$ there is a 23\% expansion in the solid volume compared to $\mathrm{Si}$; yet, when this reaction is carried out on a preform there is essentially no change in dimensions $\left(\sim_{0} .1 \%\right)$. The reason for this appears to be that the first $\mathrm{Si}_{3} \mathrm{~N}_{4}$ to form, does so by a complex solid-1iquid-vapor whisker growth into the void space of the $\mathrm{Si}$ preform. The net result is that what appears to be a rather complex series of processing steps, and 
what is a complex series of chemical reactions, yields a product of great technological import-- an engineering ceramic which can be mass produced to tight dimensional tolerances with little or no machining and at low cost.

Reaction bonded silicon nitride has improved considerably over the past few years, as shown in Fig. 6 . Nevertheless, where high strength, more oxidation resistant material is required, it would be desirable to have a readily fabricable, fully dense silicon nitride. This has been the impetus for the development of sintered silicon nitride.

Sintered Silicon Nitrides are a rather recent development. Although, $\mathrm{Si}_{3} \mathrm{~N}_{4}$ was sintered prior to $1976(34)$, the balance between dissociation of the $\mathrm{Si}_{3} \mathrm{~N}_{4}$ and densification was such that densities of only $90 \%$ were obtainable. Indeed, the possibility of sintering fully dense silicon nitride at reasonable. pressures was still an open question as late as 1976. Since then several groups have succeeded in producing sintered $\mathrm{Si}_{3} \mathrm{~N}_{4}$ of at least $95^{\circ}$ density, and a few groups have obtained greater than $99 \%$ density. Gazza (35) has reviewed the status of SSN. Table VI shows a SSN material with strengths between HPSN and RBSN. Some more recent experimental SSN materials have approached the properties of HPSN. SSN has been formed by injection molding, and provided isotropic shrinkage can be obtained components will require little machining. Recently, Giachello and Popper (36) have demonstrated that it is possible to post sinter a RBSN preform to $298 \%$ density, with increased strength and oxidation resistance. With this development one could start with a sintering preform that would yield only $6-8 \%$ shrinkage as opposed to 18-20\% shrinkage for sintering with a powder preform. It is also possible that sintered $\mathrm{Si}_{3} \mathrm{~N}_{4}$ bodies of over $95 \%$ T.D. may be used as preforms for cladless hipping. Such a development would be a major breakthrough towards attaining high reliability, affordable, high performance components such as rotors.

SiAlON's represent an important new class of ceramic materials which are solid solutions of metal oxides in the $\beta-\mathrm{Si}_{3} \mathrm{~N}_{4}$ lattice. These solid solutions distort the lattice to $\beta^{\prime} \mathrm{Si}_{3} \mathrm{~N}_{4}$ lattice (hence, $B^{\prime}$, SiAlON's). SiAlON's were originally developed from $\mathrm{Al}_{2} \mathrm{O}_{3}$ solid solution, but $\mathrm{MgO}, \mathrm{BeO}, \mathrm{Y}_{2} \mathrm{O}_{3}$, etc have ali been found to yield $\beta^{\prime}$ solid solutions, as well as a variety of other phases. SiMON's have been developed with a view toward application in heat engines $(37,38)$. However, these materials are still in early development and have not been used in engine demonstration programs to date. It is likely that they will play a role in future engine programs. SiMON phases are of major importance in determining the controlling the grain boundary phases which in turn control the behavior of HPSN and SSN. Therefore, understanding phase relationships in these systems is of major importance. These phase relationships are discussed in the papers of Prof. K.H. Jack and his students at Newcastle-Upon-Tyme (39-41).

CVD-SN in very thin layer form is currently an important electronic material. Building on this thin film technology some research in the use of CVD-SN coatings and optical windows is in progress, but bulk CVD-SN has yet to be demonstrated as a structural material.

\section{Silicon Carbide Based Ceramics}

The silicon carbide based families of ceramic materials include:

Hot Pressed SiC (HP-SiC)

Reaction Sintered (or bonded) SiC's (RS-SiC)

Sintered SiC's (S-SiC)

Silicon Carbide/Silicon Composites (Sil/Comp)

Chemically Vapor Deposited Silicon Carbide (CVD-SiC)

\begin{tabular}{|c|c|c|}
\hline REACTION-BONDED & SILICON & NITRIDES \\
\hline RECENT ADVANCES: & & \\
\hline $\begin{array}{r}- \text { INCREASING COM } \\
2.2 \mathrm{~g} / \mathrm{CC}\end{array}$ & $\begin{array}{l}\text { ONENT DEN } \\
\rightarrow 2.7 \mathrm{~g} / \mathrm{c}\end{array}$ & FITIES \\
\hline $\begin{array}{l}- \text { RATE-CONTROLLED } \\
\rightarrow \text { IMPROVED MA }\end{array}$ & $\begin{array}{l}\text { REACTION } \\
\text { ERIALS UNI }\end{array}$ & $\begin{array}{l}\text { ONDING } \\
\text { FORMITY }\end{array}$ \\
\hline Property & 1972 & 1978 \\
\hline$\rho(g / c c)$ & 2.2 & 2.7 \\
\hline 4-Pt MOR-RT (ksi) & $\sim 17$ & -36 \\
\hline $\begin{array}{l}\text { Stress Rupture } \\
\text { at } 2200 \mathrm{~F}, 30 \mathrm{ksi}\end{array}$ & Failure & $\begin{array}{l}>300 \text { Hour } \\
\text { Suspension }\end{array}$ \\
\hline $\begin{array}{l}\text { Oxidation - } \\
\text { Weight Gain in } \\
200 \text { Hours at } 1900 \mathrm{~F} \\
\text { (Worst Case) }\end{array}$ & $\sim 6 \%$ & $\sim 0.75 \%$ \\
\hline
\end{tabular}

Figure 6. REACTION BONDED SILICON NITRIDES

Hot Pressed $\mathrm{SiC}$ can be formed with various densification aids, but only HP-SiC utilizing $\mathrm{Al}_{2} \mathrm{O}_{3}$ additions has been considered for high performance engine applications (42). Properties of NC-203, the most mature example of this material are shown in Table VI, while HP-SiC is not as strong as HPSN at low temperatures, it retains useful strength out to $21400^{\circ} \mathrm{C}$. Thus, it might be an attractive material where high strength is required at $1400^{\circ} \mathrm{C}$ or beyond. The major drawback of this material is the need to diamond machine parts from a hot pressed billet. 
Reaction Sintered (or bonded) Silicon Carbides, cover a wide range of compositions and manufacturing processes (43). Typical examples of these materials include; BNF Refel, KT, NC-430, NC-435, and Ford Siliconized Silicon Carbide. While each material is formed by its own proprietary process, in general, a plastic body is formed of SiC powder, graphite, and plasticizer. In some variants of the process SiC powder plus a char forming plastic binder are used (44). The plastic body is pressed, extruded, injection molded or otherwise formed into a green body. Plasticizers are burned off or converted to a porous char by pyrolysis. Silicon metal as a liquid or vapor is intruded into the body and reacts with the graphite powder or char to form $\mathrm{SiC}$ in situ, which reaction sinters (or bonds) the component. Excess silicon is usually left to fill any voids, thus yielding a non-porous body. Such materials exhibit quite reasonable strengths, and hold them to the melting point of silicon $\left(~\left(\sim 1400^{\circ} \mathrm{C}\right)\right.$ or beyond, dependent upon the amount of free silicon retained. A variety of successful experimental gas turbine components, such as combustors or stators have been made by this materials/process route.

Sintered Silicon Carbide is a rather recent innovation. The benefit of having a fully dense silicon carbide with no silicon, and not requiring expensive machining (as with HP-SiC), was recognized very early. However, pressureless sintering of SiC to full density was thought unattainable until Prochazka demonstrated that by using $B$ and C additions, B-SiC could be sintered to near full density at $22000^{\circ} \mathrm{C}$. Prochazka also demonstrated that sintered $B-S i C$ could be formed into useful shapes by slip casting, die pressing and extrusion. Distribution of the carbon additive and exaggerated grain growth of $\alpha-S i C$ were found to interfere with densification. Coppola and McMurtry (46) developed sintered $\alpha-S i C$ in an effort to eliminate the problems associated with the $\beta \rightarrow \alpha$ transformation. Sintered $\alpha$-SiC has been demonstrated in several engine applications. Table VI provides some additional properties for sintered $\alpha-S i C$.

Reaction-Formed SiC/Si Composites, developed by Hillig (47), are the first engineered composite ceramic/ceramic materials which offers the possibility of low cost for structural components. The process consists of starting with a graphite (or carbon) cloth, tow, felt, chopped fiber array or any other possible precursor; forming a precursor preform by any one of a variety of routes; and infilterating liquid $\mathrm{Si}$ into the graphite precursor. The molten $S i$ reacts with the graphite materials to form polycrystalline SiC fibers (which may or may not have graphite fiber cores, dependent upon process parameters) in a Si matrix. The result is a fully dense oxidation resistant body with about 30 to 50 vol $\%$ Si reinforced by 50 to $70 \mathrm{vol}: \mathrm{SiC}$. (This high percentage of $\mathrm{Si}$ and the fibrous SiC morphology makes this material quite different from Refel-type materials). While the material shows promise of ease and versatility of fabrication, it is not yet clear what the costs may be. The material offers the ability to design a composite component optimized for mechanical and thermal requirements. The materials strength is at the 50,000 to $60,000 \mathrm{psi}$ level. Preliminary stress rupture data indicate that the strength of this material is independent of time below $1300^{\circ} \mathrm{C}$, unlike most high temperature ceramics (48). Perhaps the most intriguing advantage is that damaged areas have been removed and the components repaired with improved properties. The presence of free silicon would be thought to limit a use to temperatures of $22400^{\circ} \mathrm{F}$. In spite of this, the material has been used in an experimental combustion liner application at temperatures above $2600 \mathrm{~F}$ (47). Although the material is still in a very early stage of development, the fact that it is an "engineered" composite material makes it a very exciting new development.

CVD - Silicon Carbide in contrast to CVD- $\mathrm{Si}_{3} \mathrm{~N}_{4}$ has been produced in bulk. Gas turbine component fabrication capability, including radial and axial rotors has been demonstrated (49). The strength properties shown in Table VI represent the lower end of the scatter band. The very large scatter of strength in CVD-SiC is still a major problem due to columner grains and residual deposition resistance. Another major drawback from an application point of view is likely to be cost. The process may be useful in coating SiC ceramics formed by more conventional routes.

\section{Property - Requirements Comparison}

To illustrate how available materials properties compare with design requirements, we will examine the tensile strength - component stress situation. Obviously, in a real preliminary design/materials selection study, a similar process must be gone through for creep, stress rupture, oxidation, corrosion/ erosion, etc. Figures 7 and 8 show the strength vs. temperature behavior of various silicon nitrides and silicon carbides respectively. Superimposed on the same figures we have mapped the stresses expected at the major design points of vanes and blades for man-rated and limited life engines as shown in Fig. 4 . It is important to note that the design stresses are maximum principle tensile stresses, whereas the strength measurements are 4 point modulus of rupture (MOR) strengths. Therefore, in order to map the stresses we have adapted the conservative convention of setting the tensile strength as half of the $4 \mathrm{pt}$. MOR strength. This underestimates the true tensile strength of the ceramic (50) but for prelimin-
ary design it is an acceptable artifice.

As can be seen in Figures 7 and 8 , all materials with the exception of one variety of RBSN appear to be suitable as vane materials. However, economic considerations would rule out the hot pressed silicon nitrides and silicon carbides for this application. Similarly, the likelihood that combustor pattern factors would produce temperatures near or above the melting point of silicon rules out the materials with high $(\hat{\geqslant} 8 \%)$ free Si. Thus we are left with several RBSN's SSN, S-SiC, and several reaction sintered SiC's as viable candidates for vanes from the strength point of view. It is important to re-emphasize that a similar evaluation for other properties will further reduce this list. For example, a 4000 hour
requirement may eliminate RBSN materials on the basis on oxidation resistance.

A similar evaluation shows that quite a few materials appear to have adequate strength at temperature for both the blade airfoil and the airfoil platform transition requirements. (Note in this case creep considerations will very probably reduce the number of viable candidate materials). However, only HPSN or HPSiC presently appears acceptable for the dovetail. Sintered silicon carbide and sintered silicon nitride look promising if their strength can be increased by about 25-50\%.

The major point to be drawn from the above is that looking only at short time strength the current level of high temperature strength (ca 1900-2500F) is not the limiting problem, but intermediate temperature (ca 1400-1800F) strength (which occur in areas of highest stress) is. On the otherhand, if one were to go through a similar analysis for creep or time dependent strength properties, requirements for improved high temperature behavior would most likely emerge. In the next section we will show examples of how time dependent materials behavior might be factored into the preliminary design process. 


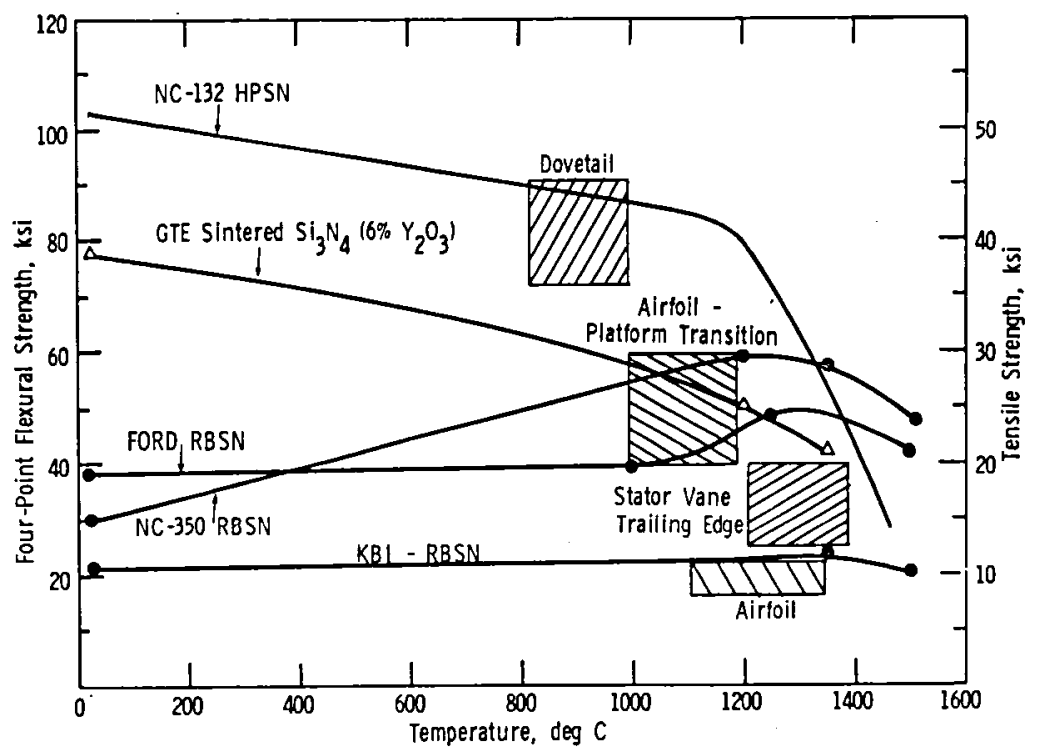

Figure 7. FLEXURAL STRENGTH OF SILICON NITRIDE MATERIALS VERSUS REQUIRED STRENGTHS FOR BLADES AND VANES

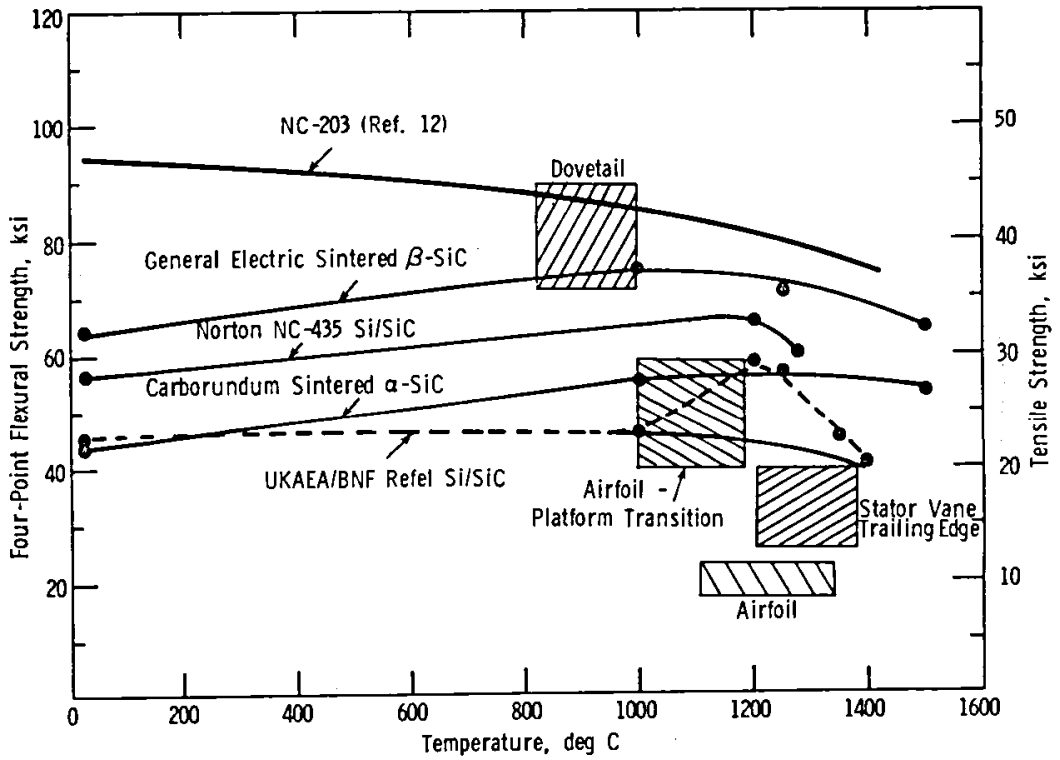

Figure 8. FLEXURAL STRENGTH OF SILICON CARBIDE MATERIALS VERSUS REQUIRED STRENGTHS FOR BLADES AND VANES

VII. Time Dependent Properties

In the gas turbine engine the ceramic material will see a very complex superposition of environmental factors. For example, high temperatures (imposing substantial radial and axial thermal gradients), varying contact and aerodynamic loads, oxidation (with the possibility of intermittent locallized reduction), erosion/corrosion, vibration etc., will all be occurring and interaction in ways not yet fully understood. This complex environment will produce equally complex materials responses. Creep, slow crack growth, pitting, surface layer formation and alteration, crack healing etc. may all be proceeding simultaneousiy, and interacting in ways not yet observed. In spite of all of this complexity and uncertainty, there is one thing which we can state with assurance. Namely, the surface and near surface cyes of the "virgin" material originally put in the engine. Therefore, it is prudent to initiate laboratory scale tests to model and measure what might happen to materials properties after environmental exposure. While it is impossible in a laboratory test on MOR bars to duplicate engine environments, it is at least possible to evaluate what long time exposure combined with thermal cycling in air or combustion gas will do to the strength of candidate ceramics materials. Quinn at AMMRC (51), Richerson and Carruthers at Airesearch strength of candidate ceramics materials. Quinn at AMMR (51), Richerson and cound that there is, in 
general, a significant reduction in the strength of the candidate ceramics by such exposure. Table VII gives some results from the work of Quinn for 6 such materials exposed to the oxidative exposure cycle reported in ref. 51. Also in Table VII are results from the work of Richerson and Carruthers on RBSN and sintered $\alpha$-SiC tested in their combustion rig (52).

Knowing that the various classes of candidate materials may undergo strength degradation in these laboratory tests, 1t would be appropriate for the designer to apply a "strength reduction factor" to those parts of his design where appropriate. In this case if a RT strength of $100,000 \mathrm{KSI}$ is required of a HPSN part that has spent several hundred hours cycling between 2500F and RT, that level of strength will not be avaflable (the strength will be $250,000 \mathrm{KSI}$ ).

High temperature strength or stress rupture data on samples exposed to such cycles is not available at present. Stress-rupture tests on uncycled samples do show time dependence for these materials so that one must assume that the strength available in the part will decrease with exposure time. Thus the available evidence indicates that the designer should use the lower strength values typical of exposed samples rather than MOR data from short time tests on "virgin" materials. Table VIII lists MOR-stress

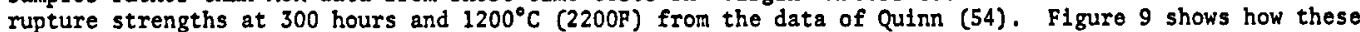
stress-rupture values reduce the options available to the designer. Also note that there are still materials with satisfactory properties at $2200 \mathrm{~F}$ for the vane, blade and airfoil. Using the stress rupture data it appears that improved materials may be required for the blade airfoil/platform transition. Again increases of the order of $20-50 \%$ would seem to be required.

Table VII. COMBINED THERMAL EXPOSURE -

THERMAL CYCLING TESTS OF ENGINE CERAMICS TO $2500 \mathrm{~F}$

\begin{tabular}{|c|c|c|c|c|}
\hline Material & $\begin{array}{l}\text { Virgin } \\
\text { MOR (ksi) }\end{array}$ & $\begin{array}{c}\text { Exposed } \\
\text { MOR (ksi) }\end{array}$ & $\begin{array}{l}\text { \% Change } \\
\text { in MOR }\end{array}$ & Laboratory and Test-Condition \\
\hline NC-132 HPSN & 104 & 50.5 & -51 & \multirow{6}{*}{$\begin{array}{l}\text { AMMRC }-360 \text { hour } 1500 \text { cycles in } \\
\text { air and flame }[51]\end{array}$} \\
\hline NC-203 HP SIC & 99 & 102 & +3 & \\
\hline NC-350 RBSN & 43 & 35 & -19 & \\
\hline KBI-RBSN & 30 & 24 & -20 & \\
\hline sillomp - silsic & 47 & 32 & -32 & \\
\hline Ford - RBSN & 42 & 36 & -15 & \\
\hline ACC RBSN-101 & 37.4 & 29.4 & $-21\}$ & \multirow{2}{*}{$\begin{array}{l}\text { Alresearch }-350 \text { hour } 17700 \\
\text { cycles in combustor gas [52] }\end{array}$} \\
\hline Sintered $a-S i c$ & 45.8 & 45.9 & o) & \\
\hline
\end{tabular}

Table VIII. 300 HOUR STRESS RUPTURE STRENGTHS AT $1200 \mathrm{C}$

\begin{tabular}{lcc}
\hline \multirow{2}{*}{ Material } & \multicolumn{2}{c}{ Strength } \\
\cline { 2 - 3 }$\sim \mathrm{ksi}$ & $\sim \mathrm{MPA}$ \\
\hline NC-132 (HPSN) & 35 & 245 \\
NC-350 (RBSN) & 50 & 345 \\
KBI-RBSN & 28 & 195 \\
Ford - RBSN & 40 & 280 \\
NC-203 (HP SiC) & 60 & 410 \\
a-Sintered SIC & 40 & 280 \\
NC-433 (RS-SIC) & 45 & 315 \\
NC-435 (RS-SIC) & 45 & 315 \\
\hline
\end{tabular}

Data from Quinn, 4-polnt flexural stress-rupture 


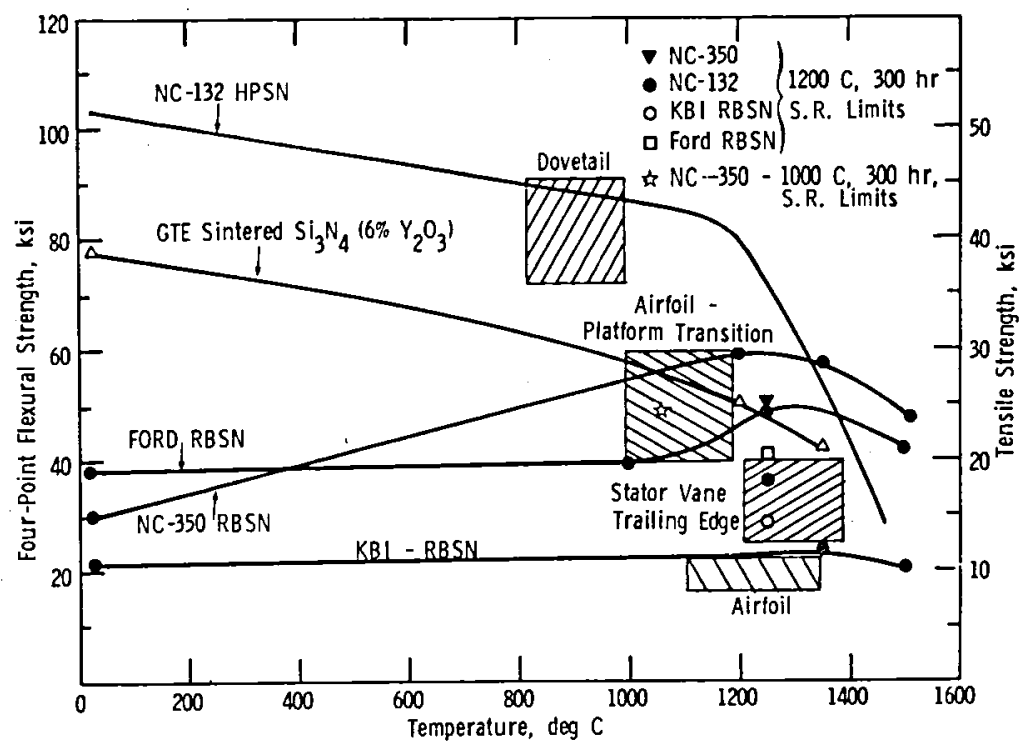

Figure 9. FLEXURAL STRENGTH OF SILICON NITRIDE MATERIALS VERSUS REQUIRED STRENGTHS FOR BLADES AND VANES

VIII. Desirable Nearterm Material Improvements

In the two foregoing sections we have shown that while adequate materials strength exists to consider the use of ceramics in some limited life airborne engine applications, due to time dependent property considerations strength improvements for both $\mathrm{Si}_{3} \mathrm{~N}_{4}$ and $\mathrm{SiC}$ materials on the order of 20 to property considerations strength improvements for both $\mathrm{Si}_{3} \mathrm{~N}_{4}$ and $\mathrm{SiC}$ materials on the order of 20 to increases in the Weibull Modulus " $m$ " are also desired (a higher " $m$ " in both the as fabricated and the service exposed conditions.) What is the likelihood of attaining property increases of this order?

For the silicon nitride families of materials the outlook is quite good for achieving the above goals from RT to $\sim 1350^{\circ} \mathrm{C}$. The use of the grain boundary engineering (GBE) approach (54, 55) coupled with microstructural optimization is leading to considerably improved properties. At a recent meeting, Dr. Komeya of Toshiba showed results on a sintered $\mathrm{Si}_{3} \mathrm{~N}_{4}$ which on a laboratory size sample under fast fracture conditions maintained 200,000 psi strength from RT to $\sim 1000^{\circ} \mathrm{C}$ and was significantly stronger than $\mathrm{NC}-132$ out to $1350^{\circ} \mathrm{C}(56)$. As this material had a crystallized $\mathrm{Y}_{2} \mathrm{O}_{3}: \mathrm{Al}_{2} \mathrm{O}_{3}: \mathrm{SiO}_{2}: \mathrm{Si}_{3} \mathrm{~N}_{4}$ grain boundary, long term phase stability and considerably less than 508 strength fall off after environmental exposure can be anticipated. However, this anticipation needs to be verified in practice. No data on Weibull Modulus of this material was presented, but HIPPING of such near full density sintered products should considerably increase the Weibuli " $\mathrm{m}$ ".

In the area of reaction bonded silicon nitride recent work by Giachello and Popper (36) has shown that RBSN can be made signiflcantly stronger from RT to about $1000^{\circ} \mathrm{C}-1100^{\circ} \mathrm{C}$ and more oxtdation resistant out to $21350^{\circ} \mathrm{C}$. This signiflcant development coupled with the relative oaso of fabrication of RBSN should yield material which meet the requirements of vares and blades shown in Figs. 7,8 and 9 .

In the area of S1C, attainment of 90,000 psi with a Weibull Modulus of $12-20$ is considered a, reasonable target for the near term. Phoenix, et al, have recently reported on progress towards attainIng this goal (57). A sintered $\alpha$-SIC with such properties would be expected to maintain them from RT to $1400^{\circ} \mathrm{C}$ with littlo time dependence of strength.

These near term materials improvements are proceeding mainly from state of the art materials processing efforts. Table IX presents some advances in processing technology which might slgniflcantly and favorably impact the homogenelty, rellability and cost of ceramic engine hardware.

Table IX

POSSIBLE NEW DIRECTIONS FOR

ENGINE CERAMICS PROCESSING

FLUIOIZED BED NITRIDATION

FLUIDIZED BED ADDITION AND PREREACTION OF DENSIFICATION AIDS

DEVELOPMENT OF SINTERING FOLLOWED BY

CLADLESS HIP

POWDER PROOUCTION FROM ORGANIC PRECURSORS

FORMATION OF HIGH STRENGTH, LOW a CERAMIC BY

DEVITRIFICATION OF $\mathrm{N}_{2}$ OR' C CONTAINING GLASS

POST FABRICATION THERMAL TREATMENTS 
The point is that many materials science and engineering approaches have yet to be exploited and the application of these approaches will result in continued improvement of the silicon nitride and silicon carbide families of materials.

\section{X. Scenario for Ceramic Introduction into Airborne Engines}

Based on what the authors have presented above, as well as, their ongoing surveillance of the state of the art in monolithic ceramics, and thermal barrier coatings the following scenario for introduction of ceramics into Airborne Engines operating at $\sim 2200$ to $2500^{\circ} \mathrm{F}$, TIT, is proposed:

\section{SCENARIO FOR THE INTRODUCTION OF CERAMICS} INTO AIRBORNE ENGINES

Bearings:

- Limited Life

- APU

- Mar Rated

Thermal Barrier Coatings

- Limited Life and APU

combustors

transitions

vanes

blades

- Man Rated

combustors

transitions

vanes

blades

Monolithic Ceramics

- Limited Life and APU

vanes

blades

- Man Rated

vanes

blades

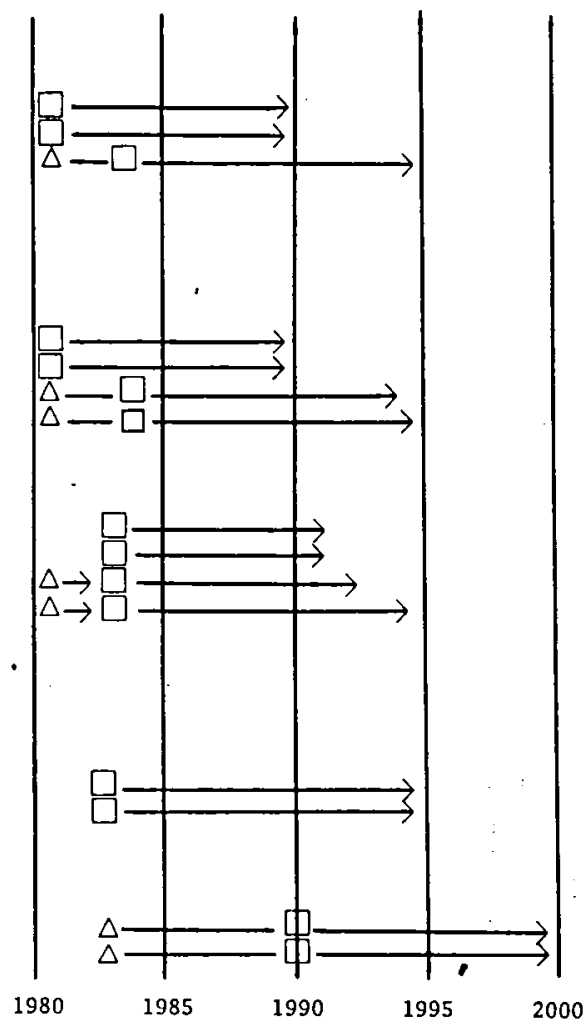

Key: $\triangle=$ Start RED

= Start Engineering Development for Specific Systems

\section{Summary}

This paper has reviewed some aspects of brittle materials design, systems requirements for small airborne engines, the requirements these impose on the ceramic materials and the ability of the existing ceramics to meet these requirements. We have seen that for some limited life and APU applications that existing ceramics have a reasonable chance of successful use as engine components. For other applications strength (also creep, and other time dependent properties) will have to be improved. Our judgment is the 20-50\% increases in strength which appear to be required for long life man rated applications are attainable by extension of the current state of the art. Based on this optimistic assessment a scenario was presented which outlines, in the authors opinion, when work should be initiated to have airborne ceramics engine ready for the mid 80 's to the end of the century. 
REFERENCES

1. Mclean, A.F., Fisher, E.S., \& Harrison, D.E., "Brittle Materials Design, High Temperature Gas Turbine" Interim Report 1, AMMRC CTR 72-3 (March 1972) (AD 894-0521)

2. Ceramics for Turbines \& Other High Temperature Engineering Applications, Ed. D.J. Godfrey, Proceedings of the British Ceramic Society, 22 (1973)

3. Ceramics for High Performance Applications, Eds, J.J. Burke, A.E. Gorum, and R.N. Katz, Brook Hill Publishing Co., Chestnut Hill, MA (1974)

4. Ceramics for High Performance Applications II, Eds, J.J. Burke, E.M. Lenoe, and R.N. Katz, Brook Hill Publishing Co., Chestnut Hill, MA (1978)

5. Workshop on Ceramics for Advanced Heat Engines, Conference Proceedings, ERDA Conf-77-0110, Orlando, FL (1977)

6. Blankenship, C.P., "Trends in High femperature Materials Technology for Advanced Aircraft Turbine Engines," SAE Paper 751050, SAE, (1975)

7. Mclean, A.F. G Baker, R.R., "Brittle Materials Design, High Temperature Gas Turbine", Interin Report 12, AMMRC TR-78-14, March 1978

8. Metcalfe, A.G., Chap 35 in Reference 3, PP 739-747

9. Wallace, F.B. \& Harper, J.E., "Ceramic Has Turbine Engine Demonstration Program," Interim Report \#13, Air research report \#76-212188(13) (May 1979)

10. Janovicz, M.A., Rockwood, F.A. \& Helms, H.E., "Ceramic Applications in Turbine Engines," DDA ZDR 9722 (1979)

11. Dukes, W.H., "Handbook of Brittle Materials Design Technology," AGARDograph \#152, North Atlantic Treaty Organization, Feb. 1971, P. 5

12. Nichollis, P.F. \& Paluszny, A., Chap. 3 in Reference 3, PP 63-78

13. Jeryan, R.A., Reference 4, Chap. w, P 35-51

14. Brooks A. \& Bellin A., "Benefits of Ceramics to Aircraft Gas Turbines," These proceedings

15. Napier, J.C. \& Arnold, J.P., "Development of Ceranic Nozzle Sections for Small Radial Gas Turbines," These proceedings

16. Peschel, W.H., Siebmanns, W. \& Trappmann, K., Chap. 26 in Reference 4, PP 481-502

17. Wallace, F.B., Stone, A.J. \& Nelson, N.R., Chap. 34 in Reference 4, PP 593-624

18. Tree; D.J. \& Kington, H.C., in "Proceedings of the 1977 DARPA/NAUSEA Ceramic Gas Turbine Demonstration Engine Review," MCIC-78-36, PP 41-76

19. "Ceramic Compnents for Turbine Engines," 5th Interim Report, Contract F 33615-77-C-5171, Air Research, June 5, 1979

20. Bersch, C.F., "Ceramics in Rolling Element Bearings," These Proceedings

21. Vasilos, T, "Densification of Nitrides by Hot Pressing", Nitrogen Ceramics, Noordhoff, Leydon, P. 367 (1977)

22. Larker, H, Adlerborn, J., Bohman, H., "Fabricating of Dense $\mathrm{Si}_{3} \mathrm{~N}_{4}$ Parts by Hot Isostatic Pressing", SAE Paper 770-35, March 1977.

23. Larker, H.T., "HIP Silicon Nitride", These Proceedings.

24. McLean, .A.F, Gorum, A.E., Lenoe, E.M., and Katz, R.N., "Status of Vehicular Turbine Engine Ceramics," Proceedings of the 3 rd Conference on Gas Turbines in a Marine Environment, U. Bath (1976).

25. Gazza, G.E., Knoch, H., Quinn, G.D., "Hot Pressed $\mathrm{Si}_{3} \mathrm{~N}_{4}$ with Improved Thermal Stability", Am. Ceram. Soc. Bulletin 57, [11], (1978) pp. 1059-60.

26. Komsya, K., Tsuge, A., Hashimoto, H., Kubo, T., and Ochiai, T., "Silicon Nitride Ceramics for fas Turbine Engines" Gas Turbine Society of Japan, Paper No. 65, Tokyo Joint Gas Turbine Conference, May 1977.

27. See Chapters 1,11 and 15 in Reference 4 .

28. McLean, A.F., and Fisher, E.A., "Brittle Materials Design, High Temperature Gas Turbine", AMMRC CTR 77-20, August 1977 , P. 45

29. Chapter 28 in Reference 4, pp. 515-526.

30. Larson, C., Bortz, S.A., Ruh, R, and Tallan, N.M., Chapter 36 in Reference 4, pp. $65-668$. 
31. McLean, A.F., Chapter 1 in Reference 4, pp. 1-34.

32. Messier, D.R., and Wong, P., Chapter 8 in Reference 3, pp. 181-194.

33. Wong, P.. and Messier, D.R., "Procedure for Fabrication of $\mathrm{Si}_{3} \mathrm{~N}_{4}$ by Rate Controlled Reaction Sintering", An. Ceram. Soc. Bulletin 57 [5], 1978, p. 525-6.

34. Terwilliger, G.R., and Lange, F.F., "Pressureless Sintering of $\mathrm{Si}_{3} \mathrm{~N}_{4}$ ", J. Mat. Sci. $\underline{10}$ [7], 1975, p. 1169-1174.

35. Gazza, G., Chapter 53 in Reference 4, pp. 1001-1010.

36. Giachello, A., Popper, P., "Post Sintering of Reaction Bonded $\mathrm{Si}_{3} \mathrm{~N}_{4}$ " Proceedings of 4 th CIMTEC, to be Published.

- 37. Arrol, W.J., Chapter 34 in Reference 3, pp. 729-738.

38. Lumby, R.J., North, B., and Taylor, A.J., Chapter 46 in Reference 4, pp. 893-906.

39. Jack, K.H., Chapter 14 in Reference 3, pp. 265-286.

40. Rea, A.W.J.M., Thompson, D.P., and Jack, K.H., Chapter 56 in Reference 4, pp. 1039-1068.

41. Jack, K.H., "SiAlONs and Related Nitrogen Ceramics", J. Mat. Sci. 11 (1976), pp. 1135-1158.

42. Lange, F.F. and Iskoe, J.L. Chapter 11 in Reference 3, pp. 223-238.

43. Alliegro, R.A., Chapter 13 in Reference 3, pp. 253-264.

44. Whalen, T.J., Noakes, J.E., Terner, L.L., Chapter 9 in Reference 4, pp. 179-193.

45. Prochazka, S., Chapter 12 in Reference 3, pp. 239-252.

46. Coppola, J.A., and Mellurtry, C.H., "Substitution of Ceramics for Ductile Materials in Design", presented at National Symposium on Ceramics in the Service of Man. 7 June 1976, Carnegi Institution, Washington D.C.

47. Hillig, W.B., Chapter 52 in Reference 4, pp. 989-1000.

48. Quinn, G.D., unpublished research.

49. Engdah1, R.E., "Progress Toward Ceramic Turbine Rotors by CVD", in Reference 5.

50. Baratta, F.I., Driscoll, G.W., and Katz, R.N., "The Use of Fracture-Mechanics and Fractography to Define Surface Finish Requirements for $\mathrm{Si}_{3} \mathrm{~N}_{4}$ " chap. 21 in ref. $\underline{3}$.

51. Katz, R.N., Lenoe, E.M., and Quinn, G.D. "Durability Testing of Structural Ceramics", Proceedings of the Thirteenth Highway Vehicle Systems Contractors Coordination Meeting, DOE CONF-771037. March 1978, p. 208-223.

52. Benn, X.W., and Carruthers, W.D., "3500 Hour Durability Testing of Commercial Ceramic Materials", 5th Interim Report on Contract DEN 3-27, June 15, 1979.

53. Siebels, J.E., "Oxidation and Strength of Silicon Nitride and Silicon Carbide", Presented at the 6th Army Technology Conference: "Ceramics for High Performance Applications-III", Orcas Island, WA, July 1979 (to be published).

54. Katz, R.N., and Gazza, G.E. "Grain Boundary Engineering and Control in Nitrogen Ceramics", Nitrogen Ceramics, Noordhoof, Leyden, 1977, p. 417-431.

55. Katz, R.N., and Gazza, G.E. "Grain Boundary Engineering in Non-Oxide Ceramics" in Processing of Crystalline Ceramics, H. Palmour, R.F. Davis, and T.M. Hare, ed., Plenum Publishing Co, New York, 1978, P. $547-560$

56. Komeya, K., Presentation at the 6th Arny Technology Conference: "Ceramics for High Performance Applications-III", Orcas Island, WA, July 1979 (to be published).

57. Phoenix, R., Presentation at the 6th Army Technology Conference: "Ceramics for High Performance Applications-III", Orcas Island, WA, July 1979 (to be published).

\section{ACONOWLEDGMENTS}

The authors would like to acknowledge the helpful discussions and inputs, with and from numerous colleagues, in particular we wish to thank; Dr. John Accurio, AMRDL-Lewis, Drs. A. Brooks and 1 . Bellin, G.E., Lynn, MA, and Dr. D. R. Messier, G. E. Gazza, and G. D. Quinn of AMMRC. 
THE NATIONAL ACADEMY OF SCIENCES was established in 1863 by Act of Congress as a private, non-profit, self-governing membership corporation for the furtherance of science and technology, required to advise the federal government upon request within its fields of competence. Under its corporate charter the Academy established the National Research Council in 1916, the National Academy of Engineering in 1964 , and the Institute of Medicine in 1970.

THE NATIONAL ACADEMY OF ENGINEERING was founded in 1964 as a nonprofit membership institution, by action of the National Academy of Sciences under the authority of its congressional charter of 1863 establishing it as a private, selfgoverning corporation to further science and technology and to advise the federal government. The two Academies share those purposes in their fields.

THE NATIONAL RESEARCH COUNCIL was established in 1916 by the National Academy of Sciences to associate the broad community of science and technology with the Academy's purposes of furthering knowledge and of advising the federal government. The Council operates in accordance with general policies determined by the Academy by authority of its Congressional charter of 1863 as a non-profit, self-governing membership corporation. Administered jointly by the National Academy of Sciences, the National Academy of Engineering, and the Institute of Medicine (all three of which operate under the charter of the National Academy of Sciences), the Council is their principal agency for the conduct of their services to the government and the scientific and engineering communities.

THE COMMISSION ON SOCIOTECHNICAL SYSTEMS is one of the major components of the National Research Council and has general responsibility for and cognizance over those program areas concerned with physical, technological, and industrial systems that are or may be deployed in the public or private sector to serve societal needs.

THE NATIONAL MATERIALS ADVISORY BOARD is a unit of the Commission on Sociotechnical Systems of the National Research Council. Organized in 1951 as the Metallurgical Advisory Board, through a series of changes and expansion of scope, it became the Materials Advisory Board and, in January 1969, the National Materials Advisory Board. In consonance with the scope of the two Academies, the general purpose of the Board is the advancement of materials science and engineering, in the national interest. The Board fulfills its purpose by: providing advice and assistance, on request, to government agencies and to private organizations on matters of materials science and technology affecting the national interest; focusing attention on the materials aspects of national problems and opportunities, both technical and nontechnical in nature, and making appropriate recommendations as to the solution of such problems and the exploitation of these opportunities; performing studies and critical analyses on materials problems of a national scope, recommending approaches to the solution of these problems, and providing continuing guidance in the implementation of resulting activities; identifying problems in the interactions of materials disciplines with other technical functions, and defining approaches for the effective utilization of materials technologies; cooperating in the development of advanced educational concepts and approaches in the materials disciplines; communicating and disseminating information on Board activities and related national concerns; promoting cooperation with and among the materials-related professional societies; maintaining an awareness of trends and significant advances in materials technology, in order to call attention to opportunities and possible roadblocks, and their implications for other fields, and recognizing and promoting the development and application of advanced concepts in materials and materials processes. 


\section{End of Document}

